Prepared by the U.S. Geological Survey Office of Water Quality, National Water Quality Laboratory

\title{
Analytical Properties of Some Commercially Available Nitrate Reductase Enzymes Evaluated as Replacements for Cadmium in Automated, Semiautomated, and Manual Colorimetric Methods for Determination of Nitrate Plus Nitrite in Water
}

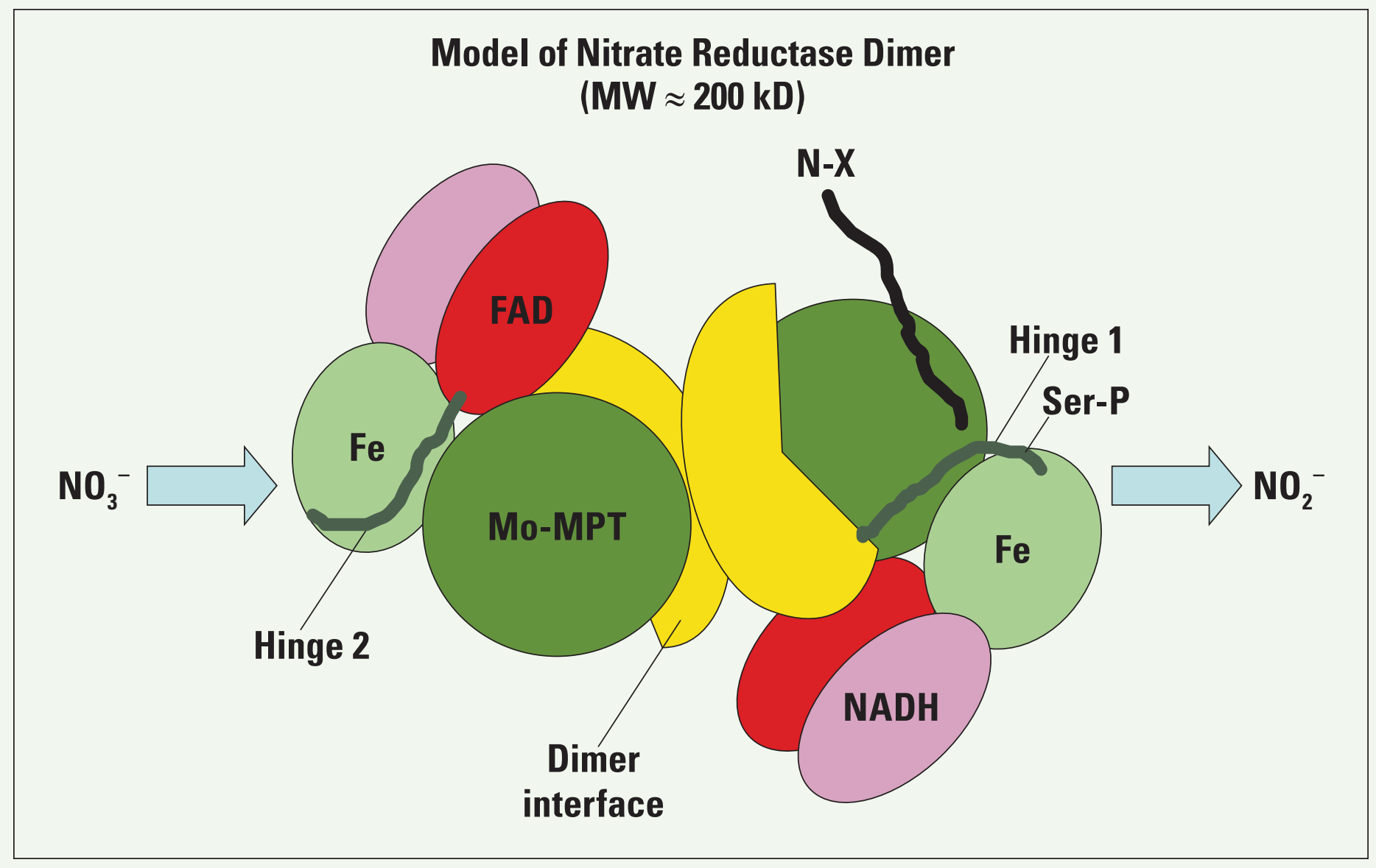

Scientific Investigations Report 2013-5033 
Front Cover. Schematic model of eukaryotic nitrate reductase showing the domain structure of each monomeric unit of homodimer. Cofactor binding sites are shown for each domain of the subunit. Reaction catalyzed by nitrate reductase is also shown. Courtesy of W.H. Campbell, Ph.D., Nitrate Elimination Company, Lake Linden, MI 49945.

Back Cover. Reaction sequence of nitrite produced by enzymatic reduction of nitrate with Griess reagents-sulfanilamide and $\mathrm{N}$-(1-Naphthyl) ethylenediamine - to form a pink azo dye with an absorption maximum of 543 nanometers. 


\section{Analytical Properties of Some Commercially Available Nitrate Reductase Enzymes Evaluated as Replacements for Cadmium in Automated, Semiautomated, and Manual Colorimetric Methods for Determination of Nitrate Plus Nitrite in Water}

By Charles J. Patton and Jennifer R. Kryskalla

Prepared by the U.S. Geological Survey Office of Water Quality,

National Water Quality Laboratory

Scientific Investigations Report 2013-5033 


\title{
U.S. Department of the Interior SALLY JEWELL, Secretary
}

\section{U.S. Geological Survey \\ Suzette M. Kimball, Acting Director}

\author{
U.S. Geological Survey, Reston, Virginia: 2013
}

For more information on the USGS - the Federal source for science about the Earth, its natural and living resources, natural hazards, and the environment, visit http://www.usgs.gov or call 1-888-ASK-USGS.

For an overview of USGS information products, including maps, imagery, and publications, visit http://www.usgs.gov/pubprod

To order this and other USGS information products, visit http://store.usgs.gov

Any use of trade, firm, or product names is for descriptive purposes only and does not imply endorsement by the U.S. Government.

Although this information product, for the most part, is in the public domain, it also may contain copyrighted materials as noted in the text. Permission to reproduce copyrighted items must be secured from the copyright owner.

Suggested citation:

Patton, C.J., and Kryskalla, J.R., 2013, Analytical properties of some commercially available nitrate reductase enzymes evaluated as replacements for cadmium in automated, semiautomated, and manual colorimetric methods for determination of nitrate plus nitrite in water: U.S. Geological Survey Scientific Investigations Report 2013-5033, 36 p., http://pubs.usgs.gov/sir/2013/5033/. 


\section{Contents}

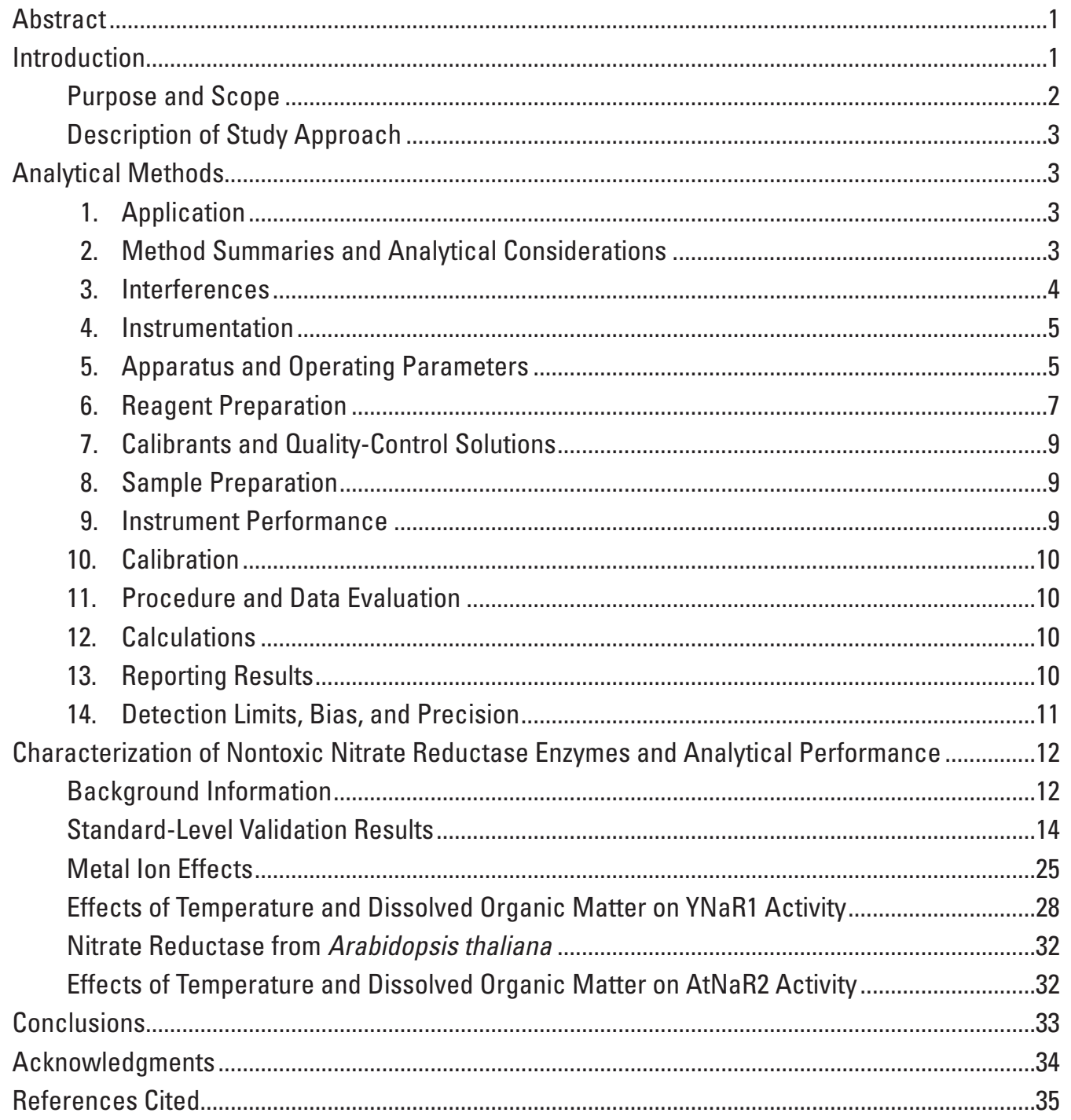

\section{Figures}

1. Sketches showing steps for offline enzymatic reduction of nitrate to nitrite using a syringe-pump-based dispenser/diluter module ................................................

2. Arrangement of components used for thermostatted nitrate reductase

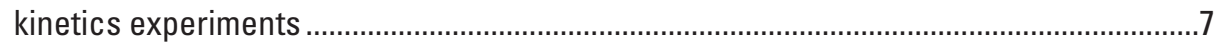

3. Typical nitrite analyzer output for nitrate reductase kinetics experiments .......................8

4. Control chart for low-level continuous flow analysis cadmium reduction and nitrate reductase reduction methods. 
5. Relative standard deviation of same-bottle duplicate, triplicate, and quintuplicate nitrate + nitrite concentrations..

6. Agreement of between-day duplicate nitrate + nitrite concentrations............................14

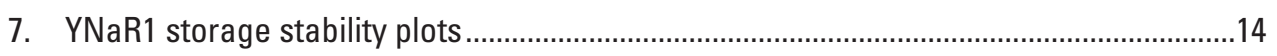

8. Graphical summary of data from an experiment to assess stability of mixed nicotinamide adenine dinucleotide nitrate reductase reagent solutions.

9. National Water Quality Laboratory login dates for groundwater and surface-water samples

10. Box plots showing concentration distributions for the population of 3,318 standard-level nitrate + nitrite concentrations determined in groundwater and surface-water samples

11. Scatter plot of standard-level nitrate + nitrite concentrations determined simultaneously by $\mathrm{CdR}$ and $\mathrm{YNaR} 1$ methods during validation experiments

12. Differences (in percent) between nitrate + nitrite concentrations in groundwater and surface-water samples.

13. Scatter plot of nitrate + nitrite concentrations determined by $\mathrm{CdR}$ and YNaR1 methods in groundwater and surface-water samples

14. Box plots showing concentration distributions for the population of 979 low-level nitrate + nitrite concentrations determined in groundwater and surface-water samples.

15. Scatter plot of nitrate + nitrite concentrations simultaneously determined by $\mathrm{CdR}$ and $\mathrm{YNaR} 1$ methods for 182 acidified samples

16. Analytical cartridge diagram for a simple, purpose-built, flow-injection nitrite analyzer.

17. Flow injection analysis peaks for batch $\mathrm{YNaR} 1$-reduction nitrate determinations

18. Graphs demonstrating effectiveness of the semiautomated batch method for reducing to nitrate to nitrite in water samples with soluble nitrate reductase

19. Linear least squares regression plots of nitrate + nitrite concentrations

20. Effect of various metal ions at times $\times 1, \times 10$, and $\times 100$ their median concentrations on nitrate concentration.

21. Graph showing the rate of nitrate reduction to nitrite by $\mathrm{YNaR} 1$ nitrate reductase in relation to reaction temperature

22. Graph showing the rate of nitrate reduction to nitrite by $\mathrm{YNaR} 1$ nitrate reductase in relation to reaction temperature .28

23. Effect of Suwannee River humic acid concentration on nitrate reduction .....................29

24. Peak heights for 5.0 milligrams nitrate-nitrogen per liter solutions. .. .30

25. Reaction rate plots for surface-water samples, each with nitrate concentrations of $\approx 0.8$ milligram nitrate-nitrogen per liter

26. Plots showing effects of Suwannee River humic acid on nitrate reductase activity in relation to reaction temperature.

27. Plots showing effect of reaction $\mathrm{pH}$ on nitrate reductase reduction rates for solutions containing 5.0 milligrams nitrate-nitrogen per liter at 25 degrees Celsius 


\section{Tables}

1. Parameter and method codes for unapproved U.S. Geological Survey enzymatic reduction nitrate + nitrite determination methods. 3

2. Effects of chloride and sulfate on reduction of 5 milligrams nitrate-nitrogen per liter solutions by $\mathrm{CdR}$ and $\mathrm{YNaR} 1$ nitrate reductase.

3. National Water Quality Laboratory standard operating procedures for automated continuous-flow analyzer cadmium reduction nitrate + nitrite determination methods.

4. Data and calculations used to estimate method detection limits for nitrate + nitrite determination by automated CFA methods.

5. Third-party check sample nitrate + nitrite data summary .............................................11

6. Nitrate + nitrite concentration summaries for low- and high-flow subsets ....................16

7. Agreement between nitrate + nitrite concentrations determined by CFA-CdR and CFA-YNaR1 reduction methods ..........................................................................

8. Two-population paired t-test results for nitrate + nitrite concentrations .........................18

9. Wilcoxon signed-rank test results for nitrate + nitrite concentrations ...........................18

10. Summary statistics for nitrate + nitrite concentrations ..............................................19

11. Metal ions tested for possible inhibition of YNaR1 enzyme and Griessreaction interference

12. Effect of storage time on the potency of Suwannee River humic acid dissolved in deionized water as an inhibitor of $\mathrm{YNaR} 1$ and AtNaR2 nitrate reductases..

\section{Conversion Factors and Abbreviated Water-Quality Units}

\begin{tabular}{|c|c|c|}
\hline Multiply & By & \begin{tabular}{|l|} 
To obtain \\
\end{tabular} \\
\hline \multicolumn{3}{|c|}{ Length } \\
\hline centimeter $(\mathrm{cm})$ & $3.94 \times 10^{-1}$ & inch (in.) \\
\hline micrometer $(\mu \mathrm{m})$ & $3.94 \times 10^{-5}$ & inch (in.) \\
\hline millimeter $(\mathrm{mm})$ & $3.94 \times 10^{-2}$ & inch (in.) \\
\hline nanometer (nm) & $3.94 \times 10^{-8}$ & inch (in.) \\
\hline \multicolumn{3}{|c|}{ Mass } \\
\hline gram $(\mathrm{g})$ & $3.53 \times 10^{-2}$ & ounce, avoirdupois \\
\hline milligram (mg) & $3.53 \times 10^{-5}$ & ounce, avoirdupois \\
\hline \multicolumn{3}{|c|}{ Volume } \\
\hline liter (L) & $2.64 \times 10^{-1}$ & gallon \\
\hline liter (L) & $3.38 \times 10^{1}$ & ounce, fluid \\
\hline microliter $(\mu \mathrm{L})$ & $2.64 \times 10^{-7}$ & gallon \\
\hline milliliter $(\mathrm{mL})$ & $2.64 \times 10^{-4}$ & gallon \\
\hline \multicolumn{3}{|c|}{ Concentration } \\
\hline $\begin{array}{l}\text { milligram nitrate nitrogen per liter } \\
\left(\mathrm{mg} \mathrm{NO}^{-}-\mathrm{N} / \mathrm{L}\right)\end{array}$ & $7.14 \times 10^{1}$ & $\begin{array}{l}\text { micromole nitrate per liter } \\
\left(\mathrm{NO}^{-}, \mathrm{u} M\right)\end{array}$ \\
\hline $\begin{array}{l}\text { milligram nitrite nitrogen per liter } \\
\left(\mathrm{mg} \mathrm{NO}_{2}^{-}-\mathrm{N} / \mathrm{L}\right)\end{array}$ & $7.14 \times 10^{1}$ & $\begin{array}{l}\text { micromole nitrite per liter } \\
\left(\mathrm{NO}_{2}^{-}, \mu M\right)\end{array}$ \\
\hline $\operatorname{molar}(M$, moles $/ \mathrm{L})$ & $1.00 \times 10^{3}$ & millimolar $(\mathrm{m} M)$ \\
\hline molar $(M$, moles $/ \mathrm{L})$ & $1.00 \times 10^{6}$ & micromolar $(\mu M)$ \\
\hline
\end{tabular}

Degrees Celsius $\left({ }^{\circ} \mathrm{C}\right)$ may be converted to degrees Fahrenheit $\left({ }^{\circ} \mathrm{F}\right)$ by using the following equation:

$$
{ }^{\circ} \mathrm{F}=1.8\left({ }^{\circ} \mathrm{C}\right)+32 .
$$




\section{Abbreviations Used in This Report}

\begin{tabular}{|c|c|}
\hline$\approx$ & Approximately equal \\
\hline \pm & Plus or minus \\
\hline$>$ & Greater than \\
\hline$>$ & Much greater than \\
\hline$<$ & Less than \\
\hline${ }^{\circ} \mathrm{C}$ & Degree Celsius \\
\hline ASTM & American Society for Testing and Materials \\
\hline AtNaR2 & $\begin{array}{l}\text { Recombinant nitrate reductase from Arabidopsis thaliana (Enzyme Commission } \\
\text { number EC 1.7.1.1) expressed in the yeast Pichia pastoris }\end{array}$ \\
\hline CdR & Cadmium reduction \\
\hline CFA & Air-segmented continuous-flow analysis (or analyzer) \\
\hline DA & Automated discrete analysis (or analyzer) \\
\hline DI (water) & $\begin{array}{l}\text { Deionized water piped throughout the National Water Quality Laboratory. } \\
\text { For purposes of nutrient analysis, the laboratory DI water is equivalent to } \\
\text { ASTM type I DI water. }\end{array}$ \\
\hline DOC & Dissolved organic carbon \\
\hline EC & $\begin{array}{l}\text { Enzyme Commission, a Swiss organization that assigns unique numerical } \\
\text { identifiers to enzymes }\end{array}$ \\
\hline EDTA & Ethylenediaminetetraacetic acid and its di-sodium salt \\
\hline EPA & U.S. Environmental Protection Agency \\
\hline FCA & $\begin{array}{l}\text { A U.S. Geological Survey National Water Quality Laboratory bottle type for } \\
\text { nutrient samples that are filtered ( } 0.45 \text { micrometer), amended with sulfuric } \\
\text { acid, and chilled at collection sites. FCA samples are shipped and stored at } \\
\text { a nominal temperature of } 4^{\circ} \mathrm{C} \pm 2^{\circ} \mathrm{C} \text {. }\end{array}$ \\
\hline FCC & $\begin{array}{l}\text { A U.S. Geological Survey National Water Quality Laboratory bottle type for } \\
\text { nutrient samples that are filtered ( } 0.45 \text { micrometer) and chilled at collection } \\
\text { sites. FCC samples are shipped and stored at a nominal temperature of } \\
4^{\circ} \mathrm{C} \pm 2^{\circ} \mathrm{C} \text {. }\end{array}$ \\
\hline FIA & Flow injection analysis (or analyzer) \\
\hline FW & Formula weight \\
\hline h & hour \\
\hline HA & High-phenolic-content humic acid \\
\hline LCL & Lower control limit \\
\hline M & $\begin{array}{l}\text { Molar (molarity); a unit of concentration equal to moles solute per liter } \\
\text { of solution }\end{array}$ \\
\hline MC & $\begin{array}{l}\text { A U.S. Geological Survey National Water Information System sample medium } \\
\text { code used to identify sample matrix types }\end{array}$ \\
\hline MDL & Method detection limit \\
\hline $\mathrm{ml}$ & Milliliter \\
\hline & Minute \\
\hline PS & 3-N-morpholino-propansulfonic acid; $p K a=7.20$ \\
\hline
\end{tabular}


NAD(P)H:NaR Bispecific forms of nitrate reductase that can use either NADH or NADPH as their cofactor

NADH Nicotinamide adenine dinucleotide in reduced form, a natural cofactor of YNaR1 and AtNaR2

NADH:NaR Forms of nitrate reductase that can use only NADH as their cofactor

NADPH Nicotinamide adenine dinucleotide phosphate in reduced form, the other natural cofactor of bispecific YNaR1 and of nitrate reductase from Aspergillus sp.

NADPH:NaR Forms of nitrate reductase that can use only NADPH as their cofactor

$\mathrm{NaR}$ Nitrate reductase in the generic sense

NaR1 Nitrate reductase purified from corn (Zea mays L.) by NECi

NECi The Nitrate Elimination Company, Lake Linden, Mich.

NED $\mathrm{N}$-(1-Naphthyl)ethylenediamine; coupling reagent in Griess-reaction nitrite assays

NIST National Institute of Standards and Technology

$\mathrm{NO}_{x} \quad$ Nitrate plus nitrite $\left(\mathrm{NO}_{3}^{-}+\mathrm{NO}_{2}^{-}\right)$

NWOL U.S. Geological Survey National Water Quality Laboratory

$\mathrm{pKb} \quad \log 10 \mathrm{~Kb}$, where $\mathrm{Kb}$ is the dissociation constant of a weak base

QC Quality control

SAN Sulfanilamide; diazotizing reagent in Griess-reaction nitrite assays

$S \quad$ second

SR HA Suwannee River humic acid isolate; a high-phenolic-content HA

$\mathrm{U} \quad$ Enzyme unit; the amount of an enzyme that catalyzes the conversion of micromole of substrate per minute at a specified $\mathrm{pH}$ and reaction temperature with a substrate concentration that yield the maximum rate of substrate conversion

UCL Upper control limit

USGS U.S. Geological Survey

WCA A U.S. Geological Survey National Water Quality Laboratory bottle type for whole-water nutrient samples that are amended with sulfuric acid and chilled at collection sites. WCA samples are shipped and stored at a nominal temperature of $4{ }^{\circ} \mathrm{C} \pm 2{ }^{\circ} \mathrm{C}$.

WG U.S. Geological Survey National Water Information System medium code for groundwater (formerly medium code 6)

WS U.S. Geological Survey National Water Information System medium code for surface water (formerly medium code 9)

YNaR1 Recombinant nitrate reductase from Pichia angusta (Enzyme Commission number EC 1.7.1.2) expressed in Pichia pastoris and purified to near homogeneity

yr year

[AtNaR2, NaR1, YNaR1 are trade names of the Nitrate Elimination Company, Inc., Lake Linden, MI 49945.] 



\title{
Analytical Properties of Some Commercially Available Nitrate Reductase Enzymes Evaluated as Replacements for Cadmium in Automated, Semiautomated, and Manual Colorimetric Methods for Determination of Nitrate Plus Nitrite in Water
}

\author{
By Charles J. Patton ${ }^{1}$ and Jennifer R. Kryskalla ${ }^{2}$
}

\begin{abstract}
A multiyear research effort at the U.S. Geological Survey (USGS) National Water Quality Laboratory (NWQL) evaluated several commercially available nitrate reductase $(\mathrm{NaR})$ enzymes as replacements for toxic cadmium in longstanding automated colorimetric air-segmented continuous-flow analyzer (CFA) methods for determining nitrate plus nitrite $\left(\mathrm{NO}_{x}\right)$ in water. This research culminated in USGS approved standard- and low-level enzymatic reduction, colorimetric automated discrete analyzer $\mathrm{NO}_{x}$ methods that have been in routine operation at the NWQL since October 2011. The enzyme used in these methods (AtNaR2) is a product of recombinant expression of $\mathrm{NaR}$ from Arabidopsis thaliana (L.) Heynh. (mouseear cress) in the yeast Pichia pastoris. Because the scope of the validation report for these new automated discrete analyzer methods, published as U.S. Geological Survey Techniques and Methods 5-B8, was limited to performance benchmarks and operational details, extensive foundational research with different enzymesprimarily YNaR1, a product of recombinant expression of $\mathrm{NaR}$ from Pichia angusta in the yeast Pichia pastoris - remained unpublished until now. This report documents research and development at the NWQL that was foundational to development and validation of the discrete analyzer methods. It includes: (1) details of instrumentation used to acquire kinetics data for several NaR enzymes in the presence and absence of known or suspected inhibitors in relation to reaction temperature and reaction $\mathrm{pH}$; and (2) validation results - method detection limits, precision and bias estimates, spike recoveries, and interference studies - for standard- and low-level automated colorimetric CFA-YNaR1 reduction $\mathrm{NO}_{x}$ methods in relation to corresponding USGS approved CFA cadmium-reduction (CdR) $\mathrm{NO}_{x}$ methods. The cornerstone of this validation is pairedsample statistical and graphical analysis of $\mathrm{NO}_{x}$ concentrations
\end{abstract}

${ }^{1}$ U.S. Geological Survey, National Water Quality Laboratory, Denver, Colo.

${ }^{2}$ VA Desert Pacific Network. Long Beach, Calif. from more than 3,800 geographically and seasonally diverse surface-water and groundwater samples that were analyzed in parallel by CFA-CdR and CFA enzyme-reduction methods. Finally, (3) demonstration of a semiautomated batch procedure in which 2-milliliter analyzer cups or disposable spectrophotometer cuvettes serve as reaction vessels for enzymatic reduction of nitrate to nitrite prior to analytical determinations. After the reduction step, analyzer cups are loaded onto CFA, flow injection, or discrete analyzers for simple, rapid, automatic nitrite determinations. In the case of manual determinations, analysts dispense colorimetric reagents into cuvettes containing post-reduction samples, allow time for color to develop, insert cuvettes individually into a spectrophotometer, and record percent transmittance or absorbance in relation to a reagent blank. Data presented here demonstrate equivalent analytical performance of enzymatic reduction $\mathrm{NO}_{x}$ methods in these various formats to that of benchmark CFA-CdR $\mathrm{NO}_{x}$ methods.

\section{Introduction}

Nitrate is one of the most universally determined anions in environmental water, drinking water, and wastewater because it can promote eutrophication and is toxic to fetuses and young of livestock and humans at concentrations that exceed about 10 milligrams nitrogen per liter (mg-N/L). A thorough review of detection and determination methods for nitrate and nitrite in a variety of matrices is available elsewhere (Moorcroft and others, 2001) and is not duplicated here. Some important references not cited in the Moorcroft review include one describing reduction of nitrate to nitrite with trivalent vanadium (Miranda, 2001), another on optimizing cadmium-reduction (CdR) assays (Gal and others, 2004), a third documenting ferrous iron interference in the Griess colorimetric indicator reaction (Colman and Schimel, 2010a, b), and several pertaining to nitrate-reductase-based nitrate assays (Senn and Carr, 1976; Guevara and others, 1998; Mori 
2000, 2001; Patton and others, 2002; MacKown and Weik, 2004; Pinto and others, 2005; Campbell and others, 2006; Patton and Kryskalla, 2011).

Typically for water analysis applications, nitrate is reduced to nitrite and subsequently determined colorimetrically with Griess reagents (Bratton and Marshall, 1939; Bendschneider and Robinson, 1952). Cadmium in various forms - electrolytically precipitated, "mossy" or "spongy," filings, granules, and filings or granules washed with solutions of mercury (II), silver (I), or copper (II) ions (Nydahl, 1976; Davison and Woof, 1978) - has long been the reducing agent of choice for colorimetric nitrate plus nitrite $\left(\mathrm{NO}_{x}\right)$ determinations. For example, copper-washed (copperized) cadmium granules packed into small columns (Wood and others, 1967) are prescribed in the longstanding U.S. Geological Survey (USGS) and U.S. Environmental Protection Agency (EPA) air-segmented continuous-flow analyzer, cadmium-reduction (CFA-CdR) methods I-2545-90 and 353.2, respectively. Wire-in-tube cadmium reactors (Stainton, 1974; Willis, 1980; Willis and Gentry, 1987; Patton and Rogerson, 2007) and open-tubular cadmium reactors (Patton, 1983; Elliot and others, 1989; Zhang and others, 2000) are well known and effective alternatives to packed-bed reactors. A definitive study of continuous-flow cadmium reactor chemistry and kinetics (Nydahl, 1976) demonstrated that reaction-stream $\mathrm{pH}$ in the range of 7.0 to 8.5 is required for near-quantitative reduction of nitrate to nitrite with only minor (less than 3 percent) reduction of nitrite to lower oxidation species. In this $\mathrm{pH}$ regime, cadmium hydroxide - produced primarily by quantitative reaction of cadmium with dissolved oxygen in samples and reagents (Nydahl, 1974) - precipitates on cadmium granules and continuously deactivates the reactor. Adding a reagent that forms soluble complexes with cadmium (II) ionsimidazole or ammonium chloride, typically - to the $\mathrm{pH}$ buffer minimizes this problem and stabilizes reduction of nitrate to nitrite during operation. Nydahl appears to be the first to recognize the unique properties of imidazole - specifically, its high buffer capacity at $\mathrm{pH} 7.5\left(\mathrm{pK}_{\mathrm{b}}=7.09\right)$ and its ability to complex cadmium (II) even in the presence of Ca (II) and $\mathrm{Mg}$ (II) ions - that account for its use in most CFA-CdR nitrate determination methods.

Widespread acceptance and application of CdR methods for nitrate determination notwithstanding, reactor geometry, activation procedures, and reagent formulations remain topics of perennial discussion among environmental analytical chemists (Gal and others, 2004; Colman and Schimel, 2010a, b). Ease-of-use, toxicity, and waste-disposal issues associated with $\mathrm{CdR}$ devices, however, led us to explore commercially available, nontoxic nitrate reductase (NaR) enzymes as replacements for granular copperized cadmium (Patton and others, 2002). The NaR reduces nitrate to nitrite with specificity exceeding that of copperized cadmium and is nontoxic. In this report we share our analytical experience with several NaRs and describe how to use them as replacements for cadmium in automatic, semiautomatic, and manual methods for colorimetric determination of $\mathrm{NO}_{x}$ in water. We provide details of reagent preparation, instrumentation, and data demonstrating statistical equivalence of $\mathrm{NO}_{x}$ concentrations determined with granular copperized cadmium and soluble NaR.

\section{Purpose and Scope}

This report documents our multiyear study to characterize several commercially available, nontoxic NaR enzymes as replacement reagents for cadmium in routine, colorimetric determinative methods for nitrate in water. We evaluated the performance of $\mathrm{NaR}$ as an analytical reagent in relation to cadmium. Cadmium has been the reagent of choice for $\mathrm{NO}_{x}$ determinations in water for over 40 years (Wood and others, 1967) and is specified in longstanding reference methods such as USGS I-2545-90 and EPA 353.2. We wrote this report primarily to provide USGS scientists and decision-makers, USGS cooperators, and other National Water Quality Laboratory (NWQL) customers with graphical and statistical summaries of validation data, including method detection limits, calibration curves, control charts, and between-day concentration variability for environmental sample replicates that support replacement of toxic cadmium with nontoxic, soluble $\mathrm{NaR}$ reagents in these time-honored methods for determining $\mathrm{NO}_{x}$ in water. Additionally, to facilitate incorporation of these green chemistry nitrate reduction reagents into the routine operations of public-, private-, and academic-sector water quality and teaching laboratories, we have included details of soluble $\mathrm{NaR}$ nitrate determination methods in several different analytical formats. To these ends we provide the following:

1. Paired graphical and statistical analyses of $\mathrm{NO}_{x}$ concentrations for about 3,800 seasonally, geographically, and compositionally diverse surface-water and groundwater samples that were analyzed by USGS CdR reference methods and our previously reported (Patton and others, 2002) CFA soluble NaR method.

2. Summaries of the effects of numerous anionic and cationic constituents of surface-water and groundwater matrices on the reduction efficiencies of copperized cadmium, several NaRs, and the Griess indicator reaction.

3. Summaries of the effects of several humic acid isolates on the activity of four commercially available NaRs in relation to reaction temperature and humic acid concentration.

4. Information necessary to replace granular, copperized cadmium reactors with soluble $\mathrm{NaR}$ on a variety of automated and manual analytical platforms. We provide this to aid public-, private-, and academic-sector analysts who might want to incorporate these green chemistry nitrate reduction reagents into routine operations in their laboratories. 


\section{Description of Study Approach}

This report provides a chronological narrative of research with several commercially available NaRs that led to validation and approval of standard- and low-level USGS method numbers I-2547-11 and I-2548-11, respectively, for enzymatic reduction colorimetric determination of $\mathrm{NO}_{x}$ in water by automated discrete analysis (DA). The narrative begins shortly after publication of an automated CFA $\mathrm{NO}_{x}$ method that used NaR purified from corn seedlings (Patton and others, 2002) and ends just before validation of automated discrete analyzer methods using AtNaR2 (Patton and Kryskalla, 2011) began. In this report, our intent is to provide a level of experimental detail that permits others to duplicate or extend work reported here.

\section{Analytical Methods}

\section{Application}

These methods (see table 1) are intended for determination of dissolved $\mathrm{NO}_{x}$ in filtered and filtered-acidified water samples. They also are applicable to wholewater-acidified samples that are laboratory filtered prior to analysis. They are direct replacements for longstanding USGS and EPA colorimetric nitrate methods and differ from them only in the reagents used to reduce nitrate to nitrite-nontoxic, soluble $\mathrm{NaR}$ replaces toxic granular, copperized cadmium - prior to colorimetric nitrite determination with Griess reagents. As is the case for CdR methods, these NaR methods are intended for surface-water and groundwater matrices-USGS National Water Information System medium codes WS and WG, respectively. We did not investigate sample media such as seawater, brines, leachates, potassium chloride soil extracts, landfill effluents, and other nonconforming matrices. Unless stated otherwise, we prepared calibrants and quality control (QC) solutions in deionized (DI) water. Nominal analytical ranges for standard- and low-level methods are 0.05 to $5.00 \mathrm{mg}-\mathrm{N} / \mathrm{L}$ and 0.01 to $1.00 \mathrm{mg}-\mathrm{N} / \mathrm{L}$, respectively.

\section{Method Summaries and Analytical Considerations}

2.1 Except as noted, analytical methods used $\mathrm{NaR}$ from Pichia angusta -Enzyme Commission (EC) 1.7.1.2produced by recombinant expression in Pichia pastoris and marketed as YNaR1 (Campbell and others, 2004; Barbier and others, 2004) by its manufacturer, the Nitrate Elimination Company (NECi), Lake Linden, Mich. Recombinant expression is a technique by which a gene that codes for $\mathrm{NaR}$ is excised from one organism and inserted into a different organism from which it is harvested. YNaR1 is bispecific [generically designated, $\mathrm{NAD}(\mathrm{P}) \mathrm{H}: \mathrm{NaR}$ ], meaning that it can use either $\beta$-nicotinamide adenine dinucleotide, reduced form (NADH) or $\beta$-nicotinamide adenine dinucleotide phosphate, reduced form (NADPH) as its obligatory electron donor ("cofactor"). Analytical properties of YNaR1 and NADH-specific NaR purified from Zea mays L. (corn) seedlings-EC 1.7.1.1 and marketed by NECi as NaR1used in our preliminary research (Patton and others, 2002) are equivalent.

In humic acid interference experiments, we tested YNaR1, NaR1, NaR from mold (Aspergillus sp., EC 1.7.1.2), and recombinant $\mathrm{NaR}$ from mouseear cress (Arabidopsis thaliana, EC 1.7.1.1, expressed in Pichia pastoris and marketed as AtNaR2). YNaR1, NaR1, and AtNaR2 are proprietary products of the Nitrate Elimination Company (NECi), Lake Linden, Mich. In the presence of obligatory cofactors, all four enzymes quantitatively reduce nitrate $\left(\mathrm{NO}_{3}^{-}\right)$to nitrite $\left(\mathrm{NO}_{2}^{-}\right)$

Table 1. Parameter and method codes for unapproved U.S. Geological Survey enzymatic reduction nitrate + nitrite determination methods I-2531-12 (automated continuous-flow analyzer), I-2532-12 (low-level automated continuous-flow analyzer), I-1531-12 (semiautomated batch reduction), and I-1532-12 (low-level semiautomated batch reduction).

[+, plus; Lab, laboratory; N, nitrogen; CFA, air-segmented continuous-flow analysis; TBA, to be assigned; FCC, filtered, chilled sample bottle type; FCA, filtered, chilled, acidified sample bottle type; $\mu \mathrm{m}$, micrometer; $\mathrm{mL}$, milliliter; $N$, normal; $\mathrm{H}_{2} \mathrm{SO}_{4}$, sulfuric acid; USGS, U.S. Geological Survey]

\begin{tabular}{|c|c|c|c|c|}
\hline Description & \multicolumn{3}{|c|}{ Codes } & $\begin{array}{c}\text { Bottle } \\
\text { type }\end{array}$ \\
\hline Nitrate + nitrite, as N, low level, colorimetry, CFA, enzymatic reduction-diazotization, filtered & TBA & 00631 & RED11 & $\mathrm{FCC}^{1}$ \\
\hline Nitrate + nitrite, as $\mathrm{N}$, colorimetry, semiautomated batch enzymatic reduction-diazotization, filtered & TBA & 00631 & RED13 & $\mathrm{FCC}^{1}$ \\
\hline $\begin{array}{l}\text { Nitrate + nitrite, as N, colorimetry, semiautomated batch enzymatic reduction-diazotization, filtered, } \\
\text { low-level }\end{array}$ & TBA & 00631 & RED14 & $\mathrm{FCC}^{1}$ \\
\hline
\end{tabular}

${ }^{1} \mathrm{FCC}$ samples must be processed through $0.45-\mu \mathrm{m}$ filters and chilled at collection sites.

${ }^{2} \mathrm{FCA}$ samples must be processed through $0.45-\mu \mathrm{m}$ filters, chilled, and amended with $1 \mathrm{~mL}$ of $4.5 \mathrm{~N} \mathrm{H}_{2} \mathrm{SO}_{4}$ solution (USGS water-quality field supply number Q438FLD) per $120 \mathrm{~mL}$ of sample at collection sites. 
in the $\mathrm{pH}$ range of 7-8 and have high activity at $\mathrm{pH} 7.5$ in phosphate or 3-N-morpholino-propansulfonic acid (MOPS) buffers (see equation 1).

$$
\mathrm{NO}_{3}^{-}+\mathrm{NADH}+\mathrm{H}^{+} \underset{(\mathrm{pH}=7-8)}{\mathrm{NaR}} \mathrm{NO}_{2}^{-}+\mathrm{NAD}^{+}+\mathrm{H}_{2} \mathrm{O}
$$

2.2 As shown in the following reaction scheme, resultant nitrite plus any nitrite present in the sample prior to enzymatic reduction, diazotizes with sulfanilamide (SAN) at $\mathrm{pH} \approx 1$. The $\mathrm{p}$-diazonium sulfanilamide thus formed subsequently reacts with $\mathrm{N}-(1-\mathrm{Naphthyl)}$ ethylenediamine (NED) the Bratton-Marshall variant of the Griess reaction- to form a pink azo dye with an absorption maximum at 543 nanometers (nm) (Bendschneider and Robinson, 1952; Fox, 1979, 1985; Pai and others, 1990).

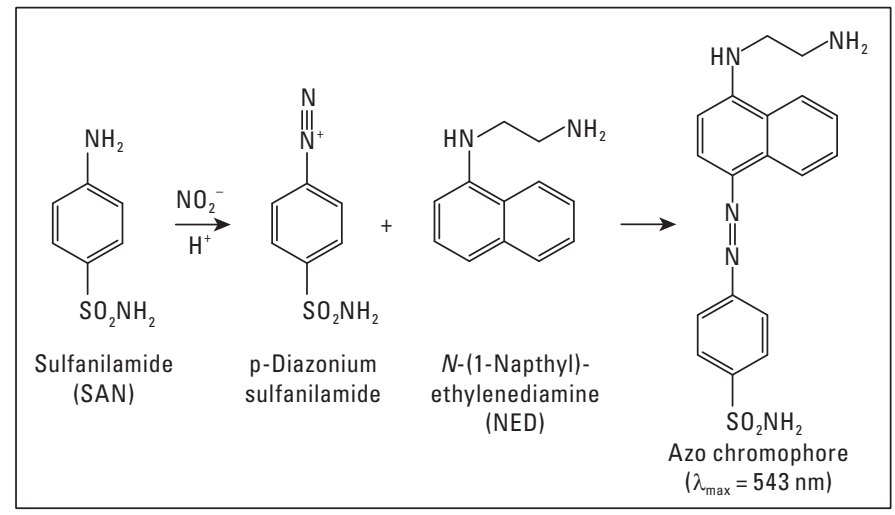

\section{Interferences}

3.1 During photometric detection any particles in samples (turbidity) scatter light and thereby contribute to apparent chromophore absorbance. Discernible sample turbidity that would otherwise falsely elevate apparent nitrate concentration, therefore, should be removed by 0.45 -micrometer membrane filtration prior to analytical determinations.

3.2 Data in table 2 confirm that chloride and sulfate slightly retard reduction of nitrate to nitrite by cadmium (Nydahl, 1976) and indicate that these anions have a similar effect on reduction of nitrate to nitrite by soluble YNaR1. We normalized percent nitrate reduction values in this table by assuming 100-percent reduction for $5 \mathrm{mg}-\mathrm{N} / \mathrm{L}$ nitrate solutions that did not contain chloride or sulfate. Considering median concentrations of chloride and sulfate determined annually at the NWQL - about $15 \mathrm{mg} / \mathrm{L}$ and $23 \mathrm{mg} / \mathrm{L}$, respectively — and the greater than 95-percent nitrate recovery at chloride and sulfate concentrations up to $1,000 \mathrm{mg} / \mathrm{L}$, these anions should interfere negligibly in surface-water and groundwater samples typically analyzed for nitrate at the NWQL. Furthermore, the similar CdR- and YNaR1-method dose/response functions for chloride and sulfate indicated in table 2 suggest that these anions may also slightly retard the colorimetric indicator reaction. In any case, these anions at concentrations up to $1,000 \mathrm{mg} / \mathrm{L}$ would have negligible effect on statistical comparisons of $\mathrm{NO}_{x}$ concentrations determined by CdR- and NaR-based methods.

\subsection{High concentrations of certain transition- and} heavy-metal ions such as iron, copper, zinc, and lead inhibit $\mathrm{NaR}$ to various extents and therefore might hinder quantitative reduction of nitrate to nitrite. Ethylenediamine tetraacetic acid (EDTA) forms strong complexes with such metal ions and effectively minimizes their potential interference. Large bufferto-sample volume ratios used in methods described here further mitigate reduction-step and colorimetric-step interferences.

3.4 High-phenolic-content humic acids (HA) in samples are powerful inhibitors of several NaRs evaluated in this work. It is noteworthy that at subambient temperatures $\left(5-20^{\circ} \mathrm{C}\right)$, HA inhibition is negligible for the four NaRs we evaluated. Except for AtNaR2, HA inhibition increases as reaction temperature increases above $20^{\circ} \mathrm{C}$. AtNaR2 is unique in maintaining high activity at $\mathrm{HA}$ concentrations up to $20 \mathrm{mg} / \mathrm{L}$ even at $37^{\circ} \mathrm{C}$.

3.5 Colorimetric Griess indicator reaction interferences have been characterized and assessed systematically by Norwitz and Keliher $(1985,1986)$. Recently elucidated Griess reaction chromophore formation suppression caused by Fe (II) concentrations greater than or equal to about $10 \mathrm{mg} / \mathrm{L}$ can be eliminated by replacing EDTA with diethylenetriaminepentaacetic acid in $\mathrm{NO}_{x}$ assay buffers (Colman and Schimel, 2010a, b). Fe (II) concentrations of this magnitude are rare in surface water and groundwater, but analysts applying methods described in this report to determination of $\mathrm{NO}_{x}$ in high-iron soil extracts, acid mine drainage water, or pore water from low-oxygen bed sediments should be aware of this potential interference and its remedy.

3.6 NADH, the cofactor reagent we used with YNaR1 and AtNaR2 enzymes, inhibits the Griess indicator reaction (Patton and others, 2002, table 1; Moody and Shaw, 2006). In our experience, quantitative reduction of nitrate to nitrite with minimum Griess reaction inhibition occurs when initial NADH

Table 2. Effects of chloride and sulfate on reduction of 5 milligrams nitrate-nitrogen per liter solutions by $\mathrm{CdR}$ and $\mathrm{YNaR} 1$ nitrate reductase.

[mg/L, milligram(s) per liter; CdR, cadmium reduction; YNaR1, recombinant nitrate reductase from Pichia angusta]

\begin{tabular}{|c|c|c|c|c|}
\hline \multirow{3}{*}{$\begin{array}{c}\text { Anion } \\
\text { concentration } \\
\text { (mg/L) }\end{array}$} & \multicolumn{4}{|c|}{$\begin{array}{c}\text { Nitrate reduction } \\
\text { (percent) }\end{array}$} \\
\hline & \multicolumn{2}{|c|}{ Chloride } & \multicolumn{2}{|c|}{ Sulfate } \\
\hline & CdR & YNaR1 & CdR & YNaR1 \\
\hline 0 & 100.0 & 100.0 & 100.0 & 100.0 \\
\hline 5 & 100.0 & 100.8 & 97.7 & 98.8 \\
\hline 10 & 98.1 & 98.1 & 97.4 & 98.3 \\
\hline 50 & 96.3 & 97.0 & 97.1 & 97.4 \\
\hline 100 & 96.0 & 96.1 & 96.9 & 97.3 \\
\hline 500 & 95.9 & 96.2 & 96.5 & 97.3 \\
\hline 1,000 & 96.5 & 97.4 & 96.6 & 97.4 \\
\hline
\end{tabular}


concentration is in two-fold molar excess to that of a method's maximum nitrate concentration in the reaction medium. All methods described here conform to this initial NADH concentration condition. It is also noteworthy that $\mathrm{NaR}$ promotes oxidation of NADH to $\mathrm{NAD}^{+}$even in the absence of nitrate. This property is of little consequence in automated methods that use separate NaR and NADH reagents, but it limits the useful lifetime of combined NaR/NADH reagent used in semiautomated batch (batch) methods to about one hour.

\section{Instrumentation}

4.1 We previously described (Patton and others, 2002) complete details of the three-channel, CFA instrument configured for simultaneous photometric determination of nitrite, $\mathrm{CdR} \mathrm{NO}_{x}$, and $\mathrm{YNaR} 1$-reduction $\mathrm{NO}_{x}$. In CFA-method validation work reported here, we substituted 3 enzyme units (U) of YNaR1 for each unit of NaR1 (section 2.1) that we had used in previous research (Patton and others, 2002). This increase in enzyme concentration allowed us to reduce the reaction coil volume to 4 milliliters $(\mathrm{mL})$. We also decreased reaction coil temperature from $30{ }^{\circ} \mathrm{C}$ to near ambient $\left(\approx 26^{\circ} \mathrm{C}\right)$ for reasons explained in section 3.4.

For low-level CdR and YNaR1 validation work, we modified $\mathrm{CdR}$ and $\mathrm{NaR}$ analytical cartridges as follows:

CdR Increased sample flow rate to 166 microliter per minute $(\mu \mathrm{L} / \mathrm{min})$ - an orange-white pump tube replaced the orange-green pump tube.

$\mathrm{NaR}$ 1. Removed dilution loop.

2. Removed and replaced resample pump tube with three pump tubes:

- 2.5 millimoles per liter ( $\mathrm{m} M$ ) EDTA diluent (orange-yellow, $118 \mu \mathrm{L} / \mathrm{min}$ ),

- air (orange-green, $74 \mu \mathrm{L} / \mathrm{min}$ ), and

- sample (orange-yellow, $118 \mu \mathrm{L} / \mathrm{min}$ ).

4.2 We also developed an offline, batch NaR-reduction method amenable to automated or manual colorimetric determination of resulting nitrite with a variety of instrument types such as CFA, flow injection analyzers (FIA), DA, and benchtop spectrophotometers. Our goal in this work was to make simple, green-chemistry $\mathrm{NO}_{x}$ analysis accessible to public-, private-, and academic-sector water-quality and teaching laboratories. Although our batch method can be carried out with traditional Class A or digital pipets, we found that programmable dispensers/dilutors (fig. 1) streamlined dispensing operations substantially. They were particularly when we used autosampler cups or disposable cuvettes as reaction vessels for the enzymatic reduction step. For example, we used a dispenser/dilutor to aspirate samples, dose them with a combined $\mathrm{YNaR} 1 / \mathrm{NADH}$ reagent, and deliver the reactive solutions into autosampler cups or disposable spectrophotometer cuvettes in a single, rapid operation. The force of dispensing sample and enzyme reagent into reaction vessels induces secondary flow that results in rapid mixing. Forty minutes to 24 hours after initiating enzymatic nitrate reduction reactions, we performed colorimetric nitrite assays either automatically by CFA, FIA, or DA at analysis rates of 180 samples per hour (samples/h), $75 \mathrm{samples} / \mathrm{h}$, or $600 \mathrm{samples} / \mathrm{h}$, respectively, or manually with a Cary 50 spectrophotometer (Agilent Technologies, Inc, Santa Clara, Calif.). In the latter case, we dispensed Griess reagents into disposable cuvettes prior to absorbance measurements at $543 \mathrm{~nm}$ with the spectrophotometer. We typically dispensed sample and mixed $\mathrm{NaR} /$ NADH reagent volumes of $25 \mu \mathrm{L}$ and $500 \mu \mathrm{L}$, respectively, for CFA and DA assays, and $50 \mu \mathrm{L}$ and $1,000 \mu \mathrm{L}$, respectively, for FIA and manual assays. Figure $1(A-C)$ illustrates preparative steps for batch-reduction procedures.

\section{Apparatus and Operating Parameters}

We used EDP-plus digital pipets (Rainin Instruments, Oakland, Calif.) fitted with $10-100-\mu \mathrm{L}, 100-1,000-\mu \mathrm{L}$, and $1.00-10.00-\mathrm{mL}$ liquid ends as appropriate for most precision dispensing such as preparing calibrants, third-party check solutions, spike solutions and spikes, and some reagents. In batch reduction procedures, we used a programmable, dualsyringe dispenser/dilutor (Model IQ 190 DS, Cavro OEM Components, San Jose, Calif.) equipped with a $100-\mu \mathrm{L}$ sample syringe and a 5- or 10-mL reagent syringe (fig. 1) to aspirate samples, dose them with mixed NADH/YNaR1 reagent, and dispense them into appropriate reaction vessels. Although figure 1 shows samples being aspirated directly from bottles, we poured small volumes of calibrants, QC solutions, and samples into 2-mL autosampler cups and placed them on an autosampler tray (fig. 1C). We then aspirated samples from these cups and dispensed them with $\mathrm{NaR} / \mathrm{NADH}$ reagent into colorimetric-method-appropriate containers. The Cavro IQ 190 is no longer in productions, but other currently available benchtop dispensers/dilutors-Hamilton 500 series (Hamilton Instruments, Reno, Nev.), for example - are functionally equivalent.

A model TLC 40 temperature-controlled cuvette holder (Quantum Northwest, Spokane, Wash.) equipped with a magnetic stirring accessory provided continuous stirring and cooling/heating to $\pm 0.03{ }^{\circ} \mathrm{C}$ for enzymatic and colorimetric reactions that we monitored over a $5-50{ }^{\circ} \mathrm{C}$ temperature range. In such experiments we used standard, 1.0-centimeter $(\mathrm{cm})$ path length, quartz cuvettes (Starna Cells, Inc., Atascadero, Calif.) as reaction vessels. Although the TLC 40 module was designed for use with Cary 50 spectrophotometers, we also mounted it on the deck of an OB-1 autosampler (Oregon Manufacturing Support, Malin, Oreg.) for automated kinetics experiments as shown in figure 2. For such experiments we connected the OB-1 sampler probe to the sample inlet of an RFA-300 CFA nitrite analyzer and set sample and wash times at 20 seconds (s) and $10 \mathrm{~s}$, respectively. 

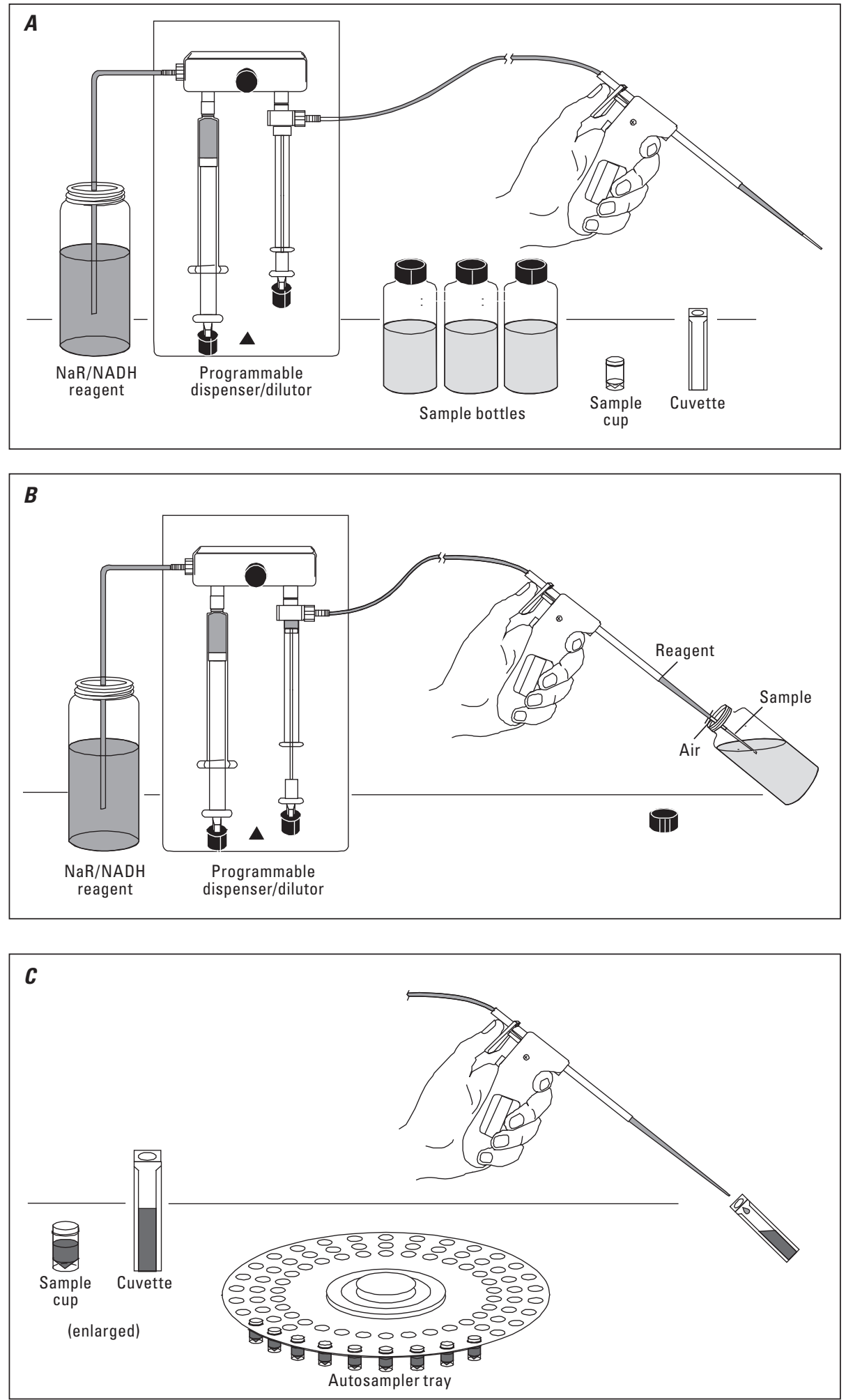

Figure 1. Sketches showing steps for offline enzymatic reduction of nitrate to nitrite using a syringe-pump-based dispenser/diluter module. $A$, reagent syringe filled and ready for sample aspiration; $B$, sample pickup; $C$, sample and reagent dispensed and mixed. (NADH, nicotinamide adenine dinucleotide in reduced form, a natural cofactor of $\mathrm{NaR}$ enzyme reagents $\mathrm{YNaR} 1$ and $\mathrm{AtNaR2}$ ) 


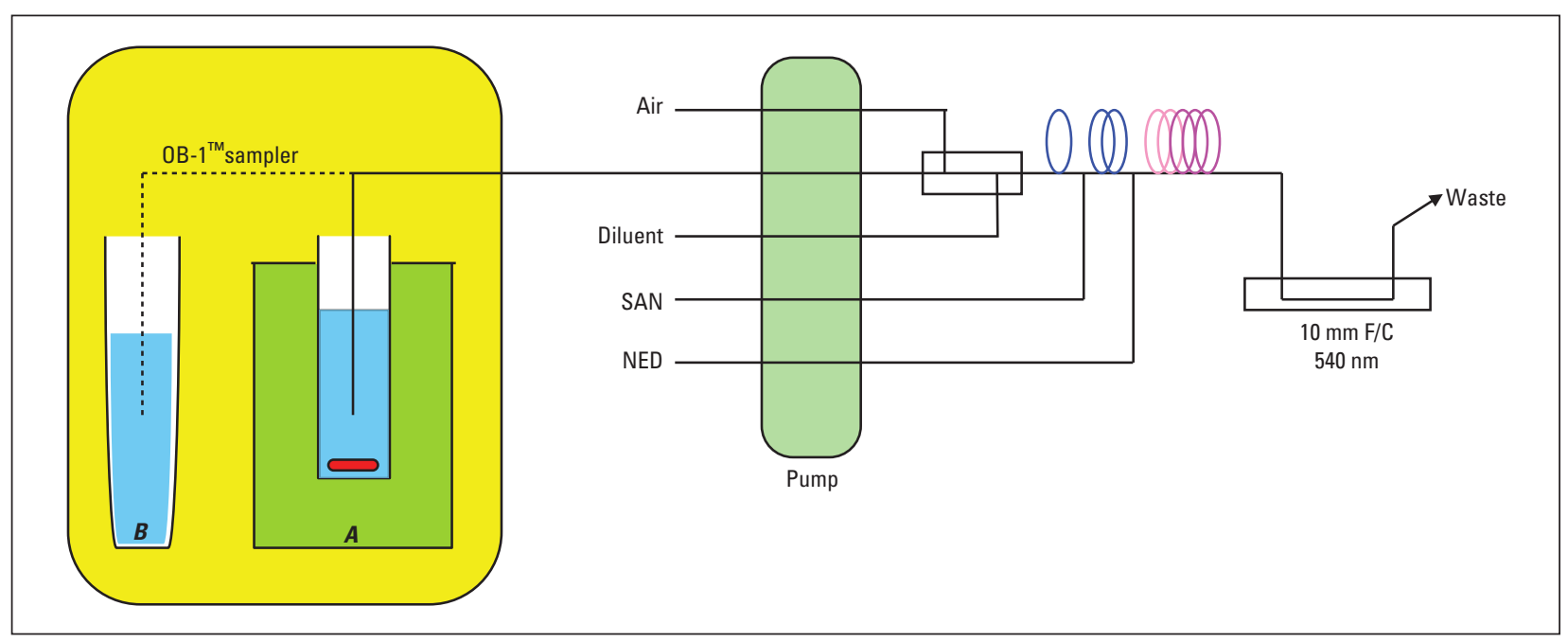

Figure 2. Arrangement of components used for thermostatted nitrate reductase (NaR) kinetics experiments. $A$, TLC 40 peltier heating and cooling module; $B, \mathrm{OB}-1$ sampler wash solution reservoir; dotted line indicates movement of the sampler probe between $A$ and $B$. Sulfanilamide and $\mathrm{N}$-(1-Naphthyl)-ethylenediamine reagents are abbreviated as SAN and NED, respectively; $\mathrm{F} / \mathrm{C}$ denotes the photometer flow cell; $\mathrm{nm}$, nanometers. See sections 5 and 6 text for additional details.

The OB-1 sampler wash reservoir (B in fig. 2) was not thermostatted. We began each experiment by pipetting $2.460 \mathrm{~mL}$ of buffered $\mathrm{NaR}$ reagent (refer to section 6.1.4) and $0.150 \mathrm{~mL}$ of sample into a magnetically stirred cuvette positioned in the TLC 40 module. After NaR reagent and sample had equilibrated to the desired temperature $\left(5-40{ }^{\circ} \mathrm{C}\right.$, typically), we added $0.540 \mathrm{~mL}$ of $\mathrm{NADH}$ reagent to initiate reduction of nitrate to nitrite.

We followed reaction progress by Griess-reaction nitrite analysis using our standard CFA nitrite analytical cartridge (Patton and others, 2002). Nominal pump tube delivery rates for air, sample, diluent, SAN reagent, and NED in this application (fig. 2) were $74 \mu \mathrm{L} / \mathrm{min}, 287 \mu \mathrm{L} / \mathrm{min}, 166 \mu \mathrm{L} / \mathrm{min}$, $74 \mu \mathrm{L} / \mathrm{min}$, and $74 \mu \mathrm{L} / \mathrm{min}$, respectively. This third-generation CFA analyzer with pecked sampling, 1-mm internal diameter analytical cartridge components, 1.5 hertz $(\mathrm{Hz})$ segmentation frequency, and 2- $\mu \mathrm{L}$ bubble-through flow cells (Patton and Wade, 1997) produced baseline resolved peaks at the 2 samples/min analysis rate we used for all such experiments. The sampling cycle (20 s sample; $10 \mathrm{~s}$ wash) began with aspiration of the first reaction solution aliquot, which we initiated within a second or two of NADH addition. The aspirated slug of enzymatic test solution continues to react, without temperature regulation, within the sample pump tube and first mixing coil of the CFA nitrite analyzer. Therefore $\mathrm{NaR}$ in the aspirated reaction solution remains active for about $60 \mathrm{~s}$ until it reaches the point of acidic SAN reagent addition. At that point $\mathrm{NaR}$ is denatured and reduction of nitrate to nitrite stops (see fig. 2). Figure 3 shows the output from a typical kinetics experiment; here, the first peak (left-to-right) represents the amount of nitrate reduced to nitrite during the 1-min transit time between the tip of the sampler needle and the point of SAN reagent addition.

\section{Reagent Preparation}

Here we provide detailed instructions for preparing enzymatic and colorimetric reagents, which are the same for CFA and batch methods. All references to DI water refer to DI water piped throughout the NWQL. For purposes of nutrient analysis, NWQL DI water is equivalent to ASTM type I DI water (American Society for Testing and Materials, 2001, p. 107-109). We triple rinsed all volumetric glassware and containers for reagent and calibrant storage with dilute ( $\approx 5$ percent volume-to-volume) hydrochloric acid and DI water just prior to use. We also triple rinsed reagent and calibrant storage containers with small portions of the solutions they were to contain before we filled them.

\subsection{Enzymatic reagents}

6.1.1 Disodium ethylenediaminetetraacetic acid (EDTA), $25 \mathrm{~m} M$ : Dissolve 9.3 grams (g) EDTA—formula weight $(\mathrm{FW})=372.24$, ultrapure grade - in approximately $800 \mathrm{~mL}$ DI water contained in a 1-L volumetric flask. Dilute the resulting solution to the mark with DI water, mix well, and transfer to a tightly capped bottle. The solution is stable at room temperature for 1 year.

6.1.2 Phosphate buffer $(\mathrm{pH}=7.5)$ : Dissolve $3.75 \mathrm{~g}$ potassium dihydrogen phosphate $\left(\mathrm{KH}_{2} \mathrm{PO}_{4}, \mathrm{FW}=136.1\right)$ and $1.4 \mathrm{~g}$ potassium hydroxide $(\mathrm{KOH}, \mathrm{FW}=56.11)$ in about $800 \mathrm{~mL}$ of DI water contained in a 1-L volumetric flask. Add $1 \mathrm{~mL} 25 \mathrm{mM}$ EDTA, dilute the resulting solution to the mark with DI water, and mix well. Transfer this solution to a tightly capped bottle where it is stable at room temperature for 1 year.

6.1.3 Nitrate reductase (NaR): Remove the cap from a vial containing $3 \mathrm{U}$ of freeze-dried Pichia angusta $\mathrm{NaR}$ (EC 1.7.1.2, formerly EC 1.6.6.2, designated "YNaR1") or $3 \mathrm{U}$ of Arabidopsis thaliana NaR (EC 1.7.1.1, designated 


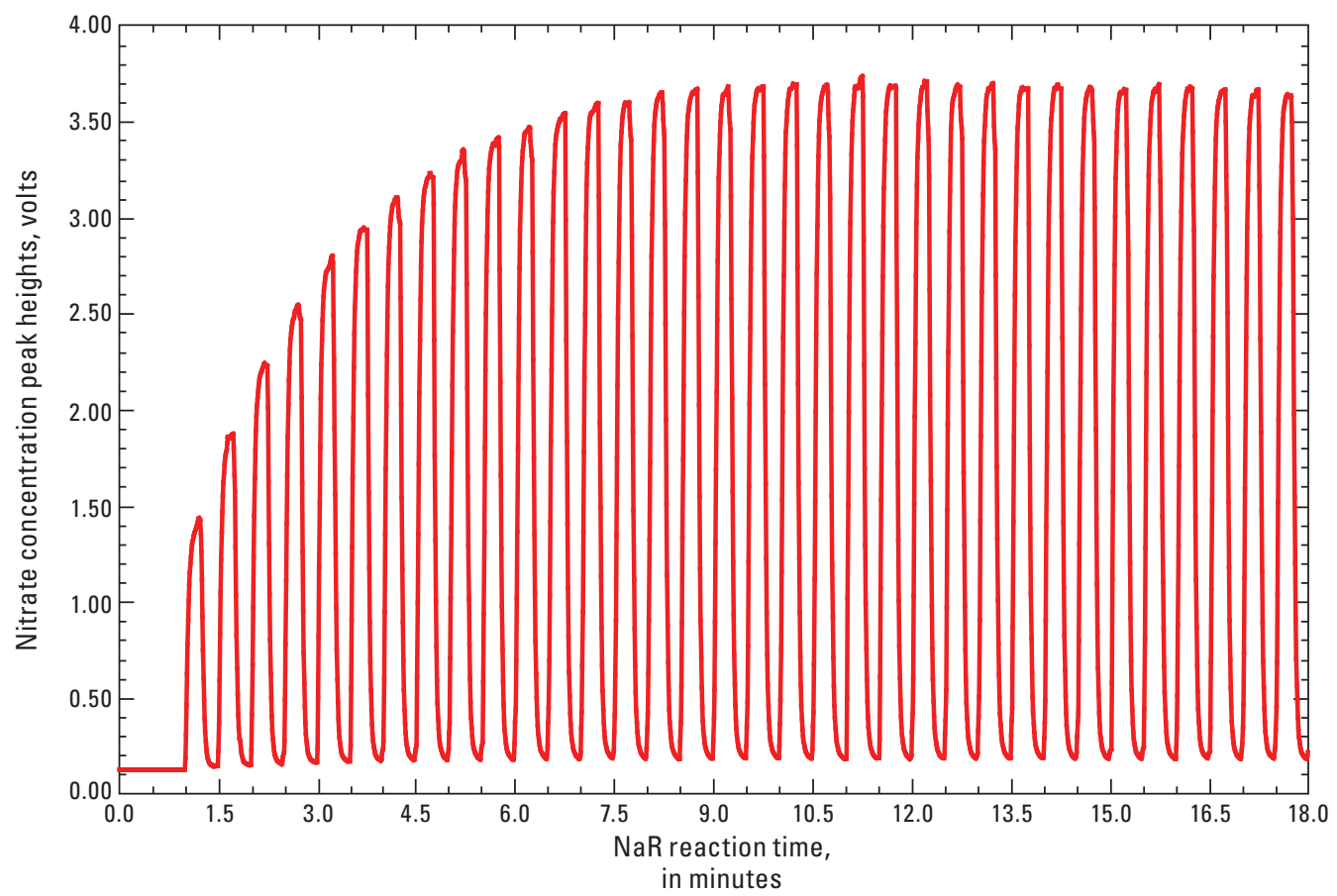

Figure 3. Typical nitrite analyzer output for nitrate reductase $(\mathrm{NaR})$ kinetics experiments. Each peak indicates the amount of nitrate reduced to nitrite by $\mathrm{NaR}$ at 30 -second intervals. Reaction times are offset by the 1-minute transit time of the reaction mixture from the thermostatted reaction cell to the sulfanilamide (SAN) reagent addition point of the continuous flow analysis (CFA) nitrite analyzer. The low $\mathrm{pH}$ of the SAN reagent quenches the enzymatic reaction.

"AtNaR2") and dispense $1 \mathrm{~mL}$ of $\mathrm{pH} 7.5$ phosphate buffer into it. Alternatively, simply squeeze the contents of one plastic ampoule containing proprietary reconstitution buffer supplied by NECi into the NaR vial. Recap the vial and invert it several times over the course of 20 min to speed dissolution of the freeze-dried enzyme.

Notes: (1) A unit (U) — not from the International System of Units (SI) - of NaR is the amount that catalyzes the conversion of 1 micromole of nitrate to nitrite in $1 \mathrm{~min}$ at $\mathrm{pH} 7.5$ and $30{ }^{\circ} \mathrm{C}$. (2) According to $\mathrm{NECi}, 3 \mathrm{U}$ of YNaR1 or AtNaR2 that have been dissolved in $\approx 1 \mathrm{~mL}$ of its proprietary reconstitution buffer-included at no charge with $\mathrm{NaR}$ orders in single-use, squeezable plastic ampoules - are stable at or below $-15^{\circ} \mathrm{C}$ for several months.

6.1.4 Working NaR reagent: Quantitatively transfer the dissolved enzyme concentrate into an appropriate containera 50-mL polypropylene, conical-bottom, screw-cap centrifuge tube works well for CFA and batch methods. Dilute reconstituted $\mathrm{NaR}$ as follows:

1. Carefully pour the dissolved enzyme concentrate from the vial in which it was reconstituted into the working reagent container.

2. Use a digital pipet to dispense $1 \mathrm{~mL}$ of $\mathrm{pH} 7.5$ phosphate buffer into the empty enzyme vial.

3. Recap the vial and invert it several times.

4. Before removing the cap, tap it sharply with your finger to dislodge adherent droplets.
5. Remove the cap and pour the resulting rinse solution into the reagent tube.

6. Repeat steps $2-5$ two more times, after which the working reagent container will contain $4 \mathrm{~mL}$ of enzyme concentrate in phosphate buffer.

7. Dispense an additional $16.0 \mathrm{~mL}$ of phosphate bufferdispensing $8 \mathrm{~mL}$ twice from a digital pipet equipped with a $10-\mathrm{mL}$ liquid end works well-into the working reagent container and mix the contents well. Working $\mathrm{NaR}$ enzyme reagent solutions are stable at $2-8{ }^{\circ} \mathrm{C}$ for about $18 \mathrm{~h}$.

If a $20-\mathrm{mL}$ batch of this reagent cannot be used within $8 \mathrm{~h}$, prepare a smaller volume - for example, $500 \mu \mathrm{L} \mathrm{NaR}$ concentrate diluted to $10 \mathrm{~mL}$ with $\mathrm{pH} 7.5$ buffer - and store remaining $500 \mu \mathrm{L}$ of $\mathrm{NaR}$ concentrate at or below $-15^{\circ} \mathrm{C}$ for future use. Alternatively, freeze remaining working $\mathrm{NaR}$ reagent at or below $-15^{\circ} \mathrm{C}$.

6.1.5 $\beta$-Nicotinamide adenine dinucleotide, reduced form, disodium salt (NADH) stock solution: Dissolve $0.100 \mathrm{~g}$ of NADH (FW $=709.4$, Sigma catalog number N 8129, $\approx 98$ percent) in approximately $40 \mathrm{~mL}$ of DI water contained in a 50-mL volumetric flask. Dilute the resulting solution to the mark with DI water and mix well. Use a digital pipet to transfer 1-mL aliquots of stock NADH reagent into 1.7-mL snap-cap vials (VWR, Radnor, Pa., catalog number 20170-650) and store them in a freezer at $-20^{\circ} \mathrm{C}$ where they are stable for 6 weeks. 
6.1.6 NADH working solution: Remove one vial of stock NADH from the freezer and allow it to thaw at ambient temperature for about $20 \mathrm{~min}$. Quantitatively transfer the stock NADH solution into in an appropriate reagent container-a 15 -mL polypropylene, conical-bottom, screw-cap centrifuge tube works well for CFA and batch methods. Dilute thawed NADH as follows:

1. Carefully pour the thawed NADH concentrate into the working reagent tube.

2. Use a digital pipet to dispense $1 \mathrm{~mL}$ of phosphate buffer into the empty snap-cap vial.

3. Recap the vial and invert it several times.

4. Before flipping the cap up, tap it sharply with your finger to dislodge adherent droplets and add this rinse to the working NADH reagent tube, which will then contain $2 \mathrm{~mL}$.

5. Use a digital pipet equipped with a $10-\mathrm{mL}$ liquid end to dispense $8.0 \mathrm{~mL}$ of phosphate buffer into the working NADH reagent tube and mix the contents well. This $10-\mathrm{mL}$ volume of working NADH reagent is stable at 2-8 ${ }^{\circ} \mathrm{C}$ for at least $24 \mathrm{~h}$.

Note: (1) In 2007, the NWQL began using NECi reagent kits that contain $3 \mathrm{U}$ of freeze-dried NaR, $2 \mathrm{mg}$ of NADH (each in a separate vial), and a plastic ampoule containing $1 \mathrm{~mL}$ of proprietary reconstitution buffer. After $1 \mathrm{~mL}$ of $\mathrm{pH}$ 7.5 phosphate buffer is added to the vial containing $2 \mathrm{mg}$ of $\mathrm{NADH}$, preparative steps are identical to those described for thawed NADH concentrate (section 6.1.5).

6.1.7 Combined NaR/NADH reagent (batch methods only): Combine and mix $20 \mathrm{~mL}$ of working NaR reagent (section 6.1.4), $10 \mathrm{~mL}$ of working NADH reagent (section 6.1.6), and $25 \mathrm{~mL}$ of DI water in a plastic container. This reagent is stable only for about 1 hour.

\subsection{Colorimetric reagents}

6.2.1 Sulfanilamide reagent (SAN): Slowly add $150 \mathrm{~mL}$ concentrated hydrochloric acid $(\mathrm{HCl}, \approx 12 \mathrm{M})$ to about $250 \mathrm{~mL}$ DI water contained in a $500-\mathrm{mL}$ volumetric flask. While the solution is still warm, add $5.0 \mathrm{~g}$ sulfanilamide $\left(\mathrm{C}_{6} \mathrm{H}_{8} \mathrm{~N}_{2} \mathrm{O}_{2} \mathrm{~S}\right.$, $\mathrm{FW}=172.2$ ) to the flask. Swirl the flask gently to dissolve the SAN. Dilute this reagent to the mark with DI water and mix it well. Store SAN at room temperature in a clear glass or translucent plastic, $500-\mathrm{mL}$ bottle where it is stable for 6 months.

6.2.2 N-(1-Naphthyl)-ethylenediamine reagent (NED): Dissolve $0.5 \mathrm{~g} \mathrm{NED}\left(\mathrm{C}_{12} \mathrm{H}_{14} \mathrm{~N}_{2} \cdot 2 \mathrm{HCl}, \mathrm{FW}=259.2\right)$ in about $400 \mathrm{~mL}$ of DI water contained in a $500-\mathrm{mL}$ volumetric flask. Dilute this reagent to the mark with DI water and mix it well. Store NED at room temperature in an amber, $500-\mathrm{mL}$ glass bottle where it is stable for 6 months.

\section{Calibrants and Quality-Control Solutions}

For continuous-flow and manual batch nitrate and nitrite calibration, we obtained National Institute of Standards and Technology (NIST)-traceable 1,000 mg-N/L nitrate and nitrite solutions commercially and used them to prepare working calibrants and spike solutions by dilution with DI water. We used electronic digital pipets and Class A volumetric flasks to prepare all calibrants and QC solutions used in validation experiments described in this report. We observed vendorspecified storage temperatures and shelf lives for primary calibrants. We prepared working calibrants, QC, and spike solutions monthly and stored them in tightly capped containers in a refrigerator.

\section{Sample Preparation}

8.1 CFA enzymatic $\mathrm{NO}_{x}$ methods require analysts to rinse and fill analyzer-appropriate cups or tubes with wellshaken sample and place them into autosampler trays. No other manual sample preparation is required.

8.2 The batch enzymatic $\mathrm{NO}_{x}$ method requires analysts to dose samples, calibrants, and reference solutions with a combined $\mathrm{NaR} / \mathrm{NADH}$ reagent buffered at $\mathrm{pH}$ 7.5. After at least $20 \mathrm{~min}$ - about twice the minimum time required for quantitative reduction of nitrate to nitrite under assay conditions specified here - and up to $24 \mathrm{~h}$ later, analysts determine resulting nitrite by automated or manual Griess reaction colorimetry. Handheld or benchtop programmable dispensers/ dilutors streamline dispensing operations, particularly if autosampler cups or disposable cuvettes are used as reaction vessels for the enzymatic reduction step (section 4.2). We provide details of post-reduction, colorimetric nitrite determinations by automated CFA, FIA, and DA in the "Characterization of Nontoxic Nitrate Reductase Enzymes and Analytical Performance" section. For manual Griess reaction colorimetry we dispensed $250 \mu \mathrm{L}$ of SAN, waited $60-120 \mathrm{~s}$, and then dispensed $250 \mu \mathrm{L}$ of NED into post-reduction solutions $(50 \mu \mathrm{L}$ of sample plus $1 \mathrm{~mL}$ of combined NaR/NADH reagent). We inserted cuvettes into the sample compartment of a Cary 50 spectrophotometer and measured absorbance at $543 \mathrm{~nm} 10 \mathrm{~min}$ to $1 \mathrm{~h}$ after addition of colorimetric reagents. Unless specified otherwise, we measured absorbance at ambient temperature $\left(\approx 23^{\circ} \mathrm{C}\right)$.

\section{Instrument Performance}

9.1 Automated CFA and DA (nitrite only) methods operate at rates of 90 and 600 tests per hour, respectively. Approximate test volumes for CFA (excluding dilution loop) and DA methods are $400 \mu \mathrm{L}$ and $125 \mu \mathrm{L}$, respectively.

9.2 For batch NaR reduction procedures, we used a programmable dispenser/dilutor (see section 5) to aspirate samples, dose them with a combined $\mathrm{YNaR} 1 / \mathrm{NADH}$ reagent, and deliver 
the reactive solutions into autosampler cups or disposable spectrophotometer cuvettes at a rate of about $80 / \mathrm{h}$. This rate includes about 30 min needed to transfer a batch of 80 samples from their storage bottles into secondary containers-2-mL analyzer cups, typically. We took this precaution to avoid the possibility of contaminating bulk samples by aspirating subsamples directly from primary storage containers. Readers should note that as described under "Background Information" in the "Characterization of Nontoxic Nitrate Reductase Enzymes and Analytical Performance" section, the useful lifetime of combined $\mathrm{NaR} / \mathrm{NADH}$ reagent is only about $1 \mathrm{~h}$. After at least $20 \mathrm{~min}$ and up to $24 \mathrm{~h}$ after initiation of enzymatic nitrate reduction, resultant nitrite can be determined by automatic or manual colorimetry as described in the "Characterization of Nontoxic Nitrate Reductase Enzymes and Analytical Performance" section.

\section{Calibration}

For automated, semiautomated, and manual NaR nitratedetermination methods described in this report, we routinely obtained calibration curves with correlation coefficients $\left(\mathrm{r}^{2}\right)$ greater than 0.999 for second-order polynomial least-squares calibration functions $\left(y=a+b x+c x^{2}\right)$ (Draper and Smith, 1966). In this equation, $y$ is the baseline and blank-corrected absorbance (peak heights in the case of CFA and FIA methods) and $\mathrm{x}$ is the nominal nitrate concentration. Typical nitrate and nitrite calibration curves for $\mathrm{NaR}$ validation experiments with CFA instruments are published elsewhere (Patton and others, 2002). Calibration ranges for all standard- and low-level $\mathrm{NO}_{x}$ methods described in this report are $0.05-5.00 \mathrm{mg}-\mathrm{N} / \mathrm{L}$ and $0.01-1.00 \mathrm{mg}-\mathrm{N} / \mathrm{L}$, respectively. Throughout this report, dilution limits are $5.00 \mathrm{mg}-\mathrm{N} / \mathrm{L}$ and $1.00 \mathrm{mg}-\mathrm{N} / \mathrm{L}$ for standard- and low-level $\mathrm{NO}_{x}$ methods, respectively.

\section{Procedure and Data Evaluation}

Except as noted in section 4.1, we have published (Patton and others, 2002) complete details, including analytical cartridge diagrams for the nitrite, and $\mathrm{CdR}$ and $\mathrm{NaR} \mathrm{NO}_{x}$ determination methods that we used for CFA-method validation data reported here. Table 3 identifies NWQL standard operating procedures that provide complete procedural details of USGS CFA-CdR methods against which we validated soluble, NaR-reduction CFA methods.

\section{Calculations}

12.1 We used vendor-supplied software-fASPac version 3.3 (Astoria-Pacific, Clackamas, Oreg.) and WinUV (Agilent Technologies, Inc., Santa Clara, Calif.) - to acquire photometric data from CFA and benchtop spectrophotometer instruments and convert them into concentration units. Unless otherwise noted, we selected quadric, linear least-squares calibration functions (Draper and Smith, 1966) of the form
Table 3. National Water Quality Laboratory (NWQL) standard operating procedures for automated continuous-flow analyzer cadmium reduction nitrate + nitrite determination methods referenced in this report.

[+, plus; Lab, laboratory; SOP, standard operating procedure]

\begin{tabular}{ccc}
\hline \multicolumn{1}{c}{ Method name } & $\begin{array}{c}\text { Lab } \\
\text { code }\end{array}$ & $\begin{array}{c}\text { NWOL } \\
\text { SOP number }\end{array}$ \\
\hline $\begin{array}{c}\text { Nitrate + nitrite, cadmium reduction, automated } \\
\text { continuous flow }\end{array}$ & 1975 & ID0163.4 \\
$\begin{array}{c}\text { Nitrate + nitrite, cadmium reduction, automated } \\
\text { continuous flow, low-level }\end{array}$ & 1979 & ID0200.0 \\
$\begin{array}{c}\text { Nitrate + nitrite, cadmium reduction, automated } \\
\text { continuous flow, acidified }\end{array}$ & 1990 & IM0208.2 \\
$\begin{array}{c}\text { Nitrate + nitrite, cadmium reduction, automated } \\
\text { continuous flow, low-level, acidified }\end{array}$ & 3112 & INCW0440.0 \\
\hline
\end{tabular}

$y=a+b x+c x^{2}$ (refer to section 10). Method-specific standard operating procedures referenced in table 3 provide calibration protocols and complete calibrant preparation details for CFA methods. We manually prepared working calibrants for CFA methods.

12.2 We used Microsoft Office 2003 Excel to compile data acquired from instrument-specific software packages, to perform arithmetic and linear least-squares regression parameter calculations, and to prepare most graphical representations of data in this report. We used Origin Pro 8.0 (OriginLab Corp., Northampton, Mass.) to prepare box plots and to perform paired t-test and Wilcoxon signed-rank test statistical analyses.

12.3 The fASPac software identified in section 12.1 provides for automatic application of dilution factors - the number by which a measured concentration must be multiplied to obtain the analyte concentration in the sample prior to dilution. We diluted off-scale samples manually using digital pipets. The software requires entering the sum of one part sample $+n$ parts diluent. For example, entering dilution factor values of 2, 5, and 10 indicate sample to diluent proportions of $1+1,1+4$, and $1+9$ - that is, twofold, fivefold, and tenfold dilutions.

\section{Reporting Results}

13.1 Reporting units for $\mathrm{NO}_{x}$ and nitrite concentrations are milligrams nitrogen per liter (mg-N/L) in accordance with long standing USGS conventions. A table at the front of this report provides factors necessary to convert these units into several other commonly used concentration units.

13.2 We report concentrations such that the rightmost digit (called the least significant digit) represents the uncertainty in the analytical result (Novak, 1985; Hansen, 1991; U.S. Geological Survey, 2002). The least significant digit is determined using guidance outlined by the American Society for Testing and Materials (1999). By internal convention the NWQL reports results to the USGS National Water Information System (NWIS) database to one digit beyond the least significant digit. 


\section{Detection Limits, Bias, and Precision}

14.1 We estimated method detection limits (MDLs) for standard- and low-level concentration range CFA-CdR and CFA-YNaR1 methods (table 4) with composite, lowconcentration environmental samples - FCC bottle typesas promulgated by the EPA in CFR 40 part 136, Appendix B (U.S. Environmental Protection Agency, 1997). Between 2003 and 2006 when we acquired data for this report, the laboratory reporting level (LRL) indicated in some figures was operationally defined by NWQL convention as the MDL multiplied by 2 .

14.2 Table 5 lists the mean and standard deviation of third-party check samples $092 \mathrm{~L}, 092 \mathrm{M}$, and $092 \mathrm{H}$ that we included with each run of environmental water samples

Table 4. Data and calculations used to estimate method detection limits for nitrate + nitrite determination by automated CFA methods using packed bed $\mathrm{CdR}$ and soluble YNaR1 nitrate reductase methods.

$[+$, plus; CFA, continuous-flow analysis; CdR, cadmium reduction; YNaR1,

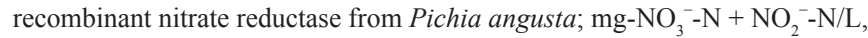
milligram(s) nitrate-nitrogen plus nitrite nitrogen per liter]

\begin{tabular}{|c|c|c|c|c|}
\hline \multirow{2}{*}{$\begin{array}{c}\text { Target concentration } \\
\text { [standard-(low-) } \\
\text { level] }\end{array}$} & \multicolumn{4}{|c|}{ Concentration found (mg- $\left.\mathrm{NO}_{3}^{-}-\mathrm{N}+\mathrm{NO}_{2}^{-}-\mathrm{N} / \mathrm{L}\right)$} \\
\hline & $\begin{array}{c}\text { CdR } \\
\text { (standard- } \\
\text { level) }\end{array}$ & $\begin{array}{c}\text { YNaR1 } \\
\text { (standard- } \\
\text { level) }\end{array}$ & $\begin{array}{l}\text { CdR } \\
\text { (low- } \\
\text { level) }\end{array}$ & $\begin{array}{l}\text { YNaR1 } \\
\text { (low- } \\
\text { level) }\end{array}$ \\
\hline $0.05(0.020)$ & 0.0544 & 0.0284 & 0.0180 & 0.0200 \\
\hline $0.05(0.020)$ & 0.0537 & 0.0283 & 0.0176 & 0.0187 \\
\hline $0.05(0.020)$ & 0.0525 & 0.0265 & 0.0173 & 0.0182 \\
\hline $0.05(0.020)$ & 0.0528 & 0.0350 & 0.0177 & 0.0184 \\
\hline $0.05(0.020)$ & 0.0519 & 0.0250 & 0.0177 & 0.0187 \\
\hline $0.05(0.020)$ & 0.0537 & 0.0319 & 0.0177 & 0.0177 \\
\hline $0.05(0.020)$ & 0.0520 & 0.0234 & 0.0170 & 0.0118 \\
\hline $0.05(0.020)$ & 0.0522 & 0.0265 & 0.0174 & 0.0179 \\
\hline Mean & 0.0529 & 0.0281 & 0.0176 & 0.0038 \\
\hline Standard deviation & 0.0009 & 0.004 & 0.0003 & 0.0007 \\
\hline Number of values & 8 & 8 & 8 & 8 \\
\hline Degrees of freedom & 7 & 7 & 7 & 7 \\
\hline t-value (1-sided, 99\%) & 2.998 & 2.998 & 2.998 & 2.998 \\
\hline Method detection limit & 0.003 & 0.01 & 0.0009 & 0.002 \\
\hline
\end{tabular}

during CFA method validation work between August 2003 and August 2004. We calculated control limits in table 5 using the USGS Branch of Quality Systems regression equations for median-based (robust) standard deviation (F-pseudosigma, " $f_{\sigma}$ ") in relation to concentration. The Branch of Quality Systems publishes these regression equations yearly on the basis of its blind sample program data on its USGS-visible intranet site (http://bqs.usgs.gov/ibsp/regress.shtml, accessed October 5, 2012). Inspection of table 5 reveals that $\mathrm{NO}_{x}$ concentration data for CFA-CdR and CFA-YNaR1 reduction methods were tightly centered around most probable values (MPV) and well within control limits. Figure 4 shows a control chart of third-party check concentrations obtained by low-level CFA-CdR and CFA-YNaR1 reduction methods during August and September 2004 validation experiments. Inspection of figure 4 indicates both $\mathrm{CdR}$ and $\mathrm{YNaR} 1$ method results were tightly clustered and within control limits. Typically, concentrations obtained by both reduction methods were slightly below the nominal concentration at which we prepared the third-party check samples.

Figure 5 shows a plot of percent relative standard deviations of replicate $\mathrm{NO}_{x}$ concentrations in relation to CFA-CdR $\mathrm{NO}_{x}$ concentrations that we determined in surface water (fig. 5A) and groundwater (fig. $5 B$ ) by standard-level CdR and YNaR1 reduction methods during CFA validation work between August 2003 and August 2004. Typically, concentrations replicated to within 25 percent near the MDL and approached about 5 percent at concentrations greater than five times the MDL.

Figure 6 shows a plot of percent relative standard deviations of duplicate $\mathrm{NO}_{x}$ concentrations in relation to $\mathrm{CdR}$ $\mathrm{NO}_{x}$ concentrations that we determined in surface water and groundwater by low-level methods during CFA validation work between August and September 2004. Relative standard deviations were 4 and 5 percent for duplicate analyses of 29 surface-water samples by CdR and YNaR1 methods, respectively, and 7 and 9 percent for duplicate analyses of seven groundwater samples, respectively.

Table 5. Third-party check sample nitrate + nitrite data summary for automated CFA-CdR and soluble CFA-YNaR1 reduction methods collected during validation experiments between August 2003 and August 2004.

[+, plus; CFA, continuous-flow analysis; $\mathrm{CdR}$, cadmium reduction; $\mathrm{YNaR} 1$, recombinant nitrate reductase from Pichia angusta $; \mathrm{NO}_{3}^{-}+\mathrm{NO}_{2}^{-}(\mathrm{mg}-\mathrm{N} / \mathrm{L})$, milligram(s) nitrate nitrogen plus nitrite nitrogen per liter; ID, identification; SD, standard deviation]

\begin{tabular}{|c|c|c|c|c|c|c|}
\hline & \multicolumn{3}{|c|}{$\mathrm{CdR} \mathrm{NO}_{3}^{-}+\mathrm{NO}_{2}^{-}(\mathrm{mg}-\mathrm{N} / \mathrm{L})$} & \multicolumn{3}{|c|}{$\mathrm{YNaR1} \mathrm{NO}_{3}^{-}+\mathrm{NO}_{2}^{-}-(\mathrm{mg}-\mathrm{N} / \mathrm{L})$} \\
\hline Reference sample ID & $092 \mathrm{~L}$ & $092 \mathrm{M}$ & $092 \mathrm{H}$ & $092 \mathrm{~L}$ & $092 \mathrm{M}$ & $092 \mathrm{H}$ \\
\hline Most probable value & 0.20 & 2.00 & 4.00 & 0.20 & 2.00 & 4.00 \\
\hline Upper control limit & 0.22 & 2.17 & 4.33 & 0.22 & 2.17 & 4.33 \\
\hline Mean concentration & 0.19 & 2.00 & 4.07 & 0.19 & 2.00 & 4.02 \\
\hline SD & 0.01 & 0.05 & 0.07 & 0.01 & 0.05 & 0.11 \\
\hline Relative SD (percent) & 3.53 & 2.26 & 1.61 & 3.67 & 2.69 & 2.63 \\
\hline
\end{tabular}




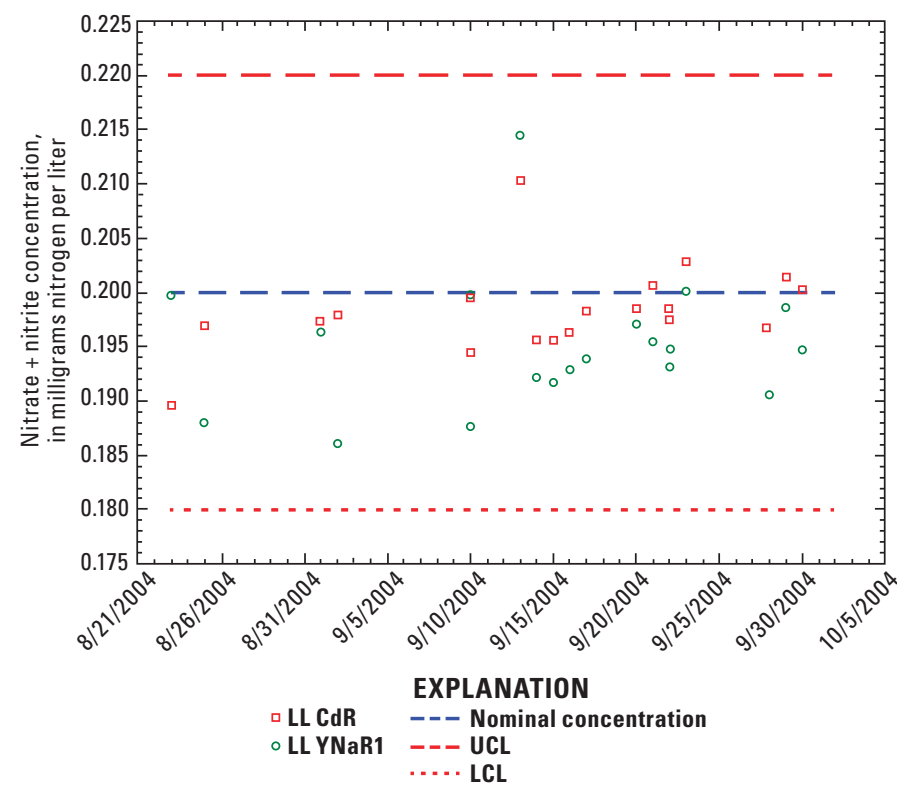

Figure 4. Control chart for low-level (LL) continuous flow analysis cadmium reduction ( $\mathrm{CdR}$ ) and nitrate reductase (YNaR1) reduction methods used during National Water Quality Laboratory validation experiments conducted between August 23, 2004 and September 30, 2004 (UCL, upper control limit; LCL, lower control limit).

\section{Characterization of Nontoxic Nitrate Reductase Enzymes and Analytical Performance}

\section{Background Information}

As our preliminary work demonstrating the feasibility of replacing packed bed CdRs with soluble NADH:NaR purified from corn seedlings (NaR1) for routine automated nitrate determinations in water (Patton and others, 2002) drew to a close, NECi was finishing development work on a new, bispecific nitrate reductase (YNaR1) manufactured by recombinant expression of the NaR gene from Pichia angusta, EC 1.7.1.2 (Barbier and others, 2004) in a Pichia pastoris system. NECi reported that YNaR1 was more robust and less costly to produce than NaR1. With partial funding from a Phase II U.S. Department of Agriculture small business innovation research (SBIR) grant_-USDA SBIR \# 2002-33610-12300, Environmentally benign automated nitrate analysis- $\mathrm{NECi}$ and the NWQL partnered through a formal, 2-year technical assistance agreement to characterize and validate YNaR1 as a soluble, nontoxic replacement reagent for granular, copperized cadmium in routine colorimetric nitrate determinations.

Our initial experiments with YNaR1 indicated that its analytical performance was similar to that of NaR1. And because YNaR1 costs less than NaR1, we doubled (and later tripled) its concentration in reagent formulations to reduce times necessary for quantitative reduction of nitrate to nitrite.
We also reasoned that increased YNaR1 concentrations would provide a hedge against low nitrate recoveries in unusual matrices - urban runoff effluents, for example - that might contain abnormally high and uncharacterized concentrations of $\mathrm{NaR}$ inhibitors. We also found that the useful lifetime of working YNaR1 reagent was considerably longer than the $8 \mathrm{~h}$ at $4{ }^{\circ} \mathrm{C}$ that we measured previously for working $\mathrm{NaR} 1$ reagent.

We established this by preparing four batches of working YNaR1 reagent (same procedures as described for $\mathrm{NaR}$ in sections 6.1.3 and 6.1.4) — two containing 25 volume percent of glycerol, a widely recognized stabilizer of enzymes and other complex proteins in aqueous solution (Bradbury and Jakoby, 1972) — and on the day of their preparation and for several days thereafter, we assessed their ability to reduce $5 \mathrm{mg}-\mathrm{N} / \mathrm{L}$ nitrate calibrants to nitrite in the standard-level, CFA-YNaR1 nitrate assay quantitatively. We stored all four batches of these working YNaR1 reagents in a refrigerator between uses, but allowed two batches - one containing glycerol, the other notto equilibrate to room temperature for about $2 \mathrm{~h}$ before each use. We maintained the temperature of the other two batches below $10{ }^{\circ} \mathrm{C}$ in a water-ice bath during each use. Figure 7 provides graphical summaries of working $\mathrm{YNaR} 1$ reagent storage stability. Inspection of this figure reveals that working YNaR1 reagents maintained below $10{ }^{\circ} \mathrm{C}$ performed comparably to freshly prepared reagent for 12 days. During this interval, glycerol had negligible effect on the stability of working YNaR1 reagents, but activity of the glycerol-containing batch that was maintained below $10{ }^{\circ} \mathrm{C}$ declined less rapidly than the other three batches after 12 days. For the two batches of working YNaR1 reagent allowed to warm to ambient temperature for several hours during each trial, the stabilizing effect of glycerol was noticeable even during the initial five days of the experiment.

As previously noted, the mixed $\mathrm{YNaR} 1 / \mathrm{NADH}$ reagent (prepared using the same procedure described for NaR/NADH in section 6.1.7) has a useful lifetime of only about an hour. This is because YNaR1 promotes oxidation of its NADH cofactor to $\mathrm{NAD}^{+}$even in the absence of nitrate. Figure 8 provides a graphical summary of experimental data that documents this phenomenon. To obtain data plotted in this figure, we prepared mixed YNaR1-NADH reagent (section 6.1.7) and after $10 \mathrm{~min}$ and at regular intervals thereafter, we used it to dose a DI water blank, a $5 \mathrm{mg}-\mathrm{N} / \mathrm{L}$ nitrate calibrant, and a surface-water sample. Inspection of figure 8 reveals that the reagent blank remained constant for the 3-h duration of the experiment. Apparent nitrate concentrations in the calibrant and surface-water sample dosed $1 \mathrm{~h}$ or more after mixed YNaR1-NADH reagent preparation, however, began to decrease exponentially about $1 \mathrm{~h}$ after its preparation. To demonstrate that this observed decrease in nitrate concentration was not caused by YNaR1 denaturation, we added $1 \mathrm{mg}$ of NADH to the remaining $30 \mathrm{~mL}$ of mixed YNaR1-NADH reagent about $5 \mathrm{~min}$ before using it to dose another blank, calibrant, and sample triad at the 3-hr mark. With reference again to figure 8 , the apparent nitrate concentrations in this 


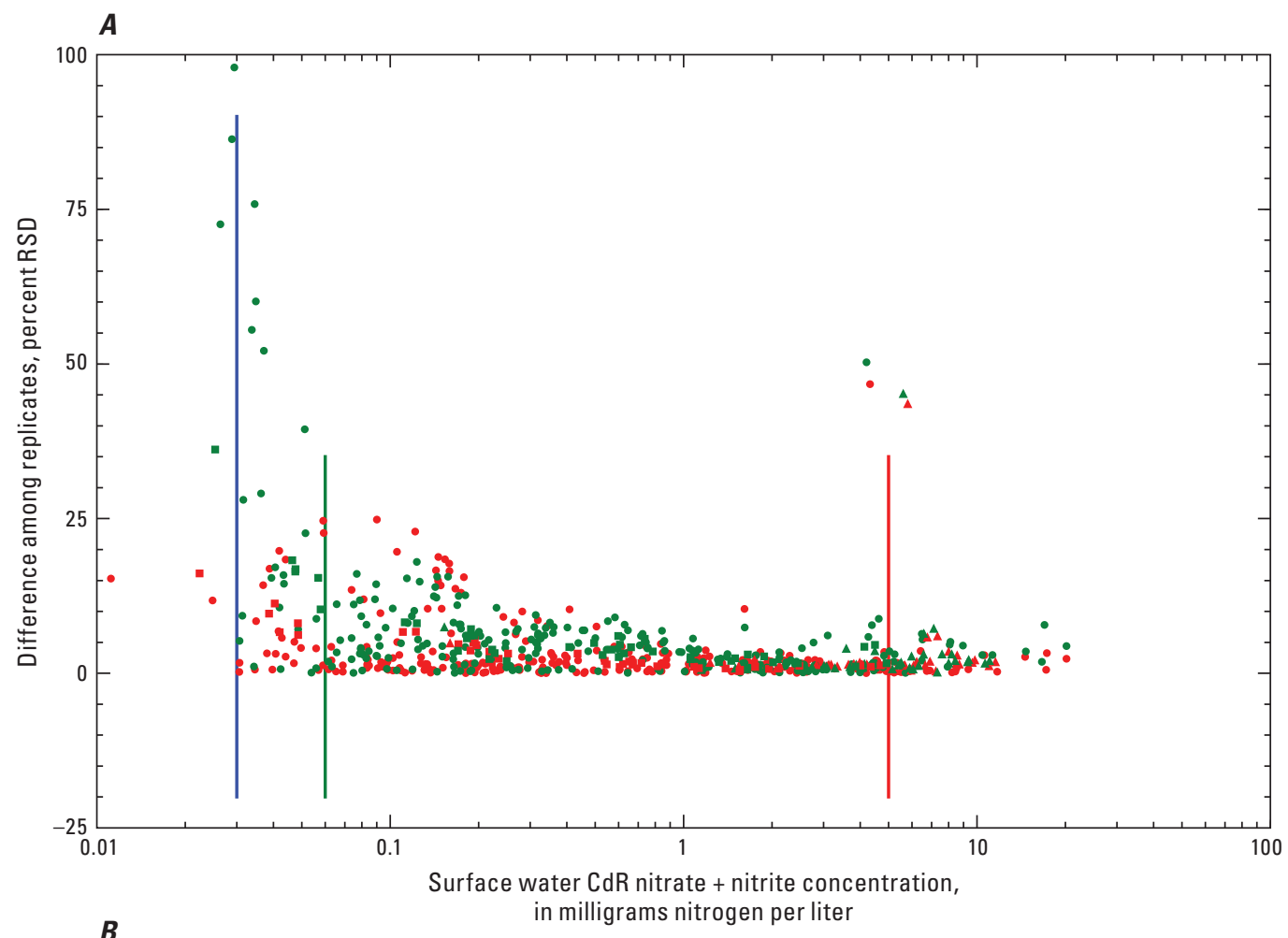

EXPLANATION

Method detection limit

Dilution limit

National Water Quality

Laboratory reporting limit

- CdR duplicates, $\mathrm{n}=\mathbf{2 5 6}$

- CdR triplicates, $\mathrm{n}=\mathbf{3 7}$

- CdR quintuplicates, $\mathrm{n}=41$

- $\quad$ NaR duplicates, $\mathrm{n}=\mathbf{2 5 6}$

$\triangle \quad$ NaR triplicates, $\mathrm{n}=\mathbf{3 7}$

- NaR quintuplicates, $\mathrm{n}=41$

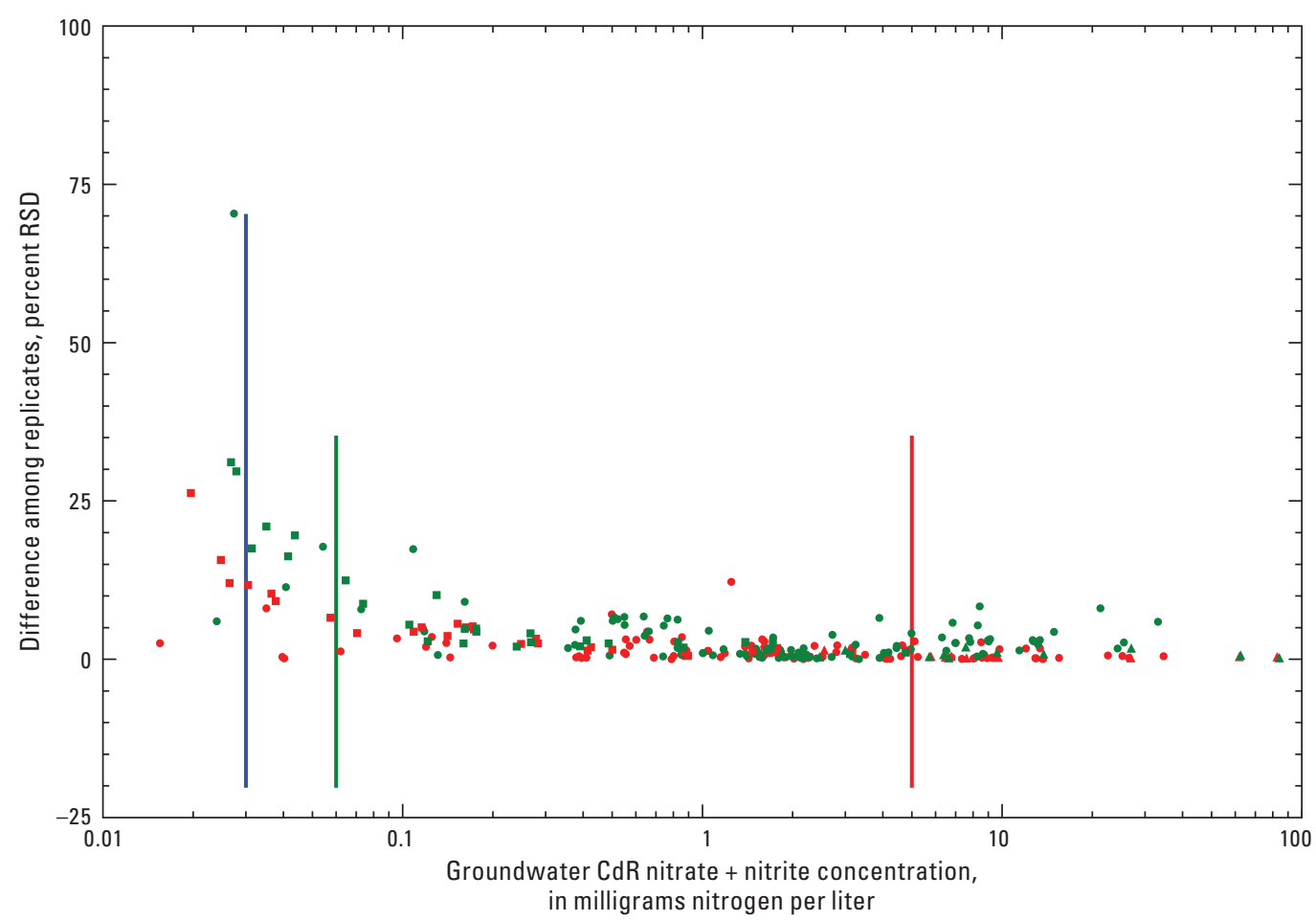

EXPLANATION

Method detection limit Dilution limit

National Water Quality

Laboratory reporting limit

CdR duplicates, $\mathrm{n}=95$

CdR triplicates, $\mathbf{n}=\mathbf{1 1}$

CdR quintuplicates, $\mathbf{n}=\mathbf{2 9}$

NaR duplicates, $\mathrm{n}=95$

NaR triplicates, $\mathbf{n}=\mathbf{1 1}$

NaR quintuplicates, $\mathrm{n}=\mathbf{2 9}$

Figure 5. Relative standard deviation (RSD) of same-bottle duplicate, triplicate, and quintuplicate nitrate + nitrite concentrations determined by standard-level continuous flow analyzer (CFA) cadmium reduction (CdR) and CFA-nitrate reductase (NaR) reduction methods. 


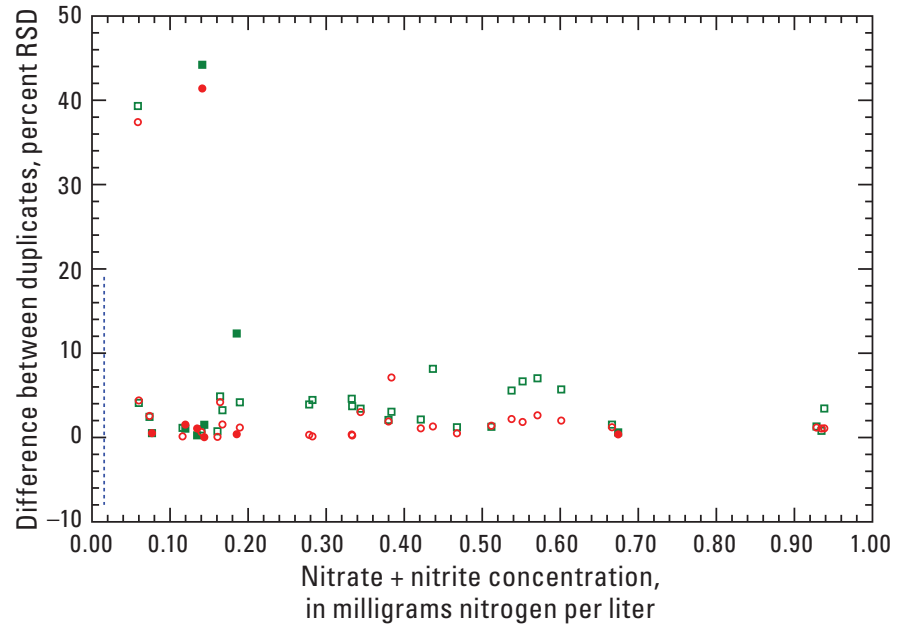

EXPLANATION

- YNaR1, surface water

- YNaR1, groundwater

- CdR, surface water

- CdR, groundwater

-...-...... NWOL reporting level

Figure 6. Agreement of between-day duplicate nitrate + nitrite concentrations for samples determined by low-level CFA-CdR and CFA-YNaR1 reduction methods. Percent relative standard deviation (RSD) for each duplicate pair is plotted as a function of mean CdR method concentration. The hash mark indicates 2004 reporting level of 0.016 milligram nitrogen per liter for NWOL low-level CFA-CdR nitrate + nitrite method (lab code 1979). (CFA, continuous flow analyzer; CdR, cadmium reduction; NWOL, National Water Quality Laboratory)

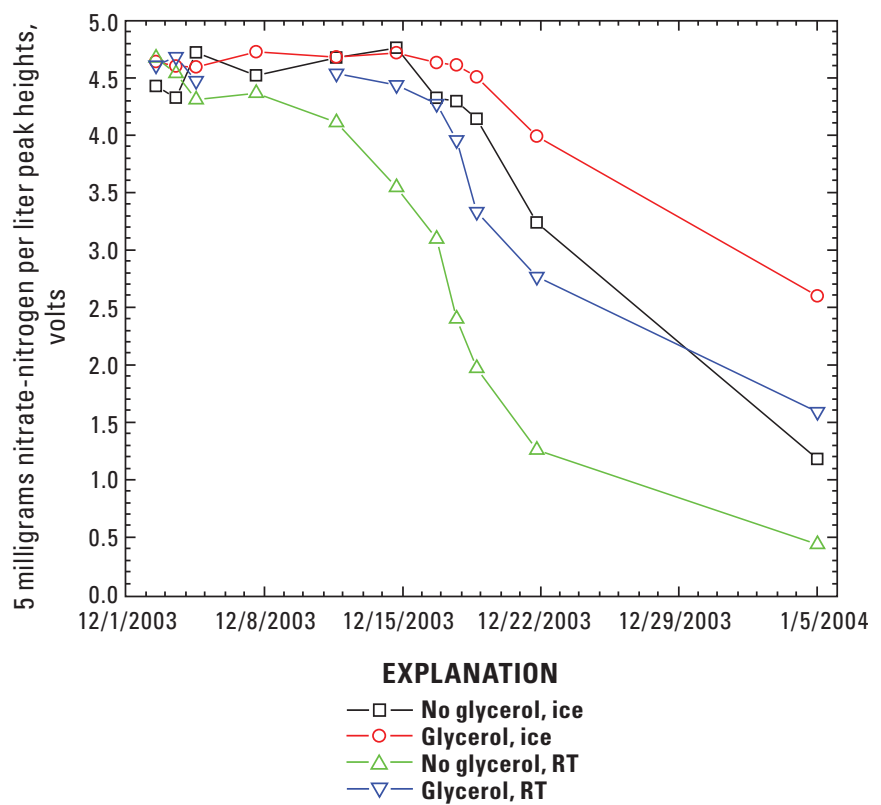

Figure 7. YNaR1 storage stability plots. Between-day storage for all four YNaR1 solutions was at 4 degrees Celsius $\left({ }^{\circ} \mathrm{C}\right) \pm 2^{\circ} \mathrm{C}$. During each 3-h use period we did not chill two of the test solutions, designated "RT," but maintained the other two, designated "Ice," at $\approx 4-8{ }^{\circ} \mathrm{C}$ in a water-ice bath. In these tests we prepared working nicotinamide adenine dinucleotide (NADH) reagent daily from frozen concentrate (see section 6.1.5). triad closely approximated those dosed within the first hour after mixed reagent preparation. We did not investigate the rate of NaR-induced NADH reduction at 10- or 100-fold lower YNaR1 concentrations, but such experiments would be useful to determine the feasibility of exchanging longer reaction times for greater enzyme economy.

With these preliminary experiments establishing the general analytical interchangeability of $\mathrm{NaR} 1$ and $\mathrm{YNaR} 1$ completed, we began using standard-level CFA-CdR (NWQL laboratory code 1975) and CFA-YNaR1 reduction methods to acquire paired, $\mathrm{NO}_{x}$ concentration data from a seasonally, geographically, and compositionally diverse subset of surfacewater and groundwater samples received at the NWQL for nutrient analyses between June 2003 and July 2004. In addition, we took advantage of the large sample load in August and September 2004 to acquire paired data for low-level $\mathrm{NO}_{x}$ concentrations with low-level CFA-CdR (NWQL laboratory code 1979) and CFA-YNaR1 reduction CFA methods. Throughout the 2003-2004 validation period, we also refined the batch enzymatic nitrate-reduction method and demonstrated its utility for "green chemistry" nitrate assays on a variety of analytical platforms. These include FIA and CFA nitrite analyzers, a discrete analyzer, and a benchtop spectrophotometer, all of which are substantially easier to operate and maintain than fully automated standard- and low-level CFA (I-2531-12 and I-2532-12, respectively) and DA (I-2547-11 and I-2548-11, respectively) methods.

\section{Standard-Level Validation Results}

As shown in figure 9, we scheduled the bulk of validation analyses to coincide with nominal periods of high (April-June) and low (August-October) streamflow conditions. Including QC solutions, calibrators, and replicates, we analyzed more than 5,000 samples for nitrite and $\mathrm{NO}_{x}$ by $\mathrm{CdR}$ - and $\mathrm{YNaR} 1$-reduction methods between April 2003 and July 2004. The validation data set consists of 3,318 paired $\mathrm{NO}_{x}$ analyses - 2,364 surface-water samples and 954 groundwater samples. Monthly sample number totals indicated in figure 9 pertain only to these samples. Inspection of figure 10, showing $\mathrm{NO}_{x}$ concentrations determined during the validation period by the two reduction methods as box plots, reveals that median and maximum nitrate concentrations in the groundwater subset are several times greater than those in the surface-water subset. The higher median and maximum nitrate concentrations in the former reflect the fact that many groundwater samples received at the NWQL for analysis are from wells affected by sewage, septage, and agricultural runoff. Mean, median, and maximum values for CFA-CdR and CFA-YNaR1 reduction methods $\mathrm{NO}_{x}$ concentrations are quite similar for samples collected during both flow regimes (table 6).

Figure 11 shows the scatter of $\mathrm{NO}_{x}$ concentrations determined by the standard-level YNaR1-reduction method (y-axis) in relation to those determined by the standard-level CdR-reduction method during the entire validation period from April 2003 to July 2004. Not shown in this graph are 


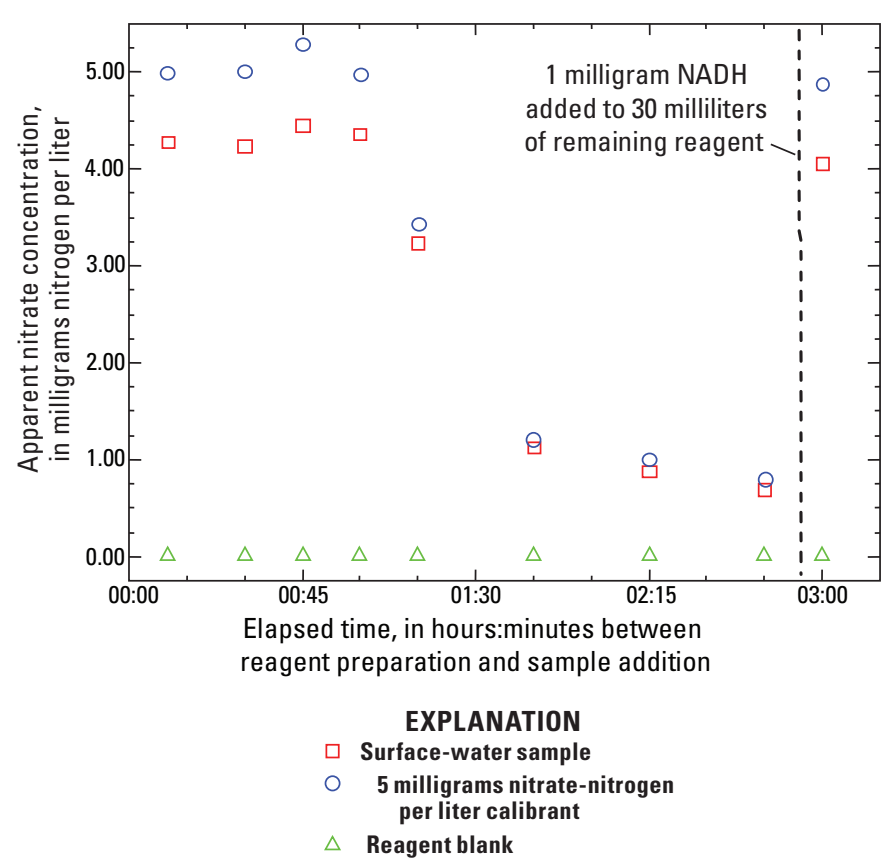

Figure 8. Graphical summary of data from an experiment to assess stability of mixed nicotinamide adenine dinucleotide (NADH) nitrate reductase (YNaR1) reagent solutions used in batch reduction methods. Refer to text for additional details.
137 data pairs with concentrations less than $0.01 \mathrm{mg} \mathrm{NO}$ - $\mathrm{N} / \mathrm{L}$ that were included in statistical comparisons. Inspection of figure 11 reveals points well distributed about the green, unity-slope line of equal relation. Clearly, however, more points lie below the line of equal relation than above it. Linear regression parameters (see text box in fig. 11) support this qualitative assessment. The correlation between $\mathrm{NO}_{x}$ concentrations determined by CFA-CdR and CFA-YNaR1 reduction methods is highly significant $\left(r^{2}=0.9997\right)$, the slope is slightly less than $1.00(0.99)$, and the y-intercept is slightly negative (-0.02), which suggest negative bias (YNaR1 method $\mathrm{NO}_{x}$ concentration $<\mathrm{CdR} \mathrm{NO}_{x}$ method concentration) in the YNaR1-reduction method of perhaps $0.03-0.05 \mathrm{mg}-\mathrm{N} / \mathrm{L}$. The NWQL long-term method detection level for standard-level $\mathrm{NO}_{x}$ concentrations (laboratory code 1975 ) was $0.06 \mathrm{mg}-\mathrm{N} / \mathrm{L}$ during the August 2003 to August 2004 period during which we acquired these data. In the context of the NWQL reporting level, bias of this magnitude is of marginal analytical significance. The substantially lower MDLs that we determined with CFA instruments used exclusively to obtain validation data reported here (see table 4), however, suggest that this slight negative bias is real.

In table 7 the data plotted in figure 11 are categorized according to agreement between $\mathrm{CFA} \mathrm{NO}_{x}$ concentrations determined by the CdR- and YNaR1-reduction methods with

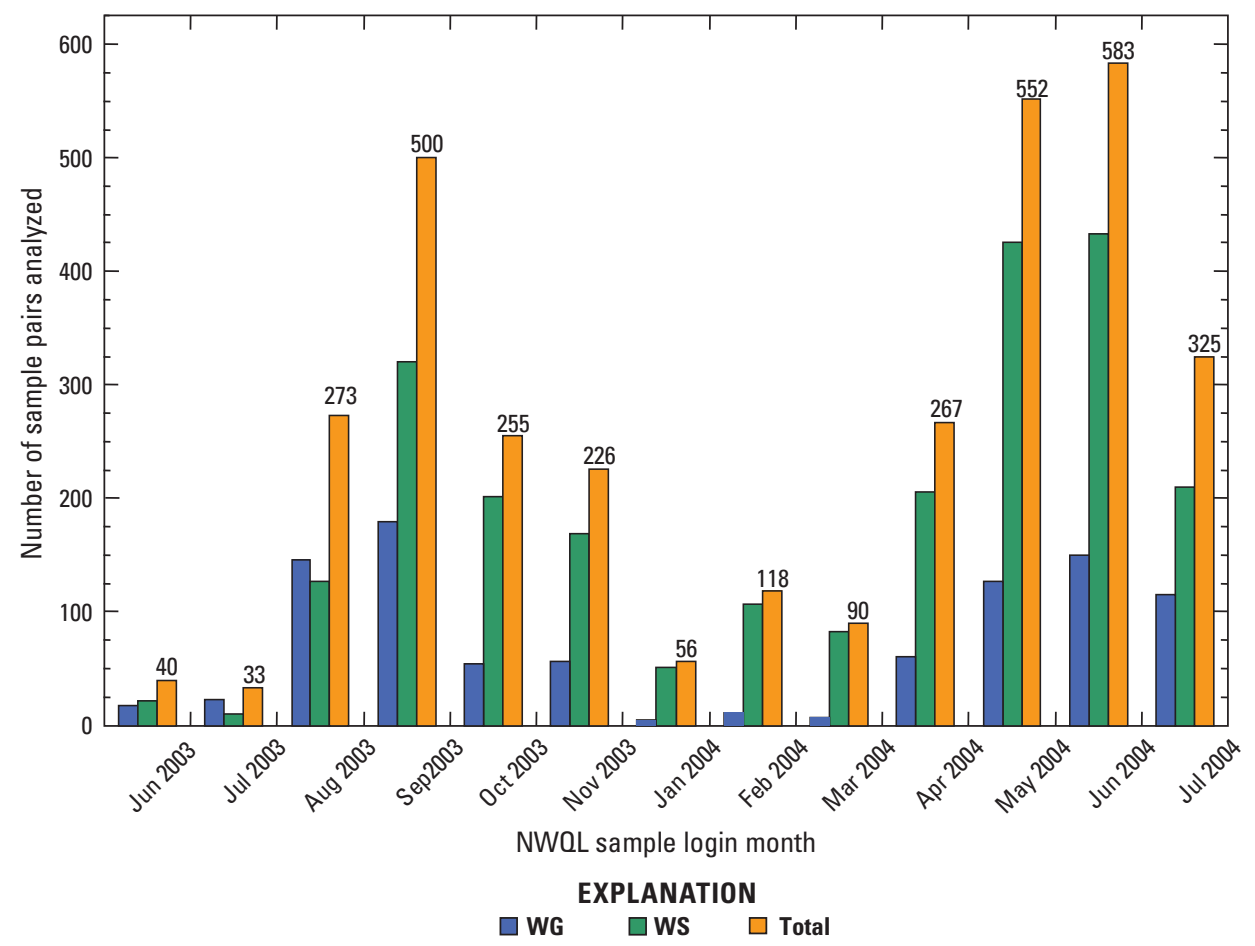

Figure 9. National Water Quality Laboratory (NWOL) login dates for groundwater samples—USGS National Water Information System (NWIS) medium code WG -and surface-water samples (NWIS medium code WS) included in the NWQL standard-level continuous flow analysis (CFA) nitrate reductase (YNaR1) nitrate method (CFA-YNaR1) validation study. 


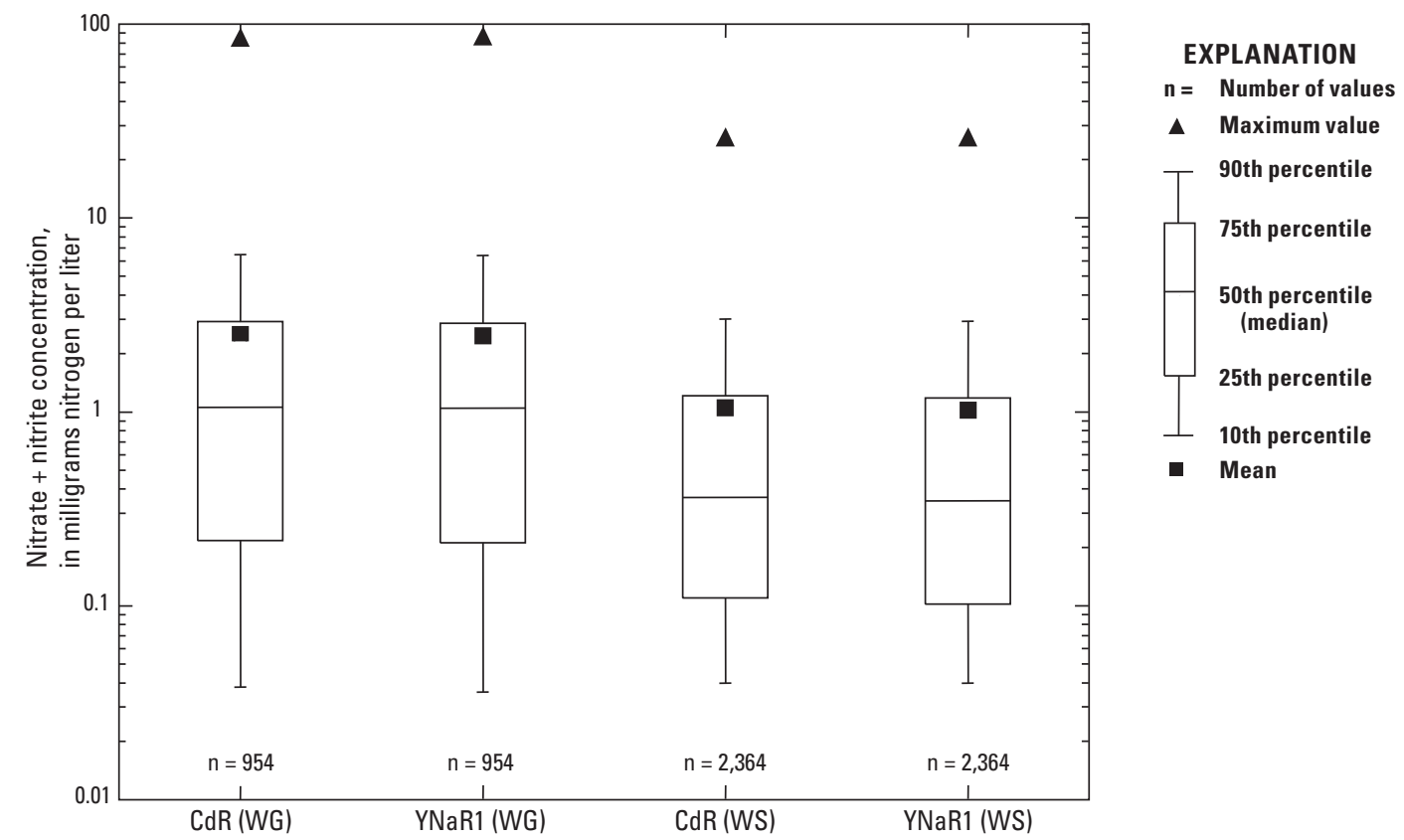

Figure 10. Box plots showing concentration distributions for the population of 3,318 standard-level nitrate + nitrite concentrations determined in groundwater samples_USGS National Water Information System (NWIS) medium code WG—and surface-water samples (NWIS medium code WS) by automated continuous flow analysis (CFA) cadmium-reduction (CdR) method and CFA nitrate reductase (YNaR1)-reduction method determined during validation experiments conducted at the National Water Quality Laboratory between April 2003 and July 2004. Square and triangle symbols in each box plot indicate mean and maximum concentrations, respectively. (mg-N/L, milligrams-nitrogen per liter)

Table 6. Nitrate + nitrite concentration summaries for low- and high-flow subsets.

[+, plus; mg-N/L, milligram(s)-nitrogen per liter; Aug, August; Nov, November; WG, U.S. Geological Survey National Water Information System medium code for groundwater; WS, U.S. Geological Survey National Water Information System medium code for surface water; CdR, cadmium reduction; YNaR1, recombinant nitrate reductase from Pichia angusta; n, number]

\begin{tabular}{|c|c|c|c|c|c|c|c|c|}
\hline & \multicolumn{2}{|c|}{$\begin{array}{l}\text { Aug-Nov } 2003 \\
\text { (WG, low flow) }\end{array}$} & \multicolumn{2}{|c|}{$\begin{array}{l}\text { April-June } 2004 \\
\text { (WG, high flow) }\end{array}$} & \multicolumn{2}{|c|}{$\begin{array}{l}\text { Aug-Nov } 2003 \\
\text { (WS, low flow) }\end{array}$} & \multicolumn{2}{|c|}{$\begin{array}{l}\text { April-June } 2004 \\
\text { (WS, high flow) }\end{array}$} \\
\hline & CdR & YNaR1 & CdR & YNaR1 & CdR & YNaR1 & CdR & YNaR1 \\
\hline $\mathrm{n}$ & 437 & 437 & 338 & 338 & 816 & 816 & 1,064 & 1,064 \\
\hline Mean $^{1}$ & 2.16 & 2.12 & 2.47 & 2.42 & 0.84 & 0.82 & 1.34 & 1.30 \\
\hline Median $^{1}$ & 0.89 & 0.88 & 1.17 & 1.09 & 0.24 & 0.23 & 0.44 & 0.41 \\
\hline Maximum $^{1}$ & 83.0 & 83.9 & 34.7 & 34.6 & 15.5 & 14.9 & 19.9 & 19.6 \\
\hline
\end{tabular}

${ }^{1}$ All concentrations in mg-N/L.

subcategories for groundwater and surface water (USGS NWIS medium codes WG and WS, respectively). In this table data pairs with concentrations that agree within \pm 10 percent are designated in-range and those that differ by more than plus10 percent or less than minus 10 percent are designated out-of-range. In table 7 and the discussions that follow, negative bias pertains to sample pairs for which differences between $\mathrm{CdR}$ and $\mathrm{YNaR} 1 \mathrm{NO}_{x}$ concentrations are greater than zero; positive bias pertains to sample pairs for which differences between $\mathrm{CdR}$ and $\mathrm{YNaR} 1 \mathrm{NO}_{x}$ concentrations are less than zero. With reference to table 7 , about 82 percent (2,622 data pairs) of results were in-range with 74 percent of YNaR1 $\mathrm{NO}_{x}$ results displaying negative bias. Furthermore, negative bias in YNaR1 method $\mathrm{NO}_{x}$ results was about the same for surface water and groundwater (75 and 72 percent, respectively). Results were similar for the smaller population of out-of-range results (559 data pairs) - negative bias in the YNaR1-method for 68 percent of surface-water and groundwater $\mathrm{NO}_{x}$ results. Paired t-test results for all data and the surface-water and groundwater data subsets (table 8 ) indicate that the means of CdR- and YNaR1-method $\mathrm{NO}_{x}$ concentrations are statistically different from zero at the 0.05 and 0.01 probability levels. Differences between population means (table 8) suggest negative bias in YNaR1-reduction method results of $0.03 \mathrm{mg}-\mathrm{N} / \mathrm{L}$ for surface water and $0.04 \mathrm{mg}-\mathrm{N} / \mathrm{L}$ for groundwater, that as discussed previously, are of marginal analytical significance. Nonparametric Wilcoxon signed-rank test results for these data (table 9) also indicate a statistically significant difference in CdR- and YNaR1-reduction method $\mathrm{NO}_{x}$ concentration populations. Negative bias in YNaR1-reduction 


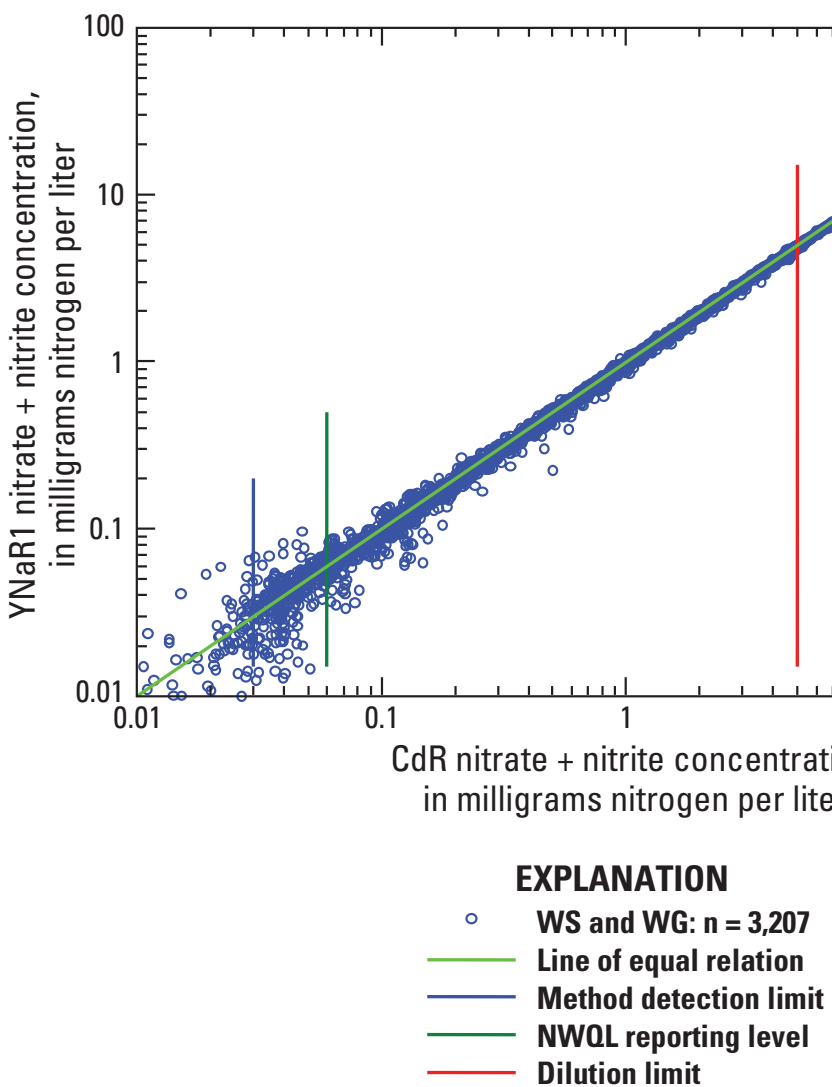

Figure 11. Scatter plot of standard-level nitrate + nitrite concentrations determined simultaneously during validation experiments at the National Water Quality Laboratory (NWQL) between August 2003 and August 2004 by automated continuous flow analysis (CFA) cadmiumreduction (CdR) and CFA nitrate reductase (YNaR1)-reduction methods. The complete data set contains 3,318 paired results, but in this plot, 137 of these with CdR- or YNaR1-method nitrate + nitrite concentrations less than 0.01 milligram nitrogen per liter are not shown.

Table 7. Agreement between nitrate + nitrite $\left(\mathrm{NO}_{x}\right)$ concentrations determined by CFA- CdR and CFA-YNaR1 reduction methods. Groundwater and surface-water samples are denoted by their medium codes WG and WS, respectively.

[In-range results are those for which differences between CFA-CdR and CFA-YNaR1 $\mathrm{NO}_{x}$ concentrations are within \pm 10 percent. Out-of-range results are those for which differences between CFA-CdR and CFA-YNaR1 $\mathrm{NO}_{x}$ concentrations are less than minus 10 percent or greater than plus 10 percent. +, plus; $\mathrm{NO}_{x}$, nitrate plus nitrite; CFA, continuous-flow analysis; CdR, cadmium reduction; YNaR1, recombinant nitrate reductase from Pichia angusta; \pm , plus or minus; WG, U.S. Geological Survey National Water Information System medium code for groundwater; WS, U.S. Geological Survey National Water Information System medium code for surface water; n/a, not applicable; <, less than; mg-N/L, milligrams-nitrogen per liter; $\geq$, greater than or equal to; - , minus; $\leq$, less than or equal to; $>$, greater than]

\begin{tabular}{|c|c|c|c|}
\hline Category & \multicolumn{3}{|c|}{$\begin{array}{c}\text { Counts } \\
\text { (percent of category) }\end{array}$} \\
\hline All samples & $3,318(\mathrm{n} / \mathrm{a})$ & $954(\mathrm{n} / \mathrm{a})$ & $2,364(\mathrm{n} / \mathrm{a})$ \\
\hline $\mathrm{YNaR} 1$ nitrate + nitrite concentration $\geq 0.01 \mathrm{mg}-\mathrm{N} / \mathrm{L}$ & $3,181(95.9)$ & $896(93.9)$ & $2,285(96.7)$ \\
\hline In-range results: -10 percent $\leq \mathrm{CdR}-\mathrm{YNaR} 1 \leq 10$ percent & $2,622(82.4)$ & $795(88.7)$ & $1,827(80.0)$ \\
\hline In-range, negative bias: $\mathrm{CdR} \mathrm{NO}_{x}-\mathrm{YNaR} 1 \mathrm{NO}_{x}>0$ & $1,947(74.3)$ & $573(72.1)$ & $1,374(75.2)$ \\
\hline Out-of-range results: -10 percent $>$ CdR-YNaR1 $>10$ percent & $559(17.6)$ & $101(11.3)$ & $458(20.0)$ \\
\hline Out-of-range, negative bias: $\mathrm{CdR} \mathrm{NO}_{x}-\mathrm{YNaR} 1 \mathrm{NO}_{x}>0$ & $381(68.2)$ & $69(68.3)$ & $312(68.1)$ \\
\hline Out-of-range, positive bias: $\mathrm{CdR} \mathrm{NO}_{x}-\mathrm{YNaR} 1 \mathrm{NO}_{x}<0$ & $178(31.8)$ & $32(31.7)$ & $146(31.9)$ \\
\hline
\end{tabular}


Table 8. Two-population paired t-test results for nitrate + nitrite concentrations determined in filtered-water samples by CFA-CdR and CFA-YNaR1 nitrate reduction methods.

[+, plus; CFA, continuous-flow analysis; CdR, cadmium reduction; YNaR1, recombinant nitrate reductase from Pichia angusta; mg-N/L, milligram(s)-nitrogen per liter; FCC, filtered, chilled (bottle type for samples); n, number of samples; WG, U.S. Geological Survey National Water Information System medium code for groundwater; WS, U.S. Geological Survey National Water Information System medium code for surface water; WCA, whole water, chilled, acidified sample bottle type; FCA, filtered, chilled, acidified sample bottle type]

\begin{tabular}{|c|c|c|c|c|c|c|c|c|c|}
\hline \multirow{3}{*}{ Standard FCC } & \multirow{3}{*}{$\mathbf{n}$} & \multicolumn{5}{|c|}{ Nitrate + nitrite concentration (mg-N/L) } & & & \\
\hline & & \multicolumn{2}{|c|}{ Mean } & \multirow{2}{*}{$\begin{array}{c}\text { Difference } \\
\text { CdR - YNaR1 }\end{array}$} & \multicolumn{2}{|c|}{$\begin{array}{l}\text { Standard } \\
\text { deviation }\end{array}$} & \multicolumn{3}{|c|}{ Significant ${ }^{1}$} \\
\hline & & CdR & YNaR1 & & CdR & YNaR1 & $\mathbf{p}_{\text {calc }}$ & $\mathbf{p}_{0.05}$ & $\mathbf{p}_{0.01}$ \\
\hline All & 3,318 & 1.56 & 1.53 & 0.03 & 3.38 & 3.36 & 0.0000 & yes & yes \\
\hline Medium code WG & 954 & 2.66 & 2.62 & 0.04 & 5.32 & 5.31 & 0.0000 & yes & yes \\
\hline Medium code WS & 2,364 & 1.11 & 1.08 & 0.03 & 1.99 & 1.94 & 0.0000 & yes & yes \\
\hline
\end{tabular}

\begin{tabular}{|c|c|c|c|c|c|c|c|c|c|}
\hline \multirow{3}{*}{ Low-level FCC } & \multirow{3}{*}{$\mathbf{n}$} & \multicolumn{5}{|c|}{ Nitrate + nitrite concentration (mg-N/L) } & & & \\
\hline & & \multicolumn{2}{|c|}{ Mean } & \multirow{2}{*}{$\begin{array}{c}\text { Difference } \\
\text { CdR - YNaR1 }\end{array}$} & \multicolumn{2}{|c|}{$\begin{array}{l}\text { Standard } \\
\text { deviation }\end{array}$} & \multicolumn{3}{|c|}{ Significant ${ }^{1}$} \\
\hline & & CdR & YNaR1 & & CdR & YNaR1 & $\mathbf{p}_{\text {calc }}$ & $\mathbf{p}_{0.05}$ & $\mathbf{p}_{0.01}$ \\
\hline All & 979 & 0.38 & 0.34 & 0.04 & 0.38 & 0.36 & 0.0000 & yes & yes \\
\hline Medium code WG & 218 & 0.36 & 0.35 & 0.01 & 0.30 & 0.30 & 0.0154 & yes & no \\
\hline Medium code WS & 761 & 0.38 & 0.34 & 0.04 & 0.39 & 0.38 & 0.0000 & yes & yes \\
\hline
\end{tabular}

\begin{tabular}{|c|c|c|c|c|c|c|c|c|c|}
\hline \multirow[b]{2}{*}{ Acidified samples } & \multirow[b]{2}{*}{$\mathbf{n}$} & \multicolumn{5}{|c|}{ Nitrate + nitrite concentration (mg-N/L) } & \multirow{2}{*}{\multicolumn{3}{|c|}{ Significant ${ }^{1}$}} \\
\hline & & \multicolumn{2}{|c|}{ Mean } & $\begin{array}{c}\text { Difference } \\
\text { CdR - YNaR1 }\end{array}$ & \multicolumn{2}{|c|}{$\begin{array}{l}\text { Standard } \\
\text { deviation }\end{array}$} & & & \\
\hline All & 182 & 0.711 & 0.713 & -0.002 & 1.1190 & 1.194 & 0.24541 & no & no \\
\hline $\mathrm{WCA}^{2}$ & 136 & 0.780 & 0.779 & 0.001 & 1.274 & 1.273 & 0.54060 & no & no \\
\hline FCA & 46 & 0.509 & 0.518 & -0.009 & 0.880 & 0.903 & 0.03492 & yes & no \\
\hline
\end{tabular}

${ }^{1} \mathrm{p}_{\text {calc }}$ is the probability that population means of nitrate + nitrite concentrations determined by the CdR-and YNaR1-reduction methods are the same-that is, difference between the population means is statistically equivalent to zero- on the basis of calculated paired t-tests (Pollard, 1979). Difference between population means is significant at the 95 percent confidence level $\left(\mathrm{p}_{0.05}\right)$ when $\mathrm{p}_{\text {calc }}$ is less than 0.05 and at the 99 percent confidence level $\left(\mathrm{p}_{0.01}\right)$ when $\mathrm{p}_{\text {calc }}$ is less than 0.01 .

${ }^{2}$ Filtered at the U.S. Geological Survey National Water Quality Laboratory prior to analysis.

Table 9. Wilcoxon signed-rank test ${ }^{1}$ results for nitrate + nitrite concentrations $(\mathrm{mg}-\mathrm{N} / \mathrm{L})$ determined in filtered-water samples by granular copperized CFA-CdR and soluble CFA-YNaR1 nitrate-reductase reduction methods.

[+, plus; mg-N/L, milligram-nitrogen per liter; CFA, continuous-flow analysis; CdR, cadmium reduction; YNaR1, recombinant nitrate reductase from Pichia angusta; n, number of samples; MC, medium code; WG, U.S. Geological Survey National Water Information System medium code for groundwater; WS, U.S. Geological Survey National Water Information System medium code for surface water; WCA, whole-water chilled acidified sample bottle type; FCA, filtered, chilled, acidified sample bottle type]

\begin{tabular}{|c|c|c|c|c|c|}
\hline \multicolumn{3}{|c|}{ Standard-level samples (n) } & \multicolumn{3}{|c|}{ Methods' results populations different?' } \\
\hline CdR-YNaR1 & Positive ranks & Negative ranks & $\mathbf{p}_{\text {calc }}$ & $\mathbf{p}_{0.05}$ & $\mathbf{p}_{0.01}$ \\
\hline All & 860 & 2,458 & $<0.0001$ & yes & yes \\
\hline MC WG & 259 & 695 & $<0.0001$ & yes & yes \\
\hline \multicolumn{6}{|c|}{ Low-level samples } \\
\hline All & 129 & 850 & $<0.0001$ & yes & yes \\
\hline MC WG & 97 & 121 & 0.1193 & no & no \\
\hline WCA and FCA & 93 & 89 & 0.8240 & no & no \\
\hline $\mathrm{WCA}^{2}$ & 60 & 76 & 0.1984 & no & no \\
\hline FCA & 33 & 13 & 0.0051 & yes & yes \\
\hline
\end{tabular}

${ }^{1}$ The paired-sample, Wilcoxon signed-rank test is a nonparametric alternative to the paired-sample t-test. It can be used to examine whether or not two paired sample populations have the same distribution. Unlike the paired-sample t-test, this function does not require either test population to be normally distributed (Pollard, 1979).

${ }^{2}$ Filtered at the U.S. Geological Survey National Water Quality Laboratory prior to analysis. 
method $\mathrm{NO}_{x} 25$ th, 50th, and 75th concentration percentiles, however, is seldom - and then only marginally so - analytically significant (table 10).

Figure 12 provides graphical summaries of in-range (fig. 12A) and out-of-range (fig. 12B) data plotted as the percent difference between CdR- and YNaR1-reduction $\mathrm{NO}_{x}$ results in relation to CdR-method $\mathrm{NO}_{x}$ results. As shown in this figure, percent differences between $\mathrm{NO}_{x}$ concentrations determined by $\mathrm{CdR}$ and $\mathrm{YNaR} 1$ methods were within 25 percent for the majority of high (381 points) and low (178 points) out-of-range data (fig. 12B). Not surprisingly, bias for $\mathrm{NO}_{x}$ concentrations determined by the $\mathrm{CdR}$ and YNaR1 methods is about as likely to be positive as negative near and below the CdR MDL (green vertical lines in both figs. $12 A$ and $12 B$ ). In the absence of supporting data, we speculate that the substantial number of positively biased YNaR1reduction method $\mathrm{NO}_{x}$ results for in-range groundwater samples (fig. 12A) might have contained reduced metals or sulfides that are common constituents in low-oxygen groundwater matrices. Such constituents, which are well-known interferences in CdR methods (Gal and others, 2004), are better tolerated by $\mathrm{NaR}$ methods. Also evident in figure $12 \mathrm{~A}$ is tighter clustering of surface-water and groundwater data pairs around the zero-percent-difference line for in-range $\mathrm{NO}_{x}$ concentrations greater than the dilution limit (indicated by red vertical lines in figure 12; refer to section 10). Dilution of these samples, with concomitant dilution of any interfering substances in the sample matrices, might account for this observation.

Figure 13 shows the scatter of $\mathrm{NO}_{x}$ concentrations determined by the low-level YNaR1-reduction method (y-axis) in relation to those determined by the low-level CdRreduction method (laboratory code 1979) during August and September 2004. Not shown in this graph are 28 data pairs with YNaR1-method $\mathrm{NO}_{x}$ concentrations less than $0.001 \mathrm{mg}-\mathrm{N} / \mathrm{L}$ that were included in two-population paired t-test and Wilcoxon signed-rank test statistical analyses. Inspection of figure 13 reveals that most points for groundwater samples are tightly clustered and well distributed around the green unity-slope line of equal relation. In contrast, most points for surface-water samples have greater variance and lie below the line of equal relation. Linear regression parameters (fig. 13, text box) support this qualitative assessment. Correlations between nitrate concentrations determined by CFA-CdR and CFA-YNaR1 reduction methods in surface water and groundwater are highly significant for both $\left(\mathrm{r}^{2} \approx 0.98\right)$. In context of the NWQL 2004 reporting level for low-level CFA-CdR $\mathrm{NO}_{x}(0.02 \mathrm{mg}-\mathrm{N} / \mathrm{L})$, bias between the two methods was negligible for groundwater samples, but significantly negative - CFA-YNaR1 $<$ CFA-CdR—-for surfacewater samples.

Table 10. Summary statistics for nitrate + nitrite concentrations determined in filtered-water samples by CFA-CdR and soluble CFA-YNaR1 nitrate-reductase-reduction methods.

[+, plus; mg-N/L, milligram(s)-nitrogen per liter; CFA, continuous-flow analysis; CdR, cadmium reduction; YNaR1, recombinant nitrate reductase from Pichia angusta; $\mathrm{n}$, number of samples; MC, USGS sample medium code; WG, U.S. Geological Survey National Water Information System medium code for groundwater; WS, U.S. Geological Survey National Water Information System medium code for surface water; WCA, whole-water chilled acidified sample bottle type; FCA, filtered, chilled, acidified sample bottle type; NWQL, National Water Quality Laboratory]

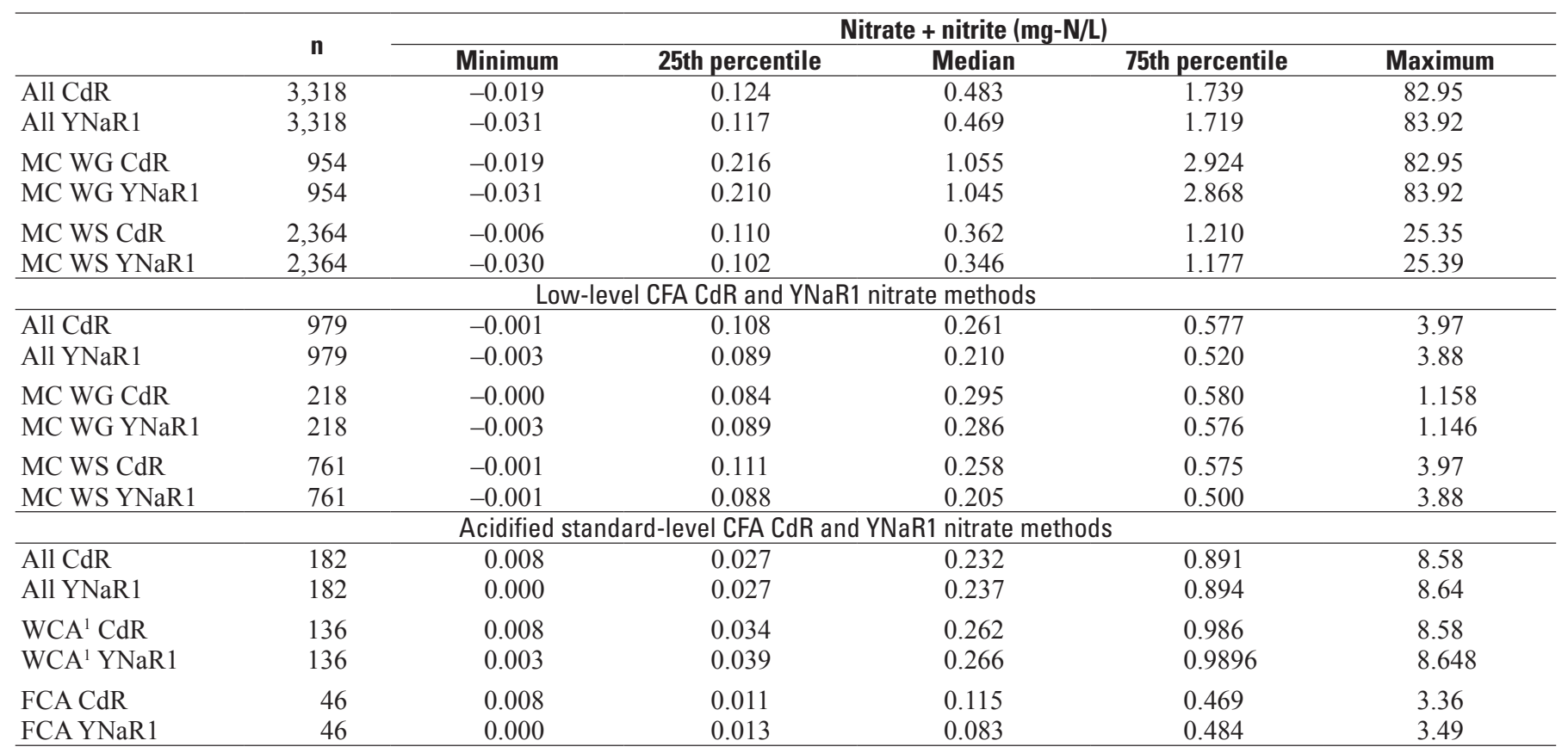

${ }^{1}$ Filtered at the NWQL prior to analysis 

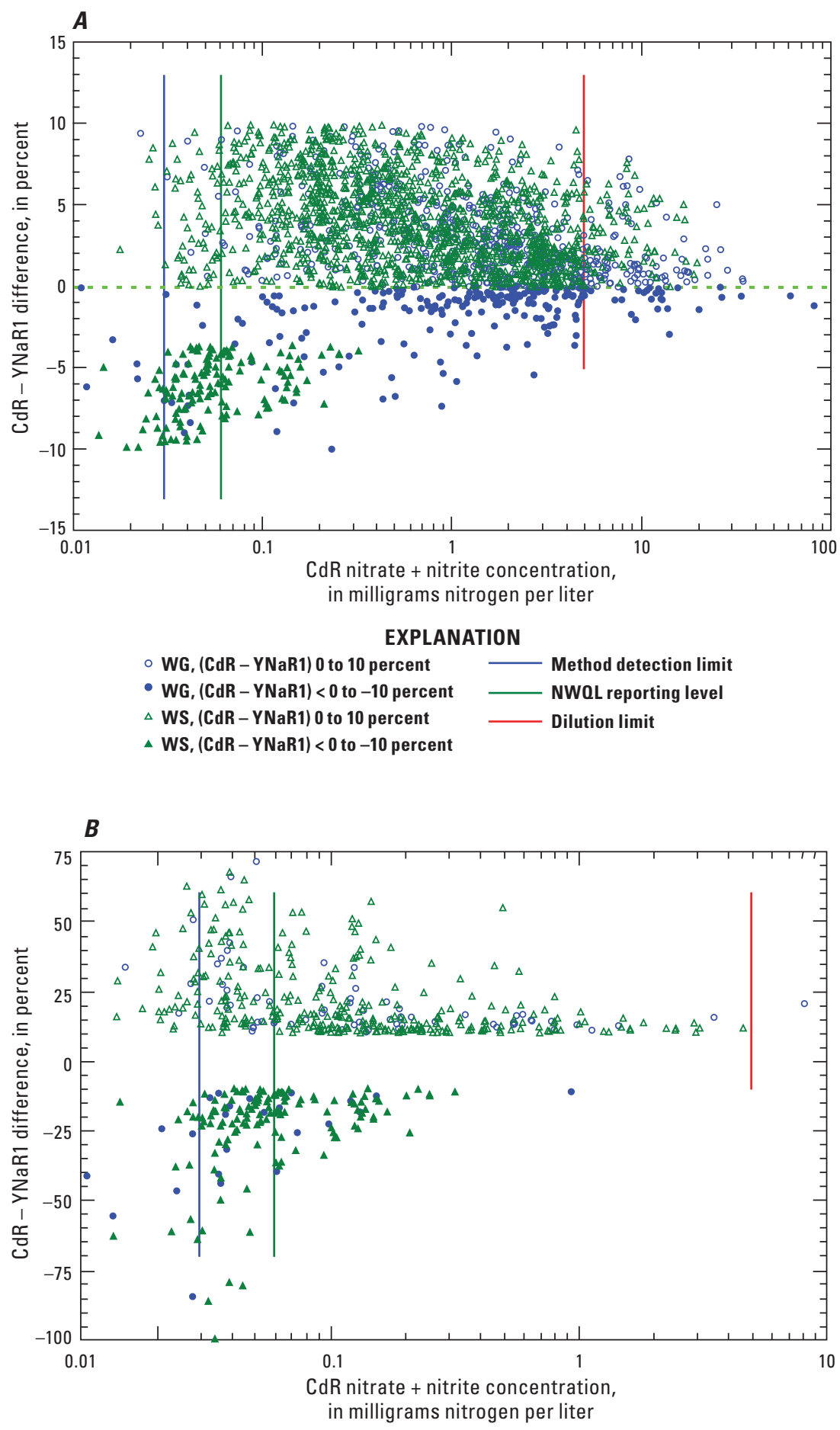

EXPLANATION

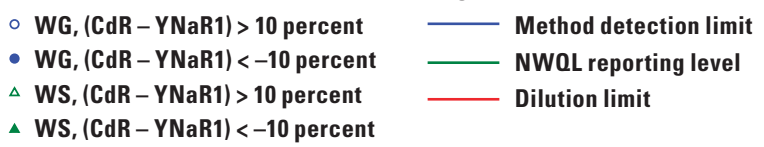

Figure 12. Differences (in percent) between nitrate + nitrite concentrations in groundwater samples—USGS National Water Information System (NWIS) medium code WG - and surface-water samples (NWIS medium code WS) simultaneously determined by National Water Quality Laboratory (NWQL) standard-level automated continuous flow analysis (CFA) cadmium-reduction (CdR) and CFA nitrate reductase (YNaR1)-reduction methods. Panel $A$, points for which concentration differences were within plus or minus 10 percent; panel $B$, points for which concentration differences were greater than $(>)$ or less than $(<) 10$ percent. 


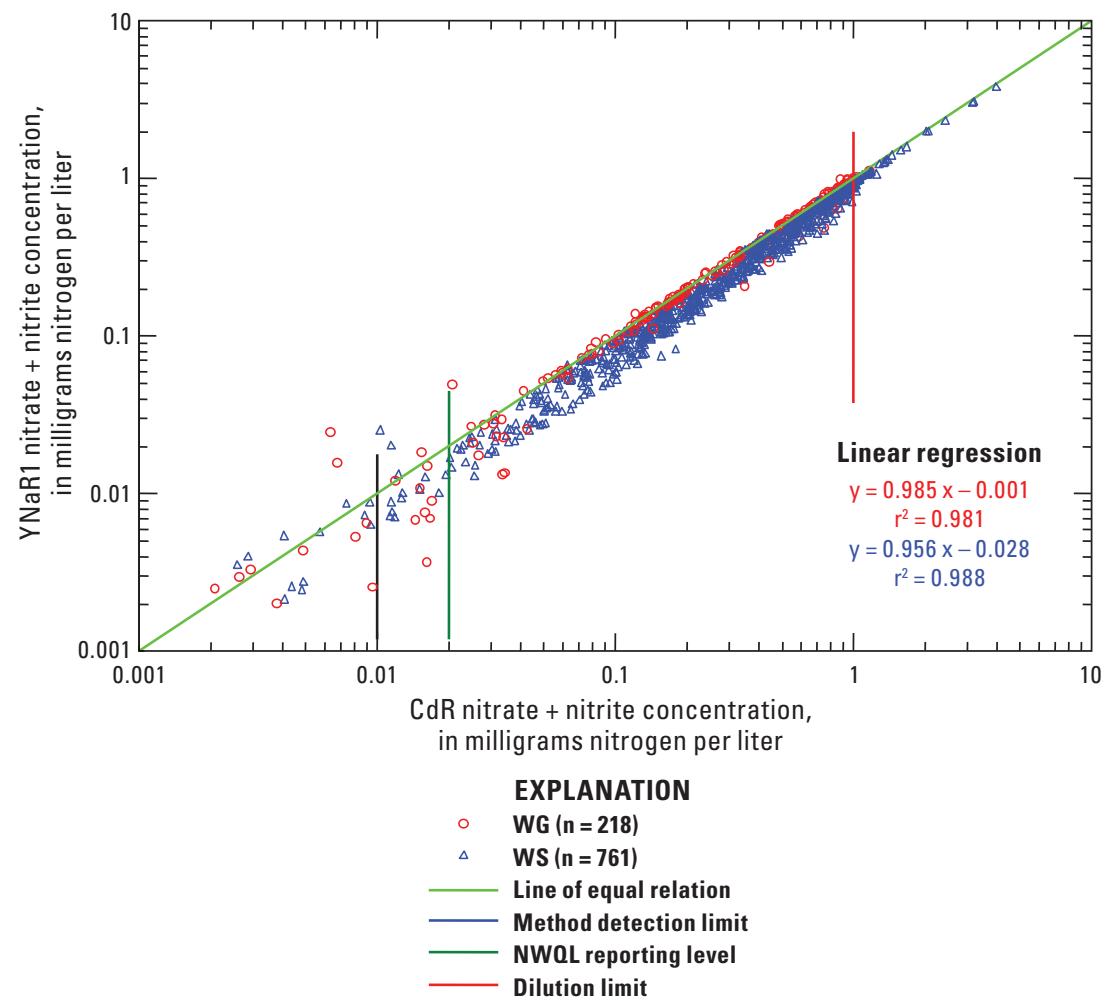

Figure 13. Scatter plot of nitrate + nitrite concentrations in groundwater samples-red circles, USGS National Water Information System (NWIS) medium code WG, $n$ = number of values—and surface-water samples (blue triangles, NWIS medium code WS) simultaneously determined by low-level automated continuous flow analysis (CFA) cadmium-reduction (CdR) and CFA nitrate reductase (YNaR1)-reduction methods. Data plotted in this figure were obtained in August and September 2004 during validation experiments at the National Water Quality Laboratory (NWOL). The complete data set contained 967 paired results, but in this figure values for nine groundwater samples and 19 surface-water samples with YNaR1-method nitrate + nitrite concentrations less than 0.001 milligram nitrogen per liter are not shown.

Table 8 and box plots (fig. 14) provide summary statistics and graphics for low-level method data sets, which confirm negligible bias in groundwater $\mathrm{NO}_{x}$ concentrations determined by $\mathrm{CdR}$ and $\mathrm{YNaR} 1$ methods. For surface water, however, table 8 and figure 14 reveal small, but analytically significant, negative bias for $\mathrm{NO}_{x}$ concentrations determined by the YNaR1 method. Referring again to figure 13, we find it particularly noteworthy that differences between surface water $\mathrm{NO}_{x}$ concentrations for $\mathrm{CdR}$ - and $\mathrm{YNaR} 1$-reduction methods diminish substantially at concentrations greater than $1.00 \mathrm{mg}-\mathrm{N} / \mathrm{L}$ - the dilution limit, indicated by a red vertical line in this figure. From this observation, we infer that dilution $(1+4$, typically) substantially mitigated the effects of putative (and only later identified) YNaR1 inhibitors in these 32 surface-water samples.

Paired t-test results for all data and the surface-water data subset (table 8) indicate that the means of low-level CdR-and YNaR1-method nitrate concentrations are statistically different from zero at the 0.05 and 0.01 probability levels. And in relation to the $0.02 \mathrm{mg}-\mathrm{N} / \mathrm{L}$ NWQL low-level CdR MDL, observed negative bias (YNaR1 $<\mathrm{CdR}$ ) of about $0.04 \mathrm{mg}-\mathrm{N} / \mathrm{L}$ difference between means is analytically significant. Paired t-test results for the groundwater subset indicate that the means are statistically different from zero at the 0.05 probability level, but not at 0.01 probability level. The less than $0.01 \mathrm{mg}-\mathrm{N} / \mathrm{L}$ population mean negative bias for groundwater samples is analytically negligible and about the same for the 25th, 50th, and 75th concentration percentiles (table 10). In contrast negative bias for $\mathrm{YNaR} 1$ method $\mathrm{NO}_{x}$ concentrations in surface water increased across these percentiles (table 10). Typically, nonparametric Wilcoxon signed-rank test results for these data (table 9) agree with t-test results. The groundwater subset population differences, however, are statistically insignificant at both the 0.05 and 0.01 probability levels.

The NWQL receives few requests for $\mathrm{NO}_{x}$ determinations in acidified samples (FCA and WCA bottle types). We did determine $\mathrm{NO}_{x}$ concentrations in about $200 \mathrm{FCA}$ and WCA samples by CdR- and YNaR1-reduction methods and found that the correspondence between the methods was excellent (fig. 15). Paired t-test and Wilcoxon signed-rank test results for acidified samples (tables 8 and 9) indicate that CdRand YNaR1-reduction methods are statistically equivalent for acidified samples. 


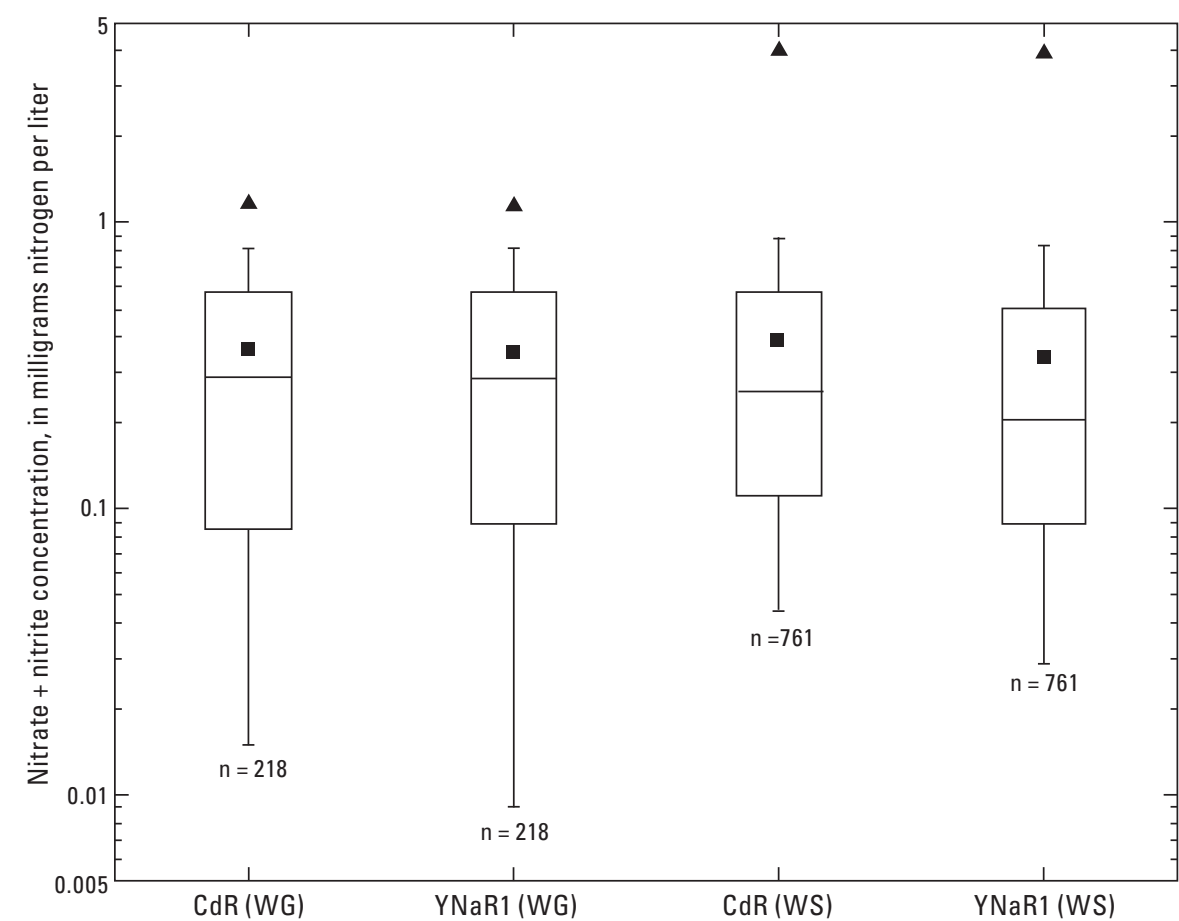

EXPLANATION

$n=$ Number of values

\ Maximum value

90th percentile

75 th percentile

50th percentile (median)

25th percentile

10th percentile

- Mean

Figure 14. Box plots showing concentration distributions for the population of 979 low-level nitrate + nitrite concentrations determined in groundwater samples_-USGS National Water Information System (NWIS) medium code WG_and surface-water samples (NWIS medium code WS) by automated continuous flow analysis (CFA) cadmium-reduction (CdR) and CFA nitrate reductase (YNaR1)-reduction methods. Data plotted in this figure were obtained during August-September 2004 validation experiments at the National Water Quality Laboratory.

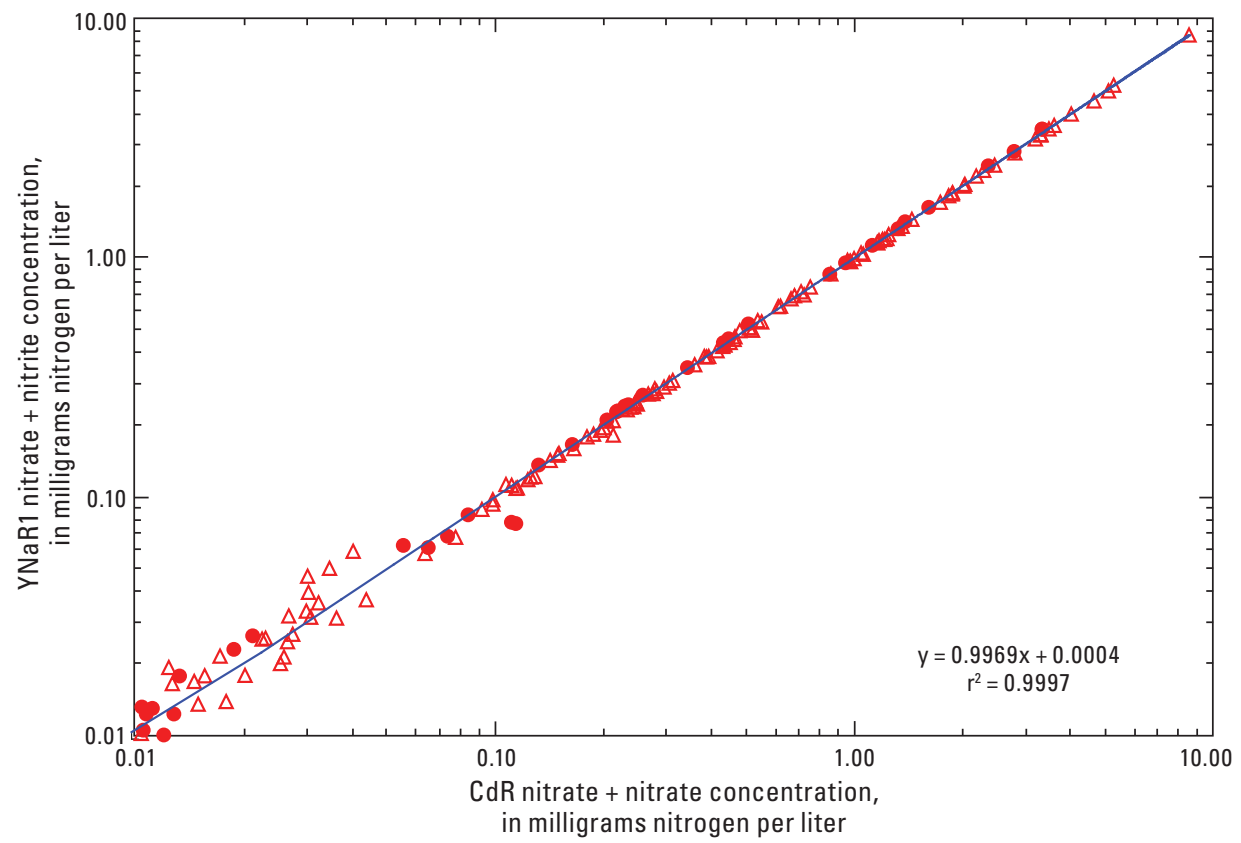

EXPLANATION

Linear (WCA and FCA samples, $\mathrm{n}=$ 182)

$\triangle$ WCA samples, $\mathrm{n}=\mathbf{1 3 6}$

- FCA samples, $n=46$

Figure 15. Scatter plot of nitrate + nitrite concentrations simultaneously determined for 182 acidified samples-National Water Quality Laboratory (NWOL) filtered-chilled-acidified (FCA) and whole-water chilled-acidified (WCA) bottle types-by automated continuous flow analysis (CFA) cadmium-reduction (CdR) and CFA nitrate reductase (YNaR1)-reduction methods. FCA samples were filtered at collection sites; WCA samples were filtered at the NWQL prior to nitrate determinations. 
We conclude this section with a few graphs from smaller data sets obtained with the YNaR1 batch reduction method (section 4.2). Figure 16 shows the analytical configuration of a purpose built flow injection analyzer assembled from modules and components available at the NWQL: an Alpkem, RFA-302 peristaltic pump; a manual, rotary, sixport sample-injection valve (Rheodyne 5020, Rohnert Park, Calif.) equipped with a $30-\mu \mathrm{L}$ sample loop; a $500-\mu \mathrm{L}$ mixer/ reactor with super serpentine geometry (Global FIA, Fox Island, Wash.); an RFA 305A photometer equipped with a $2-\mu \mathrm{L}$ flow cell $(10 \mathrm{~mm} \times 0.5 \mathrm{~mm}$ inside diameter $)$ and $540-\mathrm{nm}$ interference filters (Alpkem Corp., Clackamas, Oreg., out of business). Nominal flow rates of carrier (DI water) and reagent (10 g SAN and $1 \mathrm{~g}$ NED in 20 percent phosphoric acid) streams were each $385 \mu \mathrm{L} / \mathrm{min}$, resulting in a flow rate of about $0.75 \mathrm{~mL} / \mathrm{min}$ in the analytical stream. We used a $45-\mathrm{s}$ sampling cycle with this system-30-s load time and 15-s inject time for each sample, which equates to an analysis rate of 80 samples/h. The FIA peaks obtained with this system after offline batch reduction of nitrate to nitrite with YNaR1 are shown in figure 17.

Figure 18 pertains to results from the batch $\mathrm{YNaR} 1$ nitrate-reduction method, for which we determined resulting nitrite in three additional analytical formats. Figure $18 A$ shows peaks obtained with a simple CFA nitrite analyzer (Patton and others, 2002, fig. 3, p. 733). Here we used 2-mL analyzer cups as reaction vessels for the enzymatic reduction step as described in section 4.2. Peak identities from left to right are as follows: a $5 \mathrm{mg} \mathrm{NO}_{3}^{-}-\mathrm{N} / \mathrm{L}$ calibrant, 2 reagent blanks, six nitrate calibrants, 2 reagent blanks, 12 environmental water samples, 2 reagent blanks, 12 different environmental water samples, and 2 reagent blanks. We used separate SAN and NED reagents in the CFA nitrite method. The total analytical stream flow rate, including air segments, was about $0.5 \mathrm{~mL} / \mathrm{min}$ and the analysis rate was 120 samples $/ \mathrm{h}(20-\mathrm{s}$

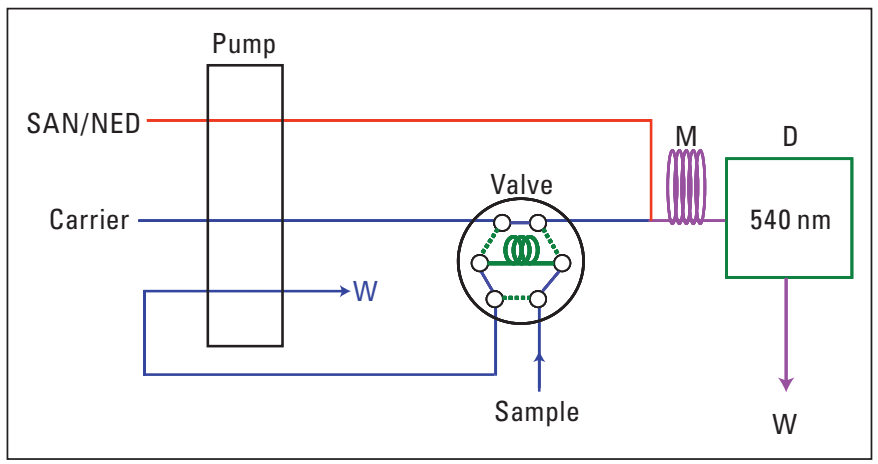

Figure 16. Analytical cartridge diagram for a simple, purposebuilt, flow-injection (FIA) nitrite analyzer. $\mathrm{M}=0.5$-millimeter inside diameter, 500-microliter mixer with super serpentine geometry; $\mathrm{D}=$ flow-through photometer equipped with a 2-microliter $(\mu \mathrm{L})$ flow cell and 540-nanometer interference filters; $\mathrm{W}=$ waste. The manual, rotary injection valve was equipped with a $30-\mu \mathrm{L}$ sample loop. Mixed sulfanilamide and N-(1-Naphthyl)ethylenediamine reagent is abbreviated as SAN/NED.

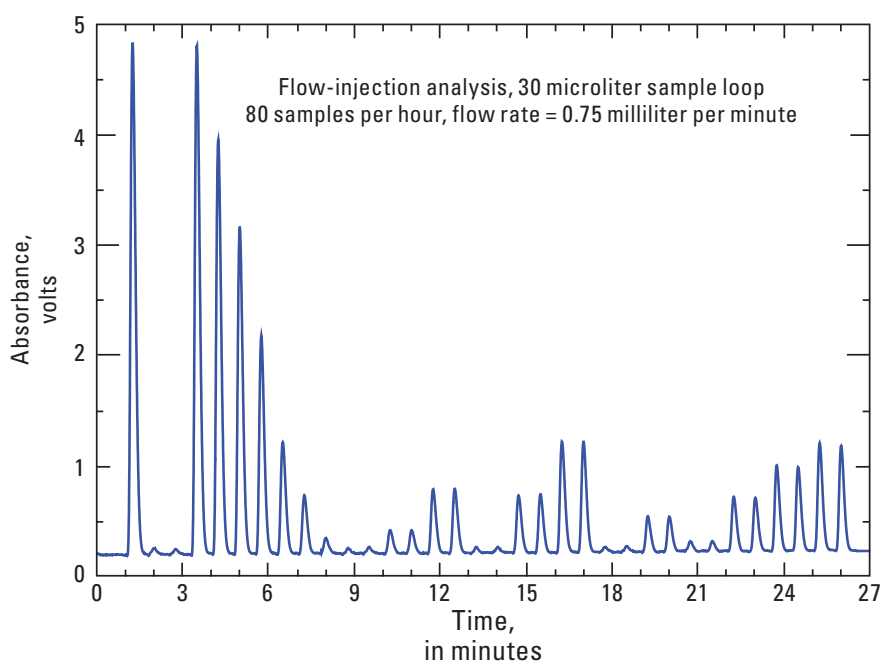

Figure 17. Flow injection analysis (FIA) peaks for batch YNaR1reduction nitrate determinations. From left to right: one 5-milligram nitrate-nitrogen calibrant, two reagent blanks, seven nitrate calibrants, two reagent blanks, and duplicate injections of 11 surface-water and groundwater samples.

sample time; 10 -s wash time). We included CFA peaks in figure $18 \mathrm{~A}$ primarily for comparison with FIA peaks shown in figure 17. Figures $18 B$ and $18 C$ show post-YNaR1 batch reduction nitrite concentrations determined by manual (Cary 50) and a random-access Olympus AU400 DA (Olympus America, Irving, Tex.) spectrophotometry in relation to those determined by USGS standard-level CFACdR colorimetric method. Unity slopes would indicate exact agreement between results determined by CFA-CdR and YNaR1 methods. Figure $18 D$ shows calculated slopes that resulted from linear least-squares regression of $\mathrm{NO}_{x}$ concentrations determined in a set of surface-water and groundwater samples by the CFA-CdR method (independent variable) and the offline, batch YNaR1-reduction method (dependent variable). Unity slope (dashed line in fig. 18D) indicates no bias in $\mathrm{NO}_{x}$ concentrations determined by CdR- and YNaR1reduction methods. In the case of the batch YNaR1-reduction method, post-reduction nitrite in samples was determined by CFA about 40 min after addition of mixed YNaR1/NADH reagent and subsequently at intervals of 3, 4.5, 6, 24, and $48 \mathrm{~h}$. Bias was negligible in batch YNaR1-reduction method $\mathrm{NO}_{x}$ concentration results when the intervals between enzymatic and colorimetric reagent additions were $24 \mathrm{~h}$ or less (fig. 18D).

Throughout the course of CFA-YNaR1 validation work, we selected samples for which CFA-YNaR1 method nitrate concentrations were less than those of the CFA-CdR method by more than 10 percent and reanalyzed them with the offline, batch YNaR1 method. Figure 19 shows $\mathrm{NO}_{x}$ concentrations measured by the automated CFA (red) and batch (blue) YNaR1 methods in relation to those measured by the CFA-CdR reduction method for 124 such "problem" samples received at the NWQL between February 25, 2004, and September 23, 2004. With reference to figure 19 , there is a striking difference 
$\boldsymbol{A}$
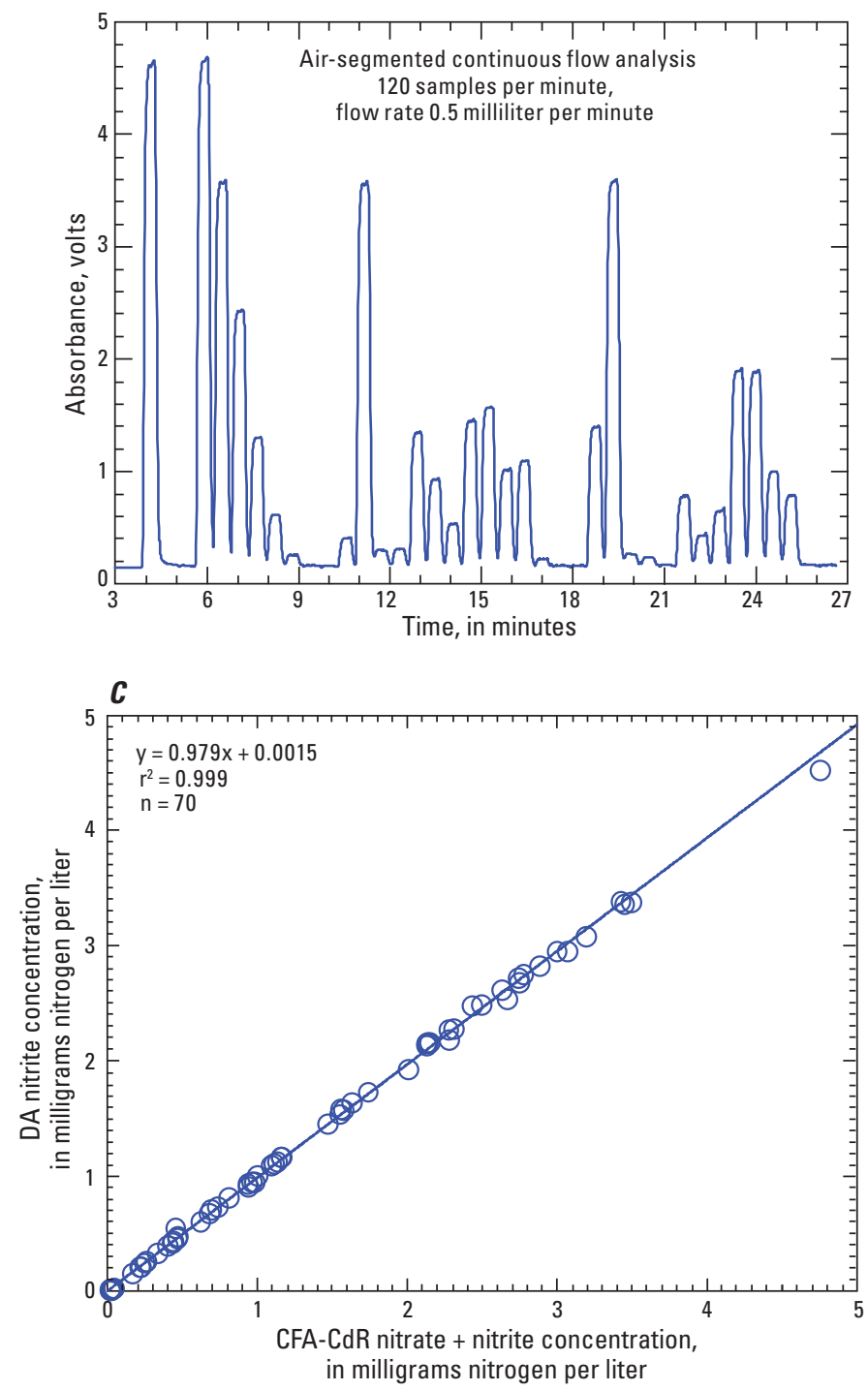

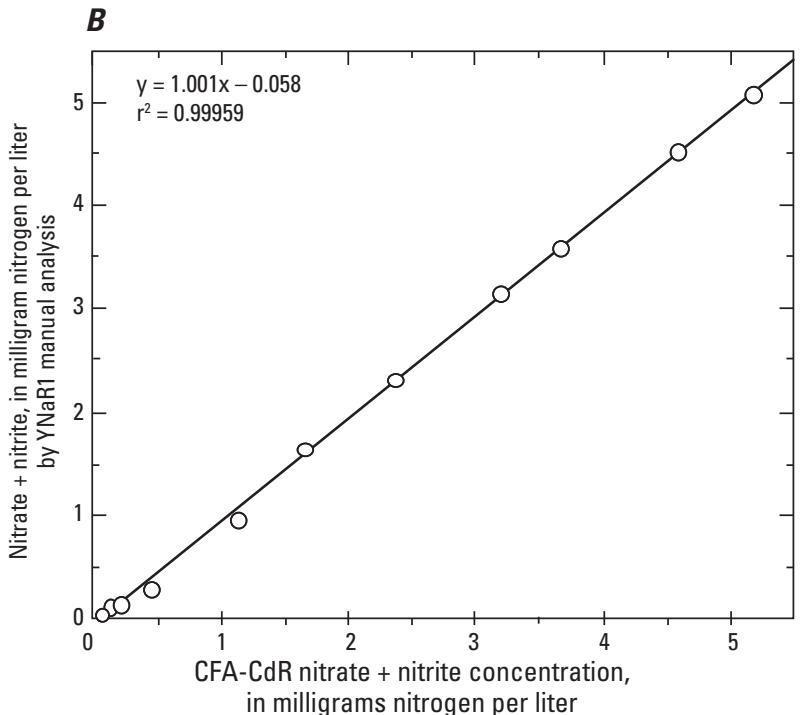

D

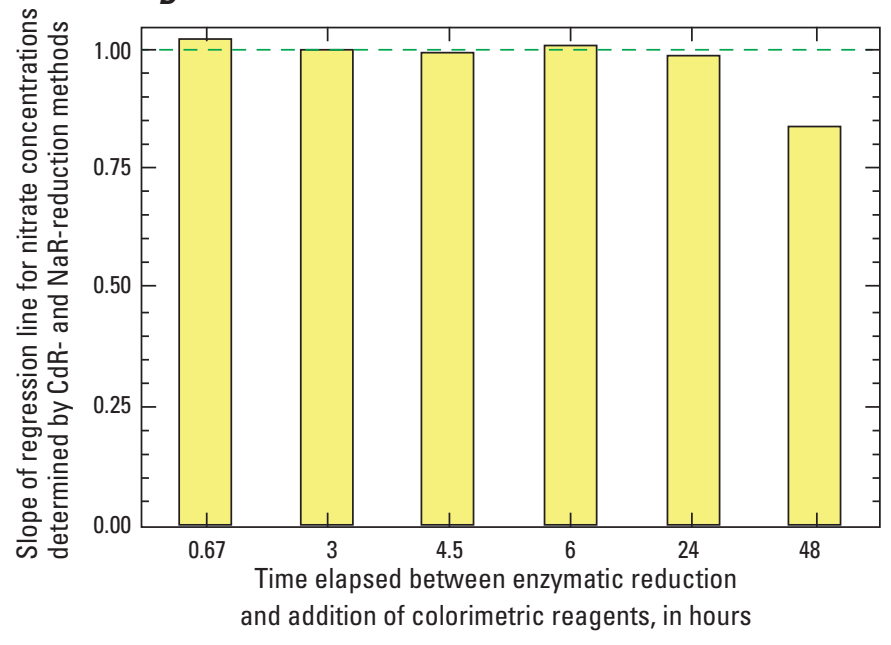

Figure 18. Graphs demonstrating effectiveness of the semiautomated batch method for reducing to nitrate to nitrite in water samples with soluble nitrate reductase (NaR). Panel $A$, photometer output (peaks) for nitrite determined in batch reduced (YNaR1) samples by automated air-segmented continuous flow analysis (CFA). Panel $B$, scatter plot demonstrating comparability of nitrate + nitrite concentrations determined by the automated CFA-cadmium reduction (CdR) method $(\mathrm{x})$ and manual colorimetry (y) following YNaR1 batch reduction in disposable spectrophotometer cuvettes (see fig. $1 C$ ). Panel $C$, scatter plot demonstrating comparability of nitrate + nitrite concentrations determined by the automated CFA-CdR method ( $\mathrm{x}$ ) and nitrite concentrations determined by the automated discrete analyzer (DA) method (y) following YNaR1 batch reduction in disposable analyzer cups (see fig. 1C). Panel $D$, bar graph demonstrating negligible nitrate + nitrite concentration differences between samples analyzed by the CFA-CdR method and those for corresponding samples analyzed by the CFA nitrite method up to 24 hours after initiation of the semiautomated YNaR1 batch reduction step. 


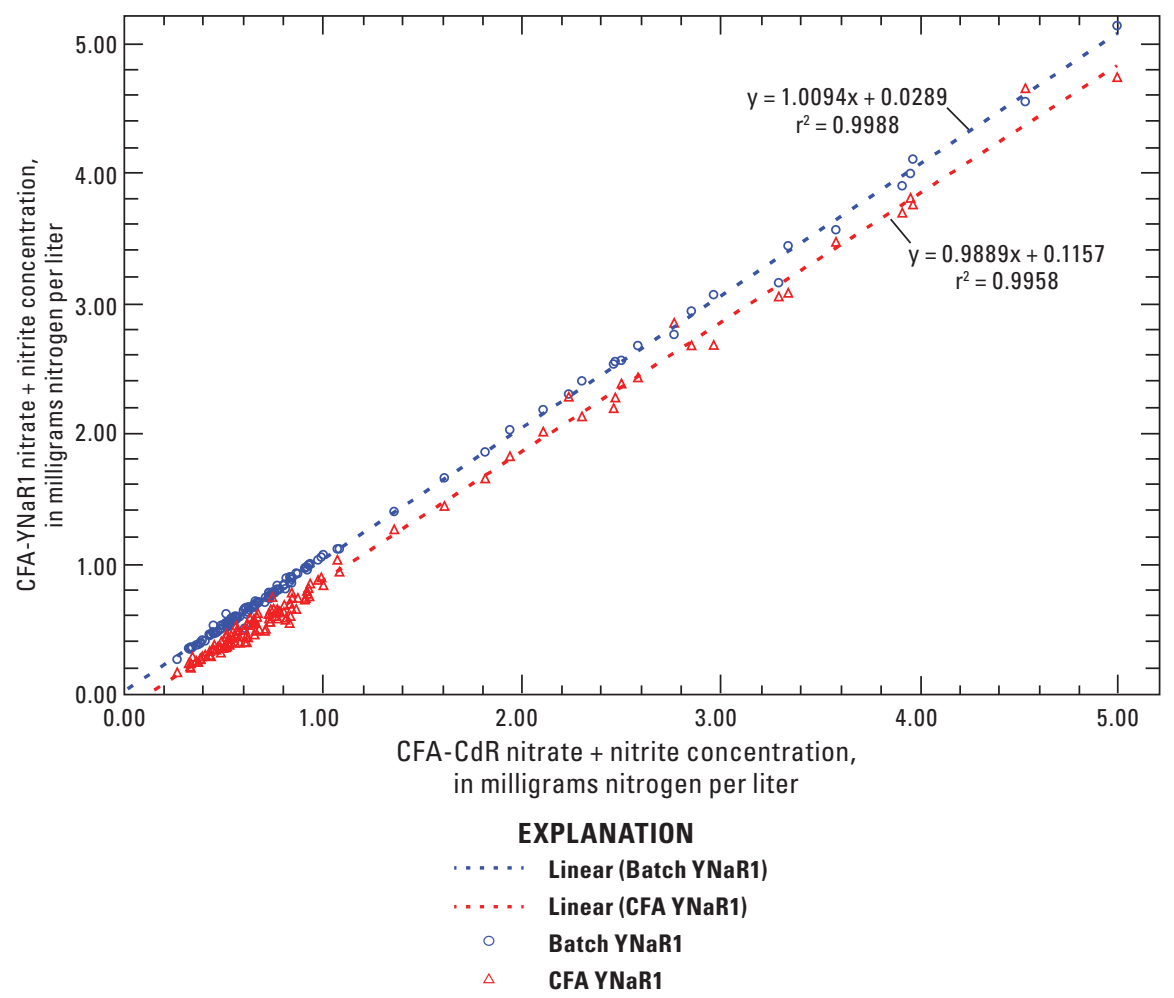

Figure 19. Linear least squares regression plots of nitrate + nitrite concentrations determined by USGS automated continuous flow analysis (CFA) cadmium reduction (CdR) method (I-2545-90; National Water Quality Laboratory code 1975) (x) in relation to nitrate + nitrite concentrations (y) determined by the automated CFA-YNaR1 reduction method (red triangles) and the semiautomated batch $\mathrm{YNaR} 1$ reduction method (blue circles). Nitrite in batch $\mathrm{YNaR} 1$ reduction method samples was determined by automated CFA, typically within 2-6 hours after addition of mixed YNaR1/nicotinamide adenine dinucleotide (NADH) reagent.

in agreement between nitrate concentrations determined by batch-YNaR1 and CFA-YNaR1 methods in relation to the CdR method. Note particularly that in comparison to those for the CFA-YNaR1 method, points for the batch-YNaR1 method exhibit less scatter around the CdR method regression line and are more evenly distributed above and below it. We initially attributed this improved agreement between batch-YNaR1 and CFA-CdR reduction methods to the longer reaction time of the former ( $\geq 40 \mathrm{~min}$, typically) compared to about $10 \mathrm{~min}$ for the CFA-YNaR1 method.

\section{Metal Ion Effects}

Midway through the CFA-YNaR1 method validation work, we began to suspect that the subset of samples for which CdR-method nitrate concentrations were substantially greater than $\mathrm{YNaR} 1$-method $\mathrm{NO}_{x}$ concentrations might have matrices containing substantial metal ion concentrations. Because major ion and trace metal data were unavailable for most samples in this study, we consulted a compilation of the yearly median concentrations in samples received at the NWQL for analyses (J.W. Pritt, written commun., 2001). Using this document, we selected metals with some of the higher abundances in samples analyzed at the NWQL for interference experiments (table 11).
Table 11 provides NWQL median, 10-times median, and 100-times median concentrations for these metals. We prepared $0.25 \mathrm{mg}-\mathrm{N} / \mathrm{L}, 2.5 \mathrm{mg}-\mathrm{N} / \mathrm{L}$, and $5.0 \mathrm{mg}-\mathrm{N} / \mathrm{L}$ nitrate solutions amended with NWQL median, 10-times median, and 100-times median concentrations of these metals (table 11). Typically, we prepared these metal ion solutions (individually or in combination) from chloride or sulfate salts. We diluted the resulting solutions to final volume with DI water and analyzed them in parallel with the three-channel CFA system (calibrated with metal-free nitrate standards) used for validation work. Figure 20 provides graphical summaries of experiments with $5.0 \mathrm{mg}-\mathrm{N} / \mathrm{L}$ nitrate solutions, which were similar to those for lower nitrate concentration solutions. Bar graph $y$-axes (apparent nitrate concentrations after calibration with metal-free standards) in figure 20 are truncated to enhance visualization of different treatments (x-axes). Metal ion concentrations indicated in all panels of figure 20 are the mean of two determinations for chromium (III) and manganese (II) solutions and the mean of three determinations for all others.

Top panels in figure 20 pertain to results obtained for the CFA-CdR method that indicate small increases in apparent nitrate concentrations at median and 10-times median individual metal ion concentrations and small decreases at 100times median concentrations. Small amounts of nitrate or nitrite in salts used to prepare stock metal solutions might account for 
Table 11. Metal ions tested for possible inhibition of YNaR1 enzyme and Griess-reaction interference.

[YNaR1, recombinant nitrate reductase from Pichia angusta; $\mu \mathrm{g} / \mathrm{L}$, microgram per liter; $\mu M$, micromoles; Ba, barium; Ca, calcium; Cr, chromium; Fe, iron; L, lithium, Mg, magnesium; Mn, manganese, Sr, strontium]

\begin{tabular}{lccccc}
\hline $\begin{array}{c}\text { Metal } \\
\text { ion }\end{array}$ & $\begin{array}{c}\text { Median } \\
\text { concentration } \\
(\boldsymbol{\mu g} / \mathbf{L})\end{array}$ & $\begin{array}{c}\text { Atomic } \\
\text { weight }\end{array}$ & $\begin{array}{c}\text { Median } \\
\text { concentration } \\
(\boldsymbol{\mu} \boldsymbol{M})\end{array}$ & $\begin{array}{c}\text { 10x median } \\
\text { concentration } \\
(\boldsymbol{\mu} \boldsymbol{M})\end{array}$ & $\begin{array}{c}\text { 100x median } \\
\text { concentration } \\
(\boldsymbol{\mu} \boldsymbol{M})\end{array}$ \\
\hline $\mathrm{Ba}^{2+}$ & $4.07 \times 10^{1}$ & 137.34 & $2.96 \times 10^{-1}$ & $2.96 \times 10^{0}$ & $2.96 \times 10^{1}$ \\
$\mathrm{Ca}^{2+}$ & $3.64 \times 10^{4}$ & 40.08 & $9.08 \times 10^{2}$ & $9.08 \times 10^{3}$ & $9.08 \times 10^{4}$ \\
$\mathrm{Cr}^{3+}$ & $2.60 \times 10^{-1}$ & 52.00 & $5.00 \times 10^{-3}$ & $5.00 \times 10^{-2}$ & $5.00 \times 10^{-1}$ \\
$\mathrm{Fe}^{2+}+\mathrm{Fe}^{3+}$ & $7.93 \times 10^{0}$ & 55.85 & $1.42 \times 10^{-1}$ & $1.42 \times 10^{0}$ & $1.42 \times 10^{1}$ \\
$\mathrm{Li}^{+}$ & $7.11 \times 10^{0}$ & 6.94 & $1.02 \times 10^{0}$ & $1.02 \times 10^{1}$ & $1.02 \times 10^{2}$ \\
$\mathrm{Mg}^{2+}$ & $8.33 \times 10^{3}$ & 24.31 & $3.43 \times 10^{2}$ & $3.43 \times 10^{3}$ & $3.43 \times 10^{4}$ \\
$\mathrm{Mn}^{2+}$ & $1.07 \times 10^{1}$ & 54.94 & $1.95 \times 10^{-1}$ & $1.95 \times 10^{0}$ & $1.95 \times 10^{1}$ \\
$\mathrm{Sr}^{2+}$ & $2.7 \times 10^{2}$ & 87.62 & $3.04 \times 10^{0}$ & $3.04 \times 10^{1}$ & $3.04 \times 10^{2}$ \\
\hline
\end{tabular}
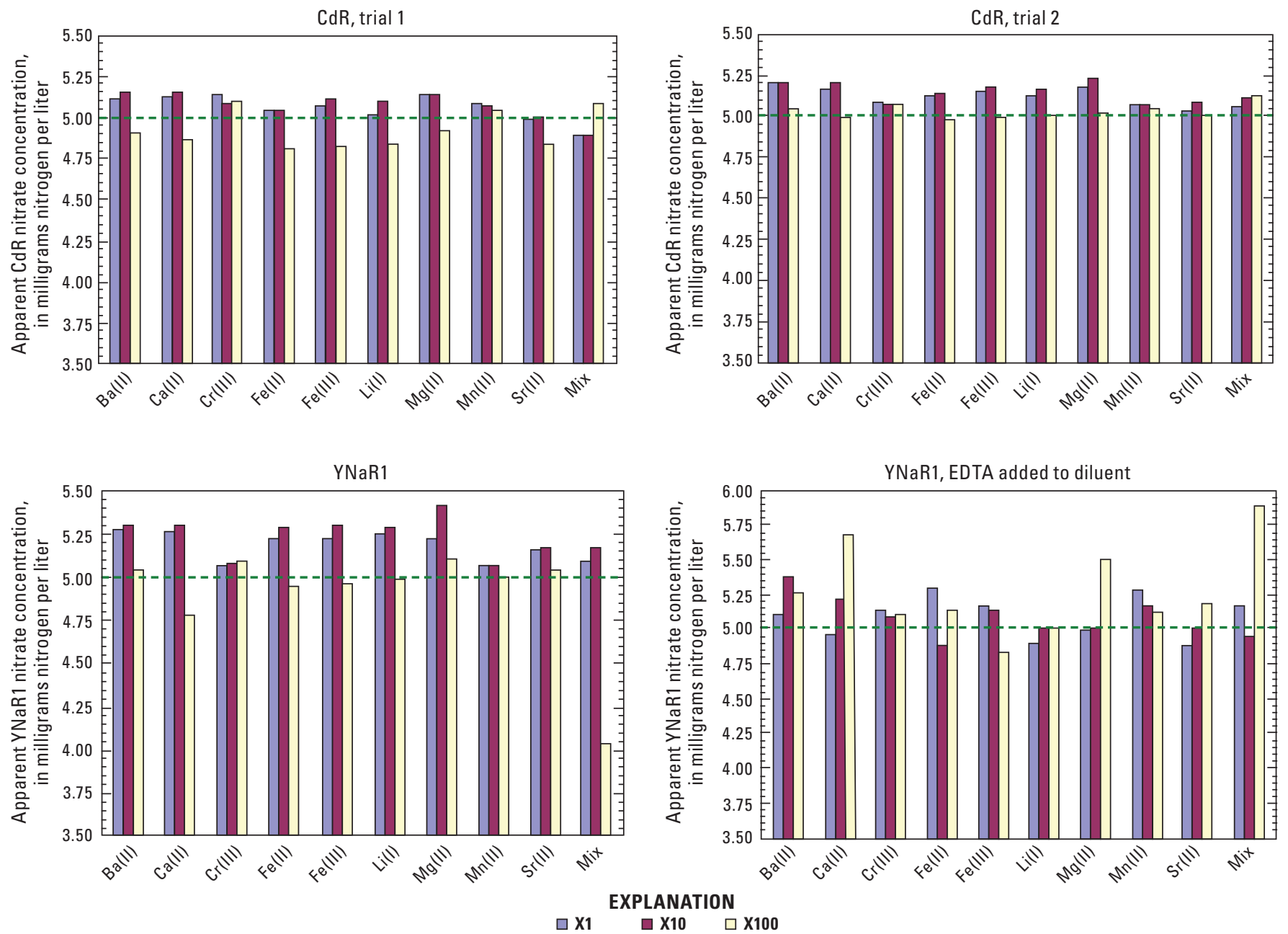

Figure 20. Effect of various metal ions at times $\mathrm{x1}, \mathrm{x} 10$, and $\mathrm{x} 100$ their median concentrations on nitrate concentration measured by continuous flow analysis (CFA) cadmium-reduction (CdR) and nitrate reductase (YNaR1)-reduction nitrate methods. Ethylenediaminetetraacetic acid is abbreviated EDTA. See table 11 for metal ion concentrations. 
these results at median and 10-times median individual metal ion concentrations. Decreases in apparent nitrate concentrations observed at 100-times median metal concentrations might be explained by chloride and sulfate counter ions in the metal stock solutions that were particularly high for calcium (II) and magne$\operatorname{sium}(\mathrm{II})-\mathrm{Cl}^{-} \approx 6,400 \mathrm{mg} / \mathrm{L}$ and $\mathrm{SO}_{4}^{2-} \approx 3,400 \mathrm{mg} / \mathrm{L}$, respectively - in the 100x median runs. Chloride and sulfate ions reduce the rate of nitrate reduction by cadmium (Nydahl, 1976; Gal and others, 2004). These effects were less pronounced in second trial runs, perhaps caused by small differences in cadmium reactor activity between trials 1 and 2 . In any case, apparent nitrate concentration changes in both CFA-CdR method trials were no more than about 5 percent at the $5 \mathrm{mg}-\mathrm{N} / \mathrm{L}$ level.

Bottom panels in figure 20 pertain to results obtained for the CFA-YNaR1 method that indicate similar trends in apparent nitrate concentrations at median, 10-times median, and 100-times individual metal ion concentrations. As we conjectured with respect to the CFA-CdR method, it seems likely that high concentrations of chloride and sulfate counter ions contributed to decreases in apparent nitrate concentrations observed for the CFA-YNaR1 method in 100-times median metal ion concentration runs. Results for a second trial of this experiment (not shown) were similar. Because the 100-times median concentration of alkaline earth metal ions lowered apparent nitrate concentrations determined by the YNaR1 method considerably, we repeated the experiment after replacing the DI water diluent on the CFA-YNaR1 analytical cartridge with $25 \mathrm{mM}$ EDTA solution. Results of this experiment are shown in the bottom right panel. In this run, calcium and magnesium at 100-times median concentrations enhanced nitrate concentration by about 15 and 10 percent, respectively. Note the scale change in relation to the other three panels.

We performed many additional experiments attempting to confirm the hypothesis that high concentrations of Group II metal ions, particularly calcium, in environmental water samples were the primary cause of differences greater than 10 percent in nitrate concentrations determined by the $\mathrm{CdR}$ and YNaR1 methods. Our goal was to establish a concentration of EDTA in the CFA-YNaR1 method reagent system that would consistently minimize the effect of this putative interference. We were unable to confirm this hypothesis, however, as summarized in the excerpt from Kryskalla's notebook entry of April 21, 2004, that follows. Annotations (by Patton) to this notebook entry appear in brackets in the excerpt that follows.

From recent studies of samples with known high $C d R-N a R$ [nitrate concentration] differences and calcium spiked [nitrate] standards...it appears that high concentrations of EDTA in the [YNaR1 method] diluent stream do not help. The plots on pages 163-167 [of this notebook] are from gradient EDTA studies that lead us to believe that lower EDTA concentrations, specifically from 1.5 to $2.5 \mathrm{mM}$, are the best option for calcium interference, and that [calcium interference does not account] for samples with high CdR-NaR differences... .
We also investigated kinetics effects of these ions on the Griess nitrite indicator reaction in the absence of $\mathrm{NaR} / \mathrm{NADH}$ reagents using a Cary 50 spectrophotometer equipped with a thermostatted reaction cell/cuvette (section 5). For these experiments, we prepared $0.40 \mathrm{mg} \mathrm{NO}_{2}^{-}-\mathrm{N} / \mathrm{L}$ solutions amended with NWQL-median concentrations of the metal ions listed in table 11 . We dispensed $1.8 \mathrm{~mL}$ of each metal-amended nitrite solution into the thermostatted cuvette. When the temperature stabilized at $25^{\circ} \mathrm{C}$, we dispensed $600 \mu \mathrm{L}$ of SAN reagent, waited $60 \mathrm{~s}$, then added $600 \mu \mathrm{L}$ of NED reagent, and initiated data collection at $540 \mathrm{~nm}$ on the Cary 50 spectrophotometer at 10 hertz (Hz). Of ions tested, only magnesium, calcium, and barium reduced the Griess reaction chromophore equilibrium concentration substantially. At the NWQL-median concentration, calcium ions suppressed the indicator reaction the most although barium ions appear to be the most potent indicator reaction suppressor on the basis of molar concentration. Graphical summaries of these results are provided elsewhere (Patton and Kryskalla, 2011; fig. 1). In these experiments, it seems unlikely that counter ions in metal stock solutions influenced results because chloride ions contributed by the sulfanilamide reagent $(\approx 0.74 M$ hydrochloric acid) dominate the reaction medium.

In the course of these indicator reaction interference experiments, we also used the same experimental configuration to investigate the effect of reaction temperature on metalfree nitrite solutions. As in previous experiments, the nitrite concentration was $0.40 \mathrm{mg}-\mathrm{N} / \mathrm{L}$, sample and reagent volumes were unchanged, but the data acquisition rate was reduced to $0.33 \mathrm{~Hz}$. Results of these experiments indicated an inverse relation between reaction temperature and reaction rate in the range of $10{ }^{\circ} \mathrm{C}$ to $50{ }^{\circ} \mathrm{C}$ (Patton and Kryskalla, 2011; fig. 2). Above $30{ }^{\circ} \mathrm{C}$, the equilibrium concentration of the indicator reaction chromophore decreased as temperature increased. These results are consistent with the instability of Griess reaction intermediates - nitrosonium $\left(\mathrm{NO}^{+}\right)$and diazonium $\left(\mathrm{R}-\mathrm{N} \equiv \mathrm{N}^{+}\right)$ ions - above about $5^{\circ} \mathrm{C}$ (Noller, 1966). Graphical summaries of these results are provided elsewhere (Patton and Kryskalla, 2011; fig. 2). Griess reaction sensitivity increased by about 30 percent when SAN and NED reagents were added separately (SAN added first) and the reaction temperature was maintained at $4{ }^{\circ} \mathrm{C}$, a finding consistent with work reported by others (Guevara and others, 1998; Miranda and others, 2001).

As we were completing CFA-YNaR1 $\mathrm{NO}_{x}$ assay validation experiments, our related project to evaluate automated DAs as replacements for CFA nutrient analyzers at the NWQL was well underway. From the outset of this project, it was clear that CdR-based nitrate assays were cumbersome on DA platforms and that a soluble-reagent nitrate assay would be essential for complete integration of DAs into routine production operations of the NWQL Nutrients Unit. Because of the excellent performance of the YNaR1 batch reduction procedure in conjunction with a simple DA nitrite assay (fig. 18C), we were optimistic that transferring the CFA-YNaR1 method to a DA platform would be straightforward and require little additional work. We were therefore puzzled and somewhat dismayed by poor correspondence between CFA-CdR and DA-YNaR1 nitrate 
concentrations during initial trials. This unanticipated result led us to consider the possibility that improved agreement between CFA-CdR method nitrate concentrations and those determined by the batch YNaR1 method for the subset of "problem" samples (see fig. 19 and associated text) was due not to longer enzymatic reduction reaction times as we had originally hypothesized, but to the lower reaction temperature at which the batch method enzymatic reduction occurred - ambient $\left(\approx 23{ }^{\circ} \mathrm{C}\right.$ ) compared to $\approx 27^{\circ} \mathrm{C}$ and $37{ }^{\circ} \mathrm{C}$ for the CFA- and DAplatform methods, respectively. Concurrently, we also began to suspect that dissolved organic matter might inhibit YNaR1 activity because many "problem" samples were pale to dark yellow. We therefore began a series of experiments to elucidate the effects of temperature and dissolved organic matter concentration on YNaR1 reactivity. Most of this work occurred between December 2004 and March 2005.

\section{Effects of Temperature and Dissolved Organic Matter on YNaR1 Activity}

We consulted Jerry Leenheer, a USGS expert in dissolved organic matter in water, who suggested that reference USGS Suwannee River humic acid (HA) isolate (Weishaar and others, 2003) at a concentration equivalent to about $20 \mathrm{mg} / \mathrm{L}$, as dissolved organic carbon (DOC), would be a good surrogate for assessment of HA effects on NaR activity. In experiments reported here, we prepared stock and working HA solutions with the assumption that all three air-dried HA isolates contained 50 percent DOC by weight. We prepared stock HA solutions with nominal $300 \mathrm{mg} / \mathrm{L}$ DOC concentrations by dissolving $6 \mathrm{mg}$ of air-dried HA isolates in $10 \mathrm{~mL}$ of DI water. Leenheer provided the Suwannee River HA isolate (SR HA) used for all experiments with HA described in this report.

In these experiments we used the large format autosampler, thermostatted reaction cell, and CFA colorimetric nitrite analyzer as previously described (section 5, fig. 2 and related text) to monitor the reduction rate of nitrate to nitrite by YNaR1 in relation to temperature in the range of $5-40{ }^{\circ} \mathrm{C}$. Sample and reagent volume ratios of enzymatic and colorimetric reactions matched those of previously described CFA and batch YNaR1 reduction methods. Enzymatic reaction volumes were as follows: $2.460 \mathrm{~mL}$ of YNaR1 reagent $(\mathrm{pH} 7.5), 0.150 \mathrm{~mL}$ sample, and $0.540 \mathrm{~mL}$ of NADH. Sample and wash times in these experiments were typically $20 \mathrm{~s}$ and $10 \mathrm{~s}$, respectively, and therefore enzymatic reaction time between points is $30 \mathrm{~s}$ in figures 21 and 22.

Inspection of figure 21 reveals that in the range of $15^{\circ} \mathrm{C}$ to $25^{\circ} \mathrm{C}$, initial rates for nitrate reduction and equilibrium nitrite concentrations were comparable after 10-min reaction times. At $30{ }^{\circ} \mathrm{C}$ the rate of nitrate reduction decreased, but after about $10 \mathrm{~min}$ the equilibrium nitrite concentration approached those obtained at lower reaction temperatures. At $35^{\circ} \mathrm{C}$ there was a substantial decrease in the rate of nitrate reduction and at the 10-min reaction time point, the equilibrium nitrite concentration was about 30 percent less than equilibrium nitrite concentrations

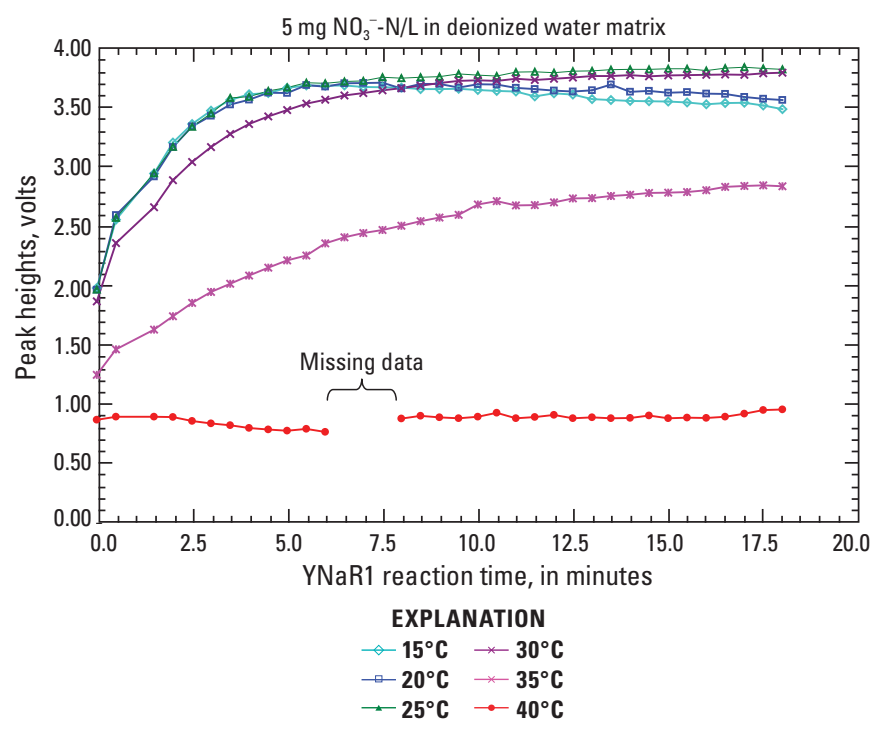

Figure 21. Graph showing the rate of nitrate reduction to nitrite by $\mathrm{YNaR} 1$ nitrate reductase in relation to reaction temperature in degrees Celsius $\left({ }^{\circ} \mathrm{C}\right)$ for 5.0 milligrams nitrate-nitrogen per liter (mg NO${ }_{3}^{-}-\mathrm{N} / \mathrm{L}$ ) at $\mathrm{pH} 7.5$.

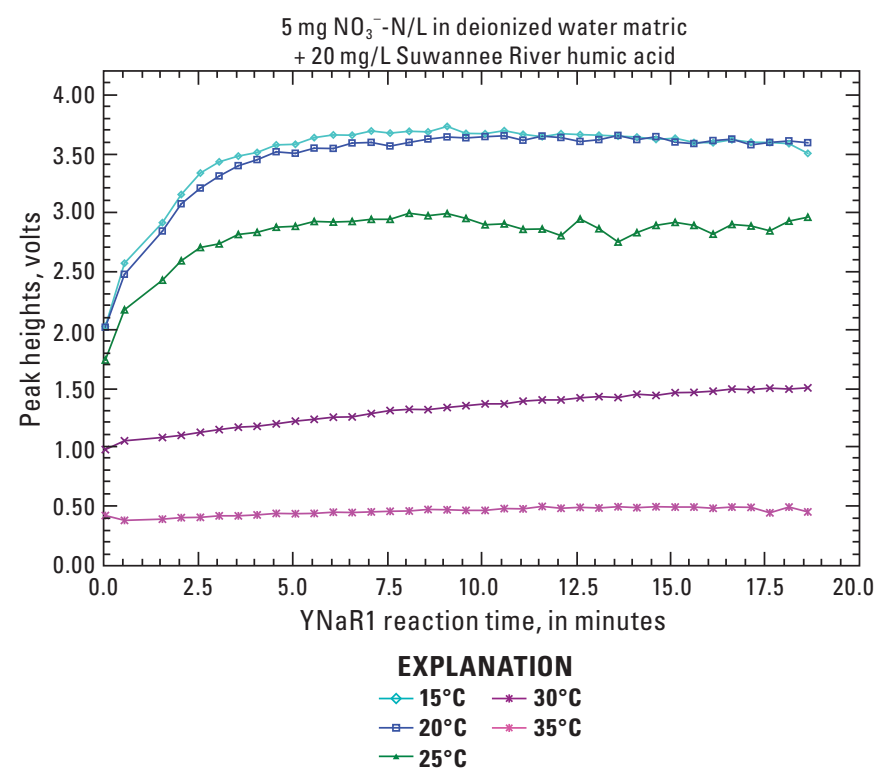

Figure 22. Graph showing the rate of nitrate reduction to nitrite by YNaR1 nitrate reductase in relation to reaction temperature in degrees Celsius $\left({ }^{\circ} \mathrm{C}\right)$ for 5.0 milligrams nitrate-nitrogen per liter ( $\mathrm{mg} \mathrm{NO}_{3}{ }^{-} \mathrm{N} / \mathrm{L}$ ) amended with Suwannee River humic acid at a concentration of 20 milligrams dissolved organic carbon per liter (mg DOC/L).

obtained at the lower reaction temperatures. At $40{ }^{\circ} \mathrm{C}$ YNaR1 activity was greatly diminished. These experiments supported our hypothesis that the $37^{\circ} \mathrm{C}$ incubator temperature of the NWQL's DA was ill-suited for reduction of nitrate to nitrite with YNaR1. Readers should note, however, that initial sample and reagent temperatures dispensed into DA cuvettes are nominally $10^{\circ} \mathrm{C}$ and $4{ }^{\circ} \mathrm{C}$, respectively — set points of sample and reagent 
carousels (Patton and Kryskalla, 2011, fig. 3 and associated text). The Aquakem 600 DA operation manual states that about $300 \mathrm{~s}$ are required for dispensed volumes $-100 \mu \mathrm{L}$ to $200 \mu \mathrm{L}$, typically - to reach thermal equilibrium with the incubator.

The enzymatic reaction temperature, therefore, is not constant initially and is likely less than $30{ }^{\circ} \mathrm{C}$ during the first one-third of the programmed 10 -min reaction interval. This temperature lag is consistent with the better yields of nitrite for many samples on the DA platform than would be predicted from experimental results summarized in figures 21 and 22 in which sample and $\mathrm{YNaR} 1$ reagent were equilibrated at specific temperatures before the enzymatic reduction reaction was initiated by addition of NADH cofactor reagent.

Figure 22 shows results obtained when we repeated the experiment described above using a $5 \mathrm{mg}-\mathrm{N} / \mathrm{L}$ nitrate solution amended with SR HA at a concentration of $20 \mathrm{mg} / \mathrm{L}$. Inspection of figure 22 reveals that SR HA had little effect on the reduction rate of nitrate to nitrite by $\mathrm{YNaR} 1$ at $15^{\circ} \mathrm{C}$ and $20^{\circ} \mathrm{C}$ reaction temperatures. At $25^{\circ} \mathrm{C}$ and $35^{\circ} \mathrm{C}$ reaction temperatures, however, SR HA acted as an increasingly potent $\mathrm{YNaR} 1$ inhibitor.

These findings support the hypothesis that lower reaction temperature rather than longer reaction time might account for better agreement of $\mathrm{NO}_{x}$ results determined by batch YNaR1 methods than for those determined by the CFA-YNaR1 method in relation to reference CFA-CdR method results. These findings also support the hypothesis that the subset of samples for which CFA-CdR and CFA-YNaR1 nitrate concentration differences were greater than 10 percent might have contained substantial concentrations of HA. We repeated these experiments at nitrate concentrations of $2.5 \mathrm{mg}-\mathrm{N} / \mathrm{L}$ and $0.5 \mathrm{mg}-\mathrm{N} / \mathrm{L}$, obtained similar results, and therefore concluded that YNaR1 inhibition by SR HA is independent of nitrate concentration. The observation that rates of $\mathrm{YNaR} 1$ nitrate reduction are faster at $10{ }^{\circ} \mathrm{C}$ and $15^{\circ} \mathrm{C}$ than at higher temperatures even in the absence of SR HA was unexpected and contrary to published values for optimum reaction temperature of $30^{\circ} \mathrm{C}$ (Campbell and others, 2004).

Next we prepared 10 SR HA solutions in the concentration range of 0 to $20 \mathrm{mg} / \mathrm{L}$ and spiked at three different nitrate concentrations - a blank plus $0.5,2.5$, and $5 \mathrm{mg}-\mathrm{N} / \mathrm{L}$ - and determined nitrate in these solutions by the CFA-CdR, CFAYNaR1, batch YNaR1 reduction methods. Figure 23 shows results for the experiments in which we spiked SR HA solutions with nitrate at a concentration of $5.0 \mathrm{mg}-\mathrm{N} / \mathrm{L}$. A six-point calibration preceded each experiment. Calibrants did not contain HA. Therefore, changes in instrument response (CFA peak heights for all three methods) reflect the effect of HA on measured nitrate concentrations.

Inspection of figure 23 reveals that SR HA caused only minor changes in nitrate peak heights for the YNaR1 batch reduction and CFA-CdR methods, but caused a pronounced decrease in apparent nitrate concentration measured by the CFA-YNaR1 method that was proportional to SR HA concentration.

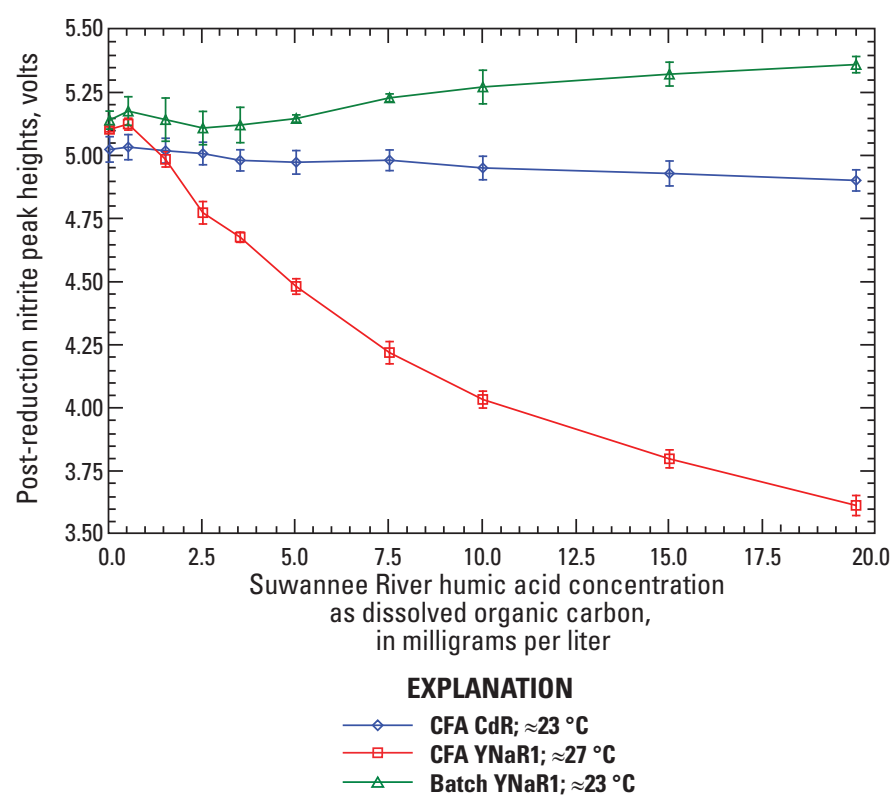

Figure 23. Effect of Suwannee River humic acid concentration on nitrate reduction-spiked at 5.0 milligrams nitrate-nitrogen per liter ( $\mathrm{mg} \mathrm{NO}_{3}^{-}-\mathrm{N} / \mathrm{L}$ ) in reagent water matrix - by continuous flow analysis (CFA) cadmium-reduction (CdR), CFA-nitrate reductase (YNaR1)-reduction, and semiautomated batch-YNaR1-reduction methods. Temperatures of CFA-CdR and batch-YNaR1 methods were not regulated; ambient laboratory temperature was $\approx 23$ degrees Celsius $\left({ }^{\circ} \mathrm{C}\right)$. CFA-YNaR1 method was regulated at $27^{\circ} \mathrm{C} \pm 1{ }^{\circ} \mathrm{C}$. Enzymatic reaction times for CFA-YNaR1 and batchYNaR1 methods were about $10 \mathrm{~min}$ and $1 \mathrm{~h}$, respectively. Plotted points are the average response of three replicate determinations and error bars indicate \pm 1 standard deviation.

In a discussion following these experiments, Leenheer predicted that low-phenolic-content HAs would be less potent $\mathrm{NaR}$ inhibitors. To test this hypothesis, he provided us with a HA sample isolated from Big Soda Lake near Fallon, Nev. This HA was chiefly a product of algal decomposition and therefore had little phenolic content. Robert Wershaw, another USGS dissolved organic matter expert, subsequently provided us with humic material that Leenheer had isolated from blackwater pools near a stockpile of wheat straw that had been decomposing for several years at a location in southeastern Kansas (Wershaw and others, 2003). According to Wershaw and Leenheer, this HA had extraordinarily high lignin content so that despite aromatic character similar to SR HA, many of its phenolic oxygens were methylated. Therefore, this might produce an inhibitory effect on YNaR1 that was intermediate to those of Suwannee River and Big Soda Lake HAs. Figure 24 provides a graphical summary of experiments to assess the effect of these three HAs on YNaR1 activity in relation to temperature. Inspection of figure 24 substantiates the hypothesis that as phenolic content of HAs increases, YNaR1 inhibition increases. As in previous experiments, HA inhibition was negligible at or below $20^{\circ} \mathrm{C}$ and increased as reaction temperature increased above $20^{\circ} \mathrm{C}$. 


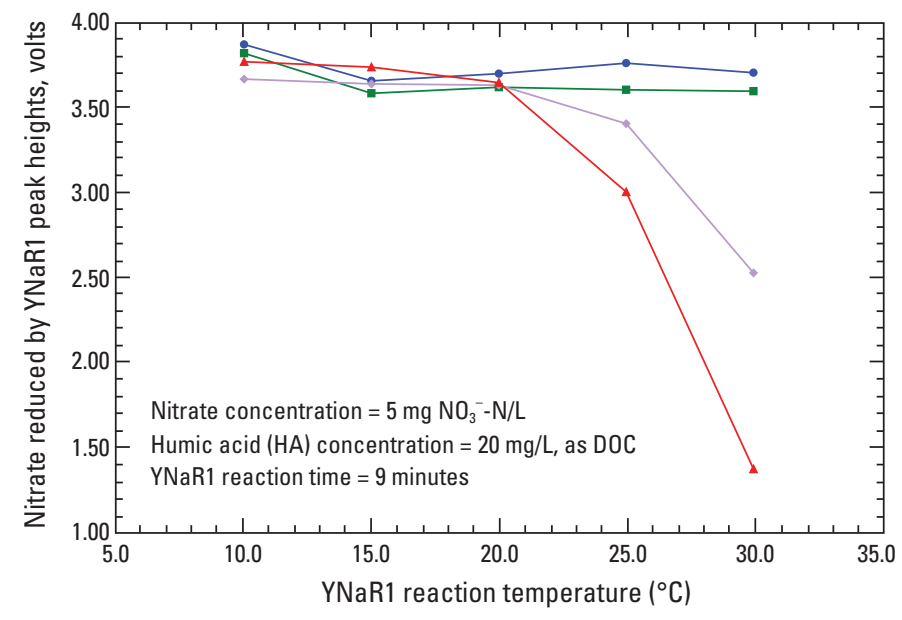

EXPLANATION

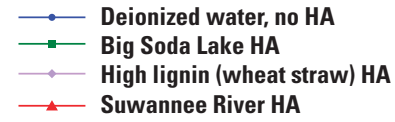

Figure 24. Peak heights for 5.0 milligrams nitrate-nitrogen per liter (mg NO${ }_{3}^{-}-\mathrm{N} / \mathrm{L}$ ) solutions spiked with three humic acids (HA) at a concentration of 20 milligrams per liter $(\mathrm{mg} / \mathrm{L})$ as dissolved organic carbon (DOC). Phenolic content of the HAs increased in the order deionized water $<$ Big Soda Lake $<$ high lignin (wheat straw) < Suwannee River in relation to nitrate reductase (YNaR1) reaction temperature in degrees Celsius $\left({ }^{\circ} \mathrm{C}\right)$.

Results of these experiments demonstrate the relation between the phenolic content of a humic substance and its potency as a YNaR1 inhibitor and provide additional support for our hypothesis that the sample subset with substantial differences between $\mathrm{NO}_{x}$ concentrations determined by CFA-CdR and CFAYNaR1 methods likely contained HAs. To test this hypothesis further, we selected two surface-water samples whose CdR nitrate concentrations were both about $0.8 \mathrm{mg}-\mathrm{N} / \mathrm{L}$. For one, the difference between $\mathrm{CdR}$ and YNaR1 nitrate concentrations was about $0.01 \mathrm{mg}-\mathrm{N} / \mathrm{L}$; for the other it was about $0.1 \mathrm{mg}-\mathrm{N} / \mathrm{L}$. Figures $25 A$ and $25 B$ provide graphical summaries of results obtained for $\mathrm{YNaR} 1$ reaction rate experiments performed on these samples in the temperature range of $10-30{ }^{\circ} \mathrm{C}$.

The correspondence between reaction rates for the surfacewater sample with negligible difference between CFA-CdR and CFA-YNaR1 $\mathrm{NO}_{x}$ concentrations (fig. 25A) and a nitrate standard in a humic-acid-free matrix (fig. 21) is striking, as is the correspondence between reaction rates for the surface-water sample with a substantial difference between CdR and YNaR1 $\mathrm{NO}_{x}$ concentrations (fig. 25B) and a nitrate standard amended with $20 \mathrm{mg} / \mathrm{L} \mathrm{SR} \mathrm{HA}$ (fig. 22). Note particularly that at $10{ }^{\circ} \mathrm{C}$ and $15^{\circ} \mathrm{C}$, reaction rates for these two samples are nearly identical, but they begin to differ markedly at reaction temperatures of $20^{\circ} \mathrm{C}$ or higher.

In another set of experiments performed with the thermostatted CFA kinetics platform (section 5), we investigated the reversibility of YNaR1 inhibition by HA in relation to temperature. In these experiments we incubated nitrate solutions containing $20 \mathrm{mg} / \mathrm{L} \mathrm{SR} \mathrm{HA} \mathrm{with} \mathrm{YNaR1} \mathrm{reagent} \mathrm{for} 5 \mathrm{~min}$ at temperatures ranging from $25-35^{\circ} \mathrm{C}$. We then lowered the solution temperature to $5^{\circ} \mathrm{C}, 10^{\circ} \mathrm{C}, 15^{\circ} \mathrm{C}$, or $20^{\circ} \mathrm{C}$ and held it constant for times ranging from 5-30 min. At the end of each subambient incubation period, we added NADH reagent to initiate enzymatic reduction of nitrate to nitrite at each subambient temperature. Figure 26 provides a graphical summary of results for pre- and post-incubation temperatures of $30^{\circ} \mathrm{C}$ and $10{ }^{\circ} \mathrm{C}$, respectively. Results presented in figure 26 are representative of those obtained with other incubation/reaction temperature combinations above and below ambient temperature. In each case the substantial loss of YNaR1 activity after $5 \mathrm{~min}$ of contact with SR HA at solution temperatures of $25^{\circ} \mathrm{C}$ or higher
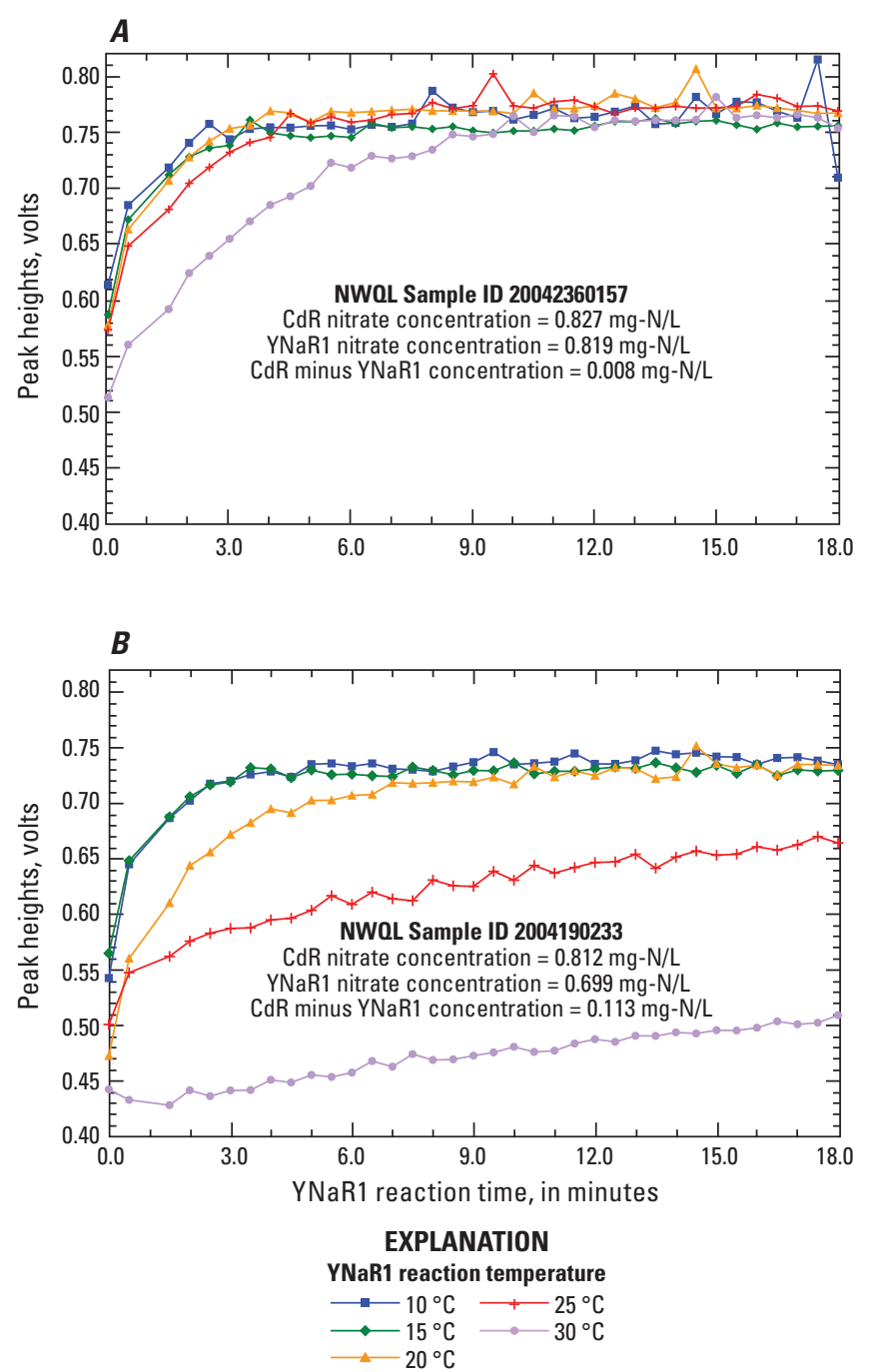

Figure 25. Reaction rate plots for surface-water samples, each with nitrate concentrations of $\approx 0.8$ milligram nitrate-nitrogen per liter ( $\mathrm{mg} \mathrm{NO}{ }_{3}^{-}-\mathrm{N} / \mathrm{L}$ ) by the continuous flow analysis, cadmium-reduction $(\mathrm{CdR})$ method at reaction temperatures from 10 degrees Celsius $\left({ }^{\circ} \mathrm{C}\right)$ to $30^{\circ} \mathrm{C}$. In panel $A$ the difference between nitrate concentrations determined by $\mathrm{CdR}$ and $\mathrm{YNaR} 1$ methods ( $\mathrm{CdR}$ minus $\mathrm{YNaR} 1$ in the figure panels) is less than $0.01 \mathrm{mg} \mathrm{NO}_{3}^{-}-\mathrm{N} / \mathrm{L}$. In panel $B$ the difference between nitrate concentrations determined by $\mathrm{CdR}$ and $\mathrm{YNaR} 1$ methods is greater than $0.1 \mathrm{mg} \mathrm{NO}_{3}^{-}-\mathrm{N} / \mathrm{L}$. In this figure, abbreviations for National Water Quality Laboratory and identifier are NWQL and $\mathrm{ID}$, respectively. 


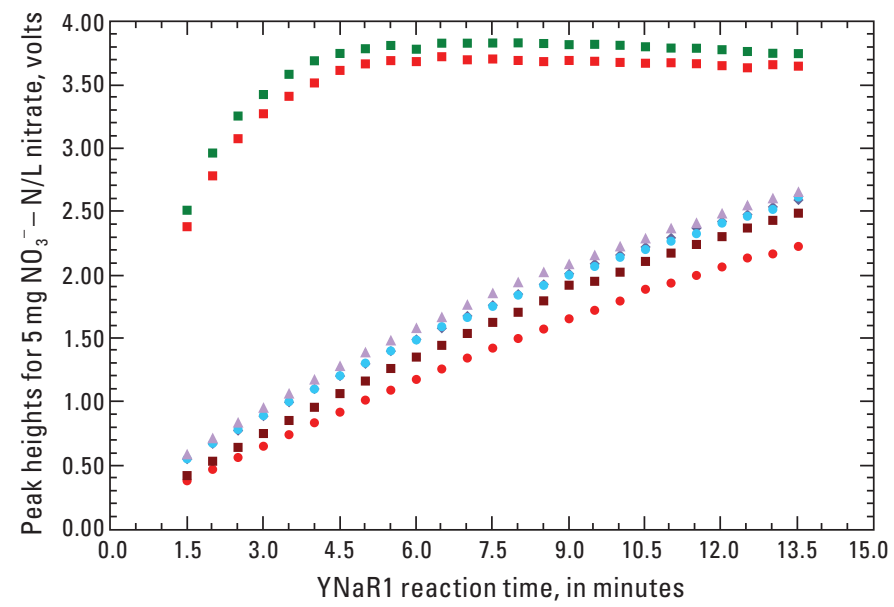

EXPLANATION

- No SR HA, $10^{\circ} \mathrm{C}$, no incubation

- No SR HA, incubate at $30^{\circ} \mathrm{C}$, immediate start at $10^{\circ} \mathrm{C}$

- SR HA, incubate at $30^{\circ} \mathrm{C}$, immediate start at $10^{\circ} \mathrm{C}$

- SR HA, incubate at $30^{\circ} \mathrm{C}, 5 \mathrm{~min}$ at $10^{\circ} \mathrm{C}$

- SR HA, incubate at $30^{\circ} \mathrm{C}, 10 \mathrm{~min}$ at $10^{\circ} \mathrm{C}$

- SR HA, incubate at $30^{\circ} \mathrm{C}, 15 \mathrm{~min}$ at $10^{\circ} \mathrm{C}$

$\triangle S R H A$, incubate at $30^{\circ} \mathrm{C}, 30 \mathrm{~min}$ at $10^{\circ} \mathrm{C}$

Figure 26. Plots showing effects of Suwannee River humic acid (SR HA) on nitrate reductase (YNaR1) activity in relation to reaction temperature. Upper points: kinetics of $\mathrm{YNaR} 1$ reduction of 5.0 milligrams nitrate-nitrogen per liter $\left(\mathrm{mg} \mathrm{NO}_{3}^{-}-\mathrm{N} / \mathrm{L}\right)$ to nitrite-HA SR-free matrix, at 10 degrees Celsius $\left({ }^{\circ} \mathrm{C}\right)$, green symbols; 20 milligrams per liter (mg/L) HA SR as dissolved organic carbon (DOC) matrix, 5 -minute pre-incubation at $30^{\circ} \mathrm{C}$ followed by reaction at $10^{\circ} \mathrm{C}$, red symbols. Lower points: kinetics of $\mathrm{YNaR} 1$ reduction of nitrate to nitrite for solutions containing $5.0 \mathrm{mg}$ $\mathrm{NO}_{3}^{-}-\mathrm{N} / \mathrm{L}$ and $20 \mathrm{mg} / \mathrm{L} \mathrm{SR} \mathrm{HA-DOC}$ after incubation at $30^{\circ} \mathrm{C}$ for 5 minutes followed by subambient incubation at $10^{\circ} \mathrm{C}$ for $5-, 10-$, 15-, and 30-minute periods before initiation of the $\mathrm{YNaR} 1$ reduction reaction by addition of nicotinamide adenine dinucleotide (NADH) reagent.

was negligibly mitigated by subambient incubation periods up to $30 \mathrm{~min}$. It appears, therefore, that at temperatures greater than about $20^{\circ} \mathrm{C}$, SR HA irreversibly inhibits $\mathrm{YNaR} 1$ activity possibly by binding to its reactive centers, by deforming its reactive conformation, or both.

We also investigated the effect of $\mathrm{pH}$ on $\mathrm{YNaR} 1$ kinetics in the presence and absence of SR HA. Here we varied the concentration of potassium hydroxide in standard $\mathrm{KH}_{2} \mathrm{PO}_{4}$ phosphate buffer ( $\mathrm{pH} 7.5$, section 6.1.2) to produce three additional buffers with $\mathrm{pH}$ values of 6.5, 7.0, and 8.0-all about $\pm 0.2 \mathrm{pH}$ units by narrow-range $\mathrm{pH}$ test strips. Figure 27 provides a graphical summary of results from these experiments, all run at $25^{\circ} \mathrm{C}$. In the absence of SR HA (fig. 27, top panel), measured reduction rates of nitrate to nitrite by YNaR1 in relation to $\mathrm{pH}$ were: $6.5 \approx 7.0>7.5>8.0$. Note that across this $\mathrm{pH}$ range, more than a 95-percent reduction of nitrate to nitrite occurred within $10 \mathrm{~min}$. As expected in the presence of $20 \mathrm{mg} / \mathrm{L} \mathrm{SR} \mathrm{HA}$ at $25^{\circ} \mathrm{C}$ (fig. 27, bottom panel), the maximum reduction of nitrate to nitrite by YNaR1 was only about 80 percent. Reduction rates of nitrate to nitrite by $\mathrm{YNaR} 1$ in relation to $\mathrm{pH}$ were: $6.5>7.0 \approx 7.5>8.0$.
One interpretation of these results is that SR HA inhibition of YNaR1 is somehow mitigated at neutral or slightly acidic $\mathrm{pH}$, perhaps due to alteration of HA conformation or solubility under these conditions. The fact that $\mathrm{CdR}$ and YNaR1 reduction method $\mathrm{NO}_{x}$ concentrations were statistically equivalent at the 95-percent confidence level for the small population of acidified samples $(n=182)$ in this study (fig. 15, table 8) also suggests possible linkage between $\mathrm{pH}$ and the potency of HAs as YNaR1 inhibitors. Additional investigation of these effects was beyond the scope of this study, but we have included these limited data because they might provide insight to others in future methoddevelopment efforts.
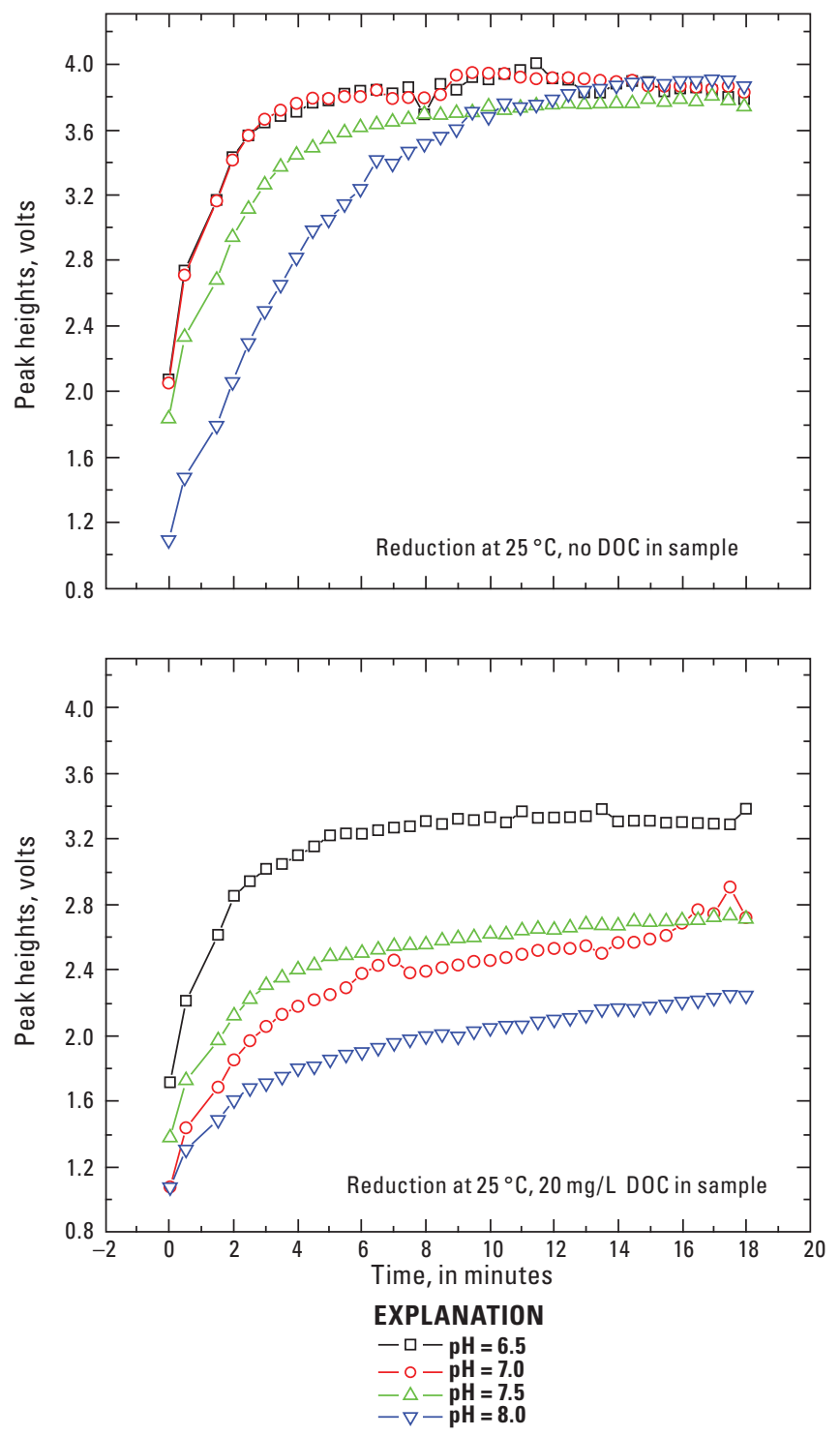

Figure 27. Plots showing effect of reaction $\mathrm{pH}$ on nitrate reductase (YNaR1) reduction rates for solutions containing 5.0 milligrams nitrate-nitrogen per liter $\left(\mathrm{mg} \mathrm{NO}_{3}{ }^{-} \mathrm{N} / \mathrm{L}\right)$ at 25 degrees Celsius $\left({ }^{\circ} \mathrm{C}\right)$. Top panel: Suwannee River humic acid-free matrix. Bottom panel: Matric contains 20 milligrams per liter (mg/L) Suwannee River humic acid as dissolved organic carbon (DOC). 


\section{Nitrate Reductase from Arabidopsis thaliana}

Identifying HAs as the probable primary YNaR1 inhibitor in surface-water and groundwater samples was a major breakthrough in this research as was the discovery that their inhibitory affects are negligible at or below reaction temperatures of about $20^{\circ} \mathrm{C}$. Applying these findings to the development of robust and easily implemented analytical procedures, however, presented us with a new set of challenges. We considered and briefly investigated equipping the analytical cartridge for the CFA-YNaR1 method with a chilled reaction coil. This proved cumbersome, however, because the rapidity with which HAs irreversibly inhibit YNaR1 at temperatures above $20^{\circ} \mathrm{C}$ made it necessary also to chill sample, diluent, buffer, and enzyme streams before they merged and mixed in transit to the chilled reaction coil. Because our primary objective had shifted to development of a soluble NaR nitrate assay for DA platforms, we expended little additional effort on CFA method development.

Although the incubator compartment and dispensing alley temperatures of DAs used at the NWQL $\left(37^{\circ} \mathrm{C}\right)$ were unsuitable for nitrate reduction by $\mathrm{YNaR} 1$, sample and reagent compartment temperatures $-10{ }^{\circ} \mathrm{C}$ and $4{ }^{\circ} \mathrm{C}$, respectivelyoffered potential locations where the enzymatic nitrate reduction step could take place below the $20^{\circ} \mathrm{C}$ HA interference threshold prior to initiation of colorimetric nitrite assays in heated zones of the DA (Patton and Kryskalla, 2011, fig. 3 and related text). Taking advantage of these DA platform features, however, would have required modifications to its operating system software, dispensing hardware, or both, and after a year of unfruitful discussion with the vendor about making such modifications, we abandoned this approach. We bypassed this apparent impasse, however, thanks to the unique properties of a different $\mathrm{NaR}$ product that NECi sent us for evaluation in autumn, 2005. NECi manufactures this enzyme, which they designate AtNaR2 (EC 1.7.1.1), by recombinant expression of the NaR gene from Arabidopsis thaliana - a widely distributed terrestrial plant commonly known as mouseear cress - in a Pichia pastoris system (Skipper and others, 2001; Campbell and others, 2006). In the sections that follow, we present descriptions and results of preliminary experiments with AtNaR2 that predicted its suitability as an analytical reagent of choice for routine analysis of $\mathrm{NO}_{x}$ in environmental water samples on DA platforms.

\section{Effects of Temperature and Dissolved Organic Matter on AtNaR2 Activity}

One of the first things we noticed about freeze-dried AtNaR2 was its color, which was discernibly more red than the beige-orange shades of freeze-dried YNaR1 and NaR1 purified from Zea mays that we had used previously (Patton and others, 2002). Our initial characterization of AtNaR2 as an analytical reagent began with a replication of experiments we had performed earlier to elucidate the effects of reaction temperature and SR HA concentration on the activity of YNaR1. As before, we used the large-format sampler, thermostatted reaction cell, and CFA colorimetric nitrite analyzer for these experiments (section 5). Within the limits of experimental error, the only procedural difference between these and previous experiments detailed under section "Effects of Temperature and Dissolved Organic Matter on YNaR1 Activity," was substituting $3 \mathrm{U}$ of AtNaR2 for $3 \mathrm{U}$ of YNaR1 per $20 \mathrm{~mL}$ pH 7.5 phosphate assay buffer used previously (section 6.1.3, note 1).

Results from these experiments indicated that $\mathrm{AtNaR} 2$ activity was high - sufficient for quantitative reduction of $5 \mathrm{mg} \mathrm{NO}_{3}^{-}-\mathrm{N} / \mathrm{L}$ to $5 \mathrm{mg} \mathrm{NO}_{2}^{-}-\mathrm{N} / \mathrm{L}$ in less than $10 \mathrm{~min}$ - and constant at reaction temperatures ranging from $10-37^{\circ} \mathrm{C}$ even in the presence of $20 \mathrm{mg} / \mathrm{L} \mathrm{SR} \mathrm{HA}$. When repeat experiments produced similar results, we shared our findings with NECi and requested another sample of AtNaR2 to use in a third set of confirmatory experiments. At about the same time, we began to evaluate other commercially available $\mathrm{NaRs}$ to assess their susceptibility to SR HA inhibition in relation to reaction temperature. In this round of experiments, we tested a new sample of AtNaR2, a different lot of YNaR1, NaR1 purified from corn seedlings (all three obtained from NECi), and NADPH-specific NaR from Aspergillus sp. (Sigma-Aldrich Corp., St. Louis, Mo., product number N 7265).

Details of these kinetics experiments and a graphical summary of results are published elsewhere (Patton and Kryskalla, 2011, fig. 6 and related text). For nitrate solutions containing $20 \mathrm{mg} / \mathrm{L}$ SR HA, apparent activity of AtNaR2 was little affected at reaction temperatures ranging between 10 ${ }^{\circ} \mathrm{C}$ and $37^{\circ} \mathrm{C}$, but apparent activities for the other three NaRs tested began to decrease precipitously when reaction temperatures exceeded $20^{\circ} \mathrm{C}$. As expected from previous experiments, the apparent activities of AtNaR1 and YNaR1 were comparable at $10^{\circ} \mathrm{C}$. Furthermore, in the absence of SR HA at $37^{\circ} \mathrm{C}$, apparent activities of YNaR1 and Aspergillus sp. NaRs were substantially less than that of $\mathrm{NaR}$ purified from corn, which approached that of AtNaR2. In summary, at the $37^{\circ} \mathrm{C}$ temperature typical in the reaction zones of many automated DAs and for nitrate solutions containing SR HA, apparent activities of the four NaRs tested were as follows: AtNaR2 $>$ NaR1 $>$ $\mathrm{NADPH}: \mathrm{NaR} \approx \mathrm{YNaR}$.

Using the kinetics platform, we also confirmed that substitution of AtNaR2 for YNaR1 did not affect volume ratios of sample, enzyme, and NADH cofactor that we had optimized previously for CFA and batch reduction $\mathrm{NO}_{x}$ methods. Details of these experiments and a graphical summary of results are published elsewhere (Patton and Kryskalla, 2011; figs. 7, 8 , and related text). As our HA studies neared completion, we tested unused portions of stock SR HA solutions for any changes in their potency as $\mathrm{YNaR} 1$ and AtNaR2 inhibitors. As listed in table 12, we used six stock SR HA solutions to spike $5 \mathrm{mg}-\mathrm{N} / \mathrm{L}$ nitrate solutions at $20 \mathrm{mg} / \mathrm{L}$. These SR HA stock solutions ranged in age from 1 to 203 days and had been stored in screw-cap polypropylene centrifuge tubes at room temperature without protection from ambient fluorescent laboratory lighting. Data in table 12 indicate that the age of SR HA solutions had little effect on their ability to inhibit YNaR1 or inability to inhibit AtNaR2. 
Table 12. Effect of storage time on the potency of Suwannee River humic acid dissolved in deionized water as an inhibitor of YNaR1 and AtNaR2 nitrate reductases. Analyses performed by the automated discrete analyzer method at $37^{\circ} \mathrm{C}$ on November 9, 2005.

[YNaR1, recombinant nitrate reductase from Pichia angusta; AtNaR2, recombinant nitrate reductase from Arabidopsis thaliana; ${ }^{\circ} \mathrm{C}$, degree Celsius; SR HA, Suwanee River high-phenolic-content humic acid; mg-N/L, milligrams-nitrogen per liter]

\begin{tabular}{|c|c|c|c|c|c|c|}
\hline Stock SR HA preparation date: & $04 / 20 / 2005$ & $6 / 21 / 2005$ & $7 / 25 / 2005$ & $9 / 13 / 2005$ & $10 / 6 / 2005$ & $11 / 8 / 2005$ \\
\hline Days in solution: & 203 & 141 & 107 & 57 & 34 & 1 \\
\hline Nitrate added (mg-N/L): & 5.00 & 5.00 & 5.00 & 5.00 & 5.00 & 5.00 \\
\hline Nitrate found with YNaR1 (mg-N/L): & 1.25 & 1.38 & 1.20 & 1.56 & 1.87 & 1.05 \\
\hline Nitrate found with AtNaR2 (mg-N/L): & 5.09 & 5.12 & 5.11 & 5.03 & 5.01 & 4.95 \\
\hline
\end{tabular}

Having verified in multiple experiments over the course of several months that, unlike YNaR1, AtNaR2 remained fully active at $37^{\circ} \mathrm{C}$ and was negligibly inhibited by HAs, we began our successful validation of standard- and low-level DA $\mathrm{NO}_{x}$ assays using AtNaR2, complete details of which are published elsewhere (Patton and Kryskalla, 2011).

\section{Conclusions}

1. Comparability between enzymatic- and cadmiumreduction $(\mathrm{CdR})$ nitrate determination methods. Paired statistical and graphical analyses of nitrate plus nitrite $\left(\mathrm{NO}_{x}\right)$ concentrations determined in more than 3,800 seasonally, geographically, and compositionally diverse surface-water and groundwater samples indicate generally comparable results obtained from automated, air-segmented continuous-flow analysis (CFA)-CdR and CFA-YNaR1 reduction methods.

\section{a. Standard-level CFA-CdR and CFA-YNaR1 methods}

i. Qualitative assessment of method differencesFor the population of 3,181 sample pairs with YNaR1 method $\mathrm{NO}_{x}$ concentrations greater than or equal to 0.01 milligram-nitrogen per liter (mg-N/L) (table 7), $\mathrm{NO}_{x}$ concentrations determined by CFA-CdR and CFA-YNaR1 methods agreed to within \pm 10 percent (table 7 , "in-range" category) for about 80 percent of surface-water samples and about 89 percent of groundwater samples. Again with reference to table 7, about 74 percent of in-range $\mathrm{YNaR} 1$ $\mathrm{NO}_{x}$ results were negatively biased - that is, CFA-CdR method $\mathrm{NO}_{x}$ concentrations $>$ CFAYNaR1 method $\mathrm{NO}_{x}$ concentrations.

ii. Statistical differences between methodsTwo-population, paired t-test and nonparametric Wilcoxon signed-rank test analyses indicate statistically significant differences for CFA-CdR and CFA-YNaR1 method population means and population distributions at the 0.05 and 0.01 probability levels (tables 8 and 9). These statistical test results are consistent with negative bias indicated by qualitative data treatments described in 1.a.i, above. Note, however, that the National Water Quality Laboratory (NWQL) reporting level is $0.04 \mathrm{mg}-\mathrm{N} / \mathrm{L}$ for standard level CFA-CdR $\mathrm{NO}_{x}$, which is slightly greater than mean (table 8) and median (table 10) concentration differences for these populations. Consequently, negative bias of this magnitude therefore is of minor analytical significance.

iii. Standard-level method bias-Negative bias in population means and medians is consistent with temperature-dependent YNaR1 inhibition by high-phenolic-content humic acid (HA) matrix constituents.

b. Low-level CFA-CdR and CFA-YNaR1 methods

i. Surface water-For the population of 761 surfacewater sample pairs with YNaR1 method NO concentrations greater than or equal to $0.001 \mathrm{mg}-\mathrm{N} / \mathrm{L}$ (fig.13), paired t-tests indicate that differences between population means were significantly different from zero at the 0.05 and 0.01 probability levels. Likewise, paired Wilcoxon signed-rank test population distributions were different at the 0.05 and 0.01 probability levels. Differences between population means $(0.04 \mathrm{mg}-\mathrm{N} / \mathrm{L}$, table 8$)$ and medians $(0.05 \mathrm{mg}-\mathrm{N} / \mathrm{L}$, table 10$)$ are greater than NWQL low-level CFA-CdR method reporting level $(0.01 \mathrm{mg}-\mathrm{N} / \mathrm{L})$; therefore, negative bias (CdR results > YNaR1 results) was analytically significant.

ii. Groundwater-For the population of 218 groundwater sample pairs with YNaR1 method $\mathrm{NO}_{x}$ concentrations greater than or equal to $0.001 \mathrm{mg}-\mathrm{N} / \mathrm{L}$ (fig.13), paired t-tests (table 8) indicate that differences between population means were significantly different from zero at the 0.05 probability level, but not at the 0.01 probability level. Paired Wilcoxon signed-rank tests (table 9) indicate that population distributions were the same at the 0.05 and 0.01 probability levels. Lack of bias indicated by these statistical tests is consistent with population mean (table 8) and median (table 10) differences, and the NWQL low-level CdR method reporting level - all of which share values of about $0.01 \mathrm{mg}-\mathrm{N} / \mathrm{L}$. 
iii. Low-level method bias - Negative bias in population means and medians in surface-water results for the low-level YNaR1 method is consistent with temperature-dependent inhibition by HA matrix constituents.

c. Standard-level CFA-CdR and CFA-YNaR1 methods (acidified samples):

i. Statistical differences-For the population of $182 \mathrm{NO}_{x}$ concentrations (fig. 15) determined in acidified samples by standard-level CFACdR and CFA-YNaR1 methods, paired t-tests (table 8) showed that the difference between population means for WCA samples (table 1) was not significantly different from zero at the 0.05 and 0.01 probability levels. For FCA samples (table 1), the difference between population means was significantly different from zero at the 0.05 probability level, but not at the 0.01 probability level. The difference between population means $(-0.009 \mathrm{mg}-\mathrm{N} / \mathrm{L}$, table 8$)$, however, is not analytically significant. Paired Wilcoxon signed-rank tests (table 9) indicate that population distributions were the same at the 0.05 and 0.01 probability levels for WCA samples, but were different at both probability levels for the FCA sample population. As was the case for t-tests, calculated bias (0.03 mg-N/L, table 10) was less than the reporting level.

ii. Humic acid (HA) effects in acidified samplesAbsence of analytically significant bias in these data might indicate that the conformation or solubility of HAs change to less potent YNaR1 inhibitors in acidified sample matrices.

\section{Enzymatic and colorimetic indicator reaction} interferences. In general, anions (table 2) and cations (table 11, fig. 20) at concentrations up to 100-times their median concentrations in typical freshwater matrices have negligible effect on the activity of YNaR1 nitrate reductase (NaR). Only magnesium, calcium, and barium reduced the Griess nitrite indicator reaction chromophore equilibrium concentration substantially. Calcium ions exert the greatest suppression at NWQL-median concentrations although barium ions were the most potent indicator reaction suppressor on the basis of molar concentration. Other factors being equal, the rate and yield of Griess indicator reaction chromophore are inversely proportional to reaction temperature in the range of 10 degrees Celsius $\left({ }^{\circ} \mathrm{C}\right)$ to $50^{\circ} \mathrm{C}$.

3. Humic acid interferences. High-phenolic-content HA are potent inhibitors of YNaR1, corn-seedling, and Aspergillus sp. NaRs at reaction temperatures greater than $20^{\circ} \mathrm{C}$. The extent of inhibition for these enzymes is proportional to the phenolic character of the HA and reaction temperature, increasing as temperature and $\mathrm{HA}$ concentration increase in the range of $20-37^{\circ} \mathrm{C}$. Inhibition by $\mathrm{HA}$ is negligible for these enzymes at reaction temperatures less than $20^{\circ} \mathrm{C}$. In contrast, HAs do not inhibit
AtNaR2 at temperatures ranging between $5-37^{\circ} \mathrm{C}$. These unique characteristics make AtNaR2 the reagent of choice for NWQL automated discrete analysis (DA) $\mathrm{NO}_{x}$ determination methods (Patton and Kryskalla, 2011) and for other surface-water and groundwater $\mathrm{NO}_{x}$ assays that are most easily performed at or above typical ambient laboratory temperatures.

4. Applicability of enzymatic reduction nitrate methods. This report demonstrates that nontoxic, soluble NaR reducing reagents can be substituted for granular copperized cadmium in longstanding U.S. Geological Survey (USGS) and U.S. Environmental Protection Agency (EPA) approved methods. It is noteworthy that these new enzymatic reduction methods use the same colorimetic reagents as approved USGS and EPA CdR methods. This report also provides limited statistical and graphical analyses of smaller data sets demonstrating the feasibility of coupling the offline batch enzymatic reduction of nitrate to nitrite followed by colorimetic nitrate determinations by a variety of analytical approaches including:

- automated CFA and flow-injection analysis (FIA),

- DA, or

- bench-top or portable photometers and spectrophotometers.

Guidance provided here should facilitate adoption of green, enzymatic reduction analytical methods for $\mathrm{NO}_{x}$ determinations in public-, private-, and academic-sector laboratories.

\section{Acknowledgments}

We are grateful to Christine McEvoy for technical assistance in the summer of 2003. At that time, she was a chemistry major at the College of Wooster in Wooster, Ohio, and her participation in our research was funded through the USGS Summer Student Intern Program. Authors Kryskalla and Patton thank the Nitrate Elimination Company in Lake Linden, Michigan, for partially funding their 2003 and 2004 research at the NWQL through a U.S. Department of Agriculture Phase-II small business innovation research (SBIR) grant (USDA SBIR \# 2002-33610-12300, Environmentally benign automated nitrate analysis) and for continuing collaborative support and providing NADH:NaR from Arabidopsis thaliana in 2005 and 2006.

The report also benefited from reviews by Harold Ardourel, Jeff McCoy, Douglas Stevenson, and John Zorgoski at the NWQL, Nancy Simon at the USGS National Research Program in Reston, Va., Carl Zimmermann and Carolyn Keefe at the University of Maryland Chesapeake Biological Laboratory in Solomons, Md., and others at the USGS Office of Water Quality and the NWQL.

We also acknowledge Mary Olson, Colleen Gupta, Eric Schwab, Chris Klimper, and other past and present members of the NWQL Analytical Services Nutrients Unit for their interest and technical support during the development of automated and manual enzymatic reduction nitrate methods described in this report. 


\section{References Cited}

American Society for Testing and Materials, 1999, E29-93a, Standard practice for using significant digits in test data to determine conformance to specifications: Annual book of ASTM standards, Reporting test results, Section 7.4, V. 14.02 .

American Society for Testing and Materials, 2001, Annual book of ASTM standards, Section 11, Water (D1193, Standard specification for reagent water): West Conshohocken, Pa., v. 11.01, p. 107-109.

Barbier, G.G., Joshi, J.C., Campbell, E.R., and Campbell, W.H., 2004, Purification and biochemical characterization of simplified eukaryotic nitrate reductase expressed in Pichia pastoris: Protein Expression and Purification, v. 37 , p. 61-71.

Bendschneider, Kenneth, and Robinson, R.J. ,1952, A new spectrophotometric method for the determination of nitrite in sea water: Journal of Marine Research, v 11, p. 87-96.

Bradbury, S.L,. and Jakoby, W.B., 1972, Glycerol as an enzyme-stabilizing agent: Effects on aldehyde dehydrogenase: Proceedings of the National Academy of Science, v. 69, p. 2373-2376.

Bratton, A. Calvin and Marshall, E.K. 1939, A new coupling component for sulfanilamide determination: Journal of Biological Chemistry, v. 128, p. 537-550.

Campbell, W.H., Kinnunen-Skidmore, T., Brodeur-Campbell, M.J., and Campbell, E.R., 2004, New and improved nitrate reductase for enzymatic nitrate analysis: American Laboratory, v. 22, no. 10 , p. 12.

Campbell, Wilbur H., Song, P, Barbier, G.G., 2006, Nitrate reductase for nitrate analysis in water: Environmental Chemistry Letters, v. 4, p. 69-73.

Colman, Benjamin P. and Schimel, Joshua P., 2010a, Understanding and eliminating iron interference in colorimetric nitrate and nitrite analysis: Environmental Monitoring and Assessment, v. 165, p. 633-641.

Colman, Benjamin P. and Schimel, Joshua P., 2010 b, Erratum to understanding and eliminating iron interference in colorimetric nitrate and nitrite analysis: Environmental Monitoring and Assessment, v. 165, p. 693.

Davison, W., and Woof, C., 1978, Comparison of different forms of cadmium as reducing agents for the batch determination of nitrate: Analyst, v. 103, p. 403-406.

Draper, N.R., and Smith, Harry, 1966, Applied regression analysis: New York, Wiley, 407 p.
Elliot, C.L., Snyder, G.H., and Cisar, J.L., 1989, A modified AutoAnalyzer II method for the determination of $\mathrm{NO}_{3}{ }^{-} \mathrm{N}$ in water using a hollow-Cd reduction coil: Communications in Soil Science and Plant Analysis, v. 20, p. 1873-1879.

Fox, J.B., 1979, Kinetics and mechanisms of the Griess reaction: Analytical Chemistry, v. 51, p. 1493-1502.

Fox, J.B., 1985, The determination of nitrite-A critical review: CRC Critical Reviews in Analytical Chemistry, v. 15 , p. 283-313.

Gal, Carmen, Frenzel, Wolfgang, and Möller, Jürgen, 2004, Re-examination of the cadmium reduction method and optimisation of conditions for the determination of nitrate by flow injection analysis: Microchimica Acta, v. 146, p. $155-164$.

Guevara, I., Iwanejko, J., Dembinska-Kiec, A., Pankiewicz, J., Wanat, A., Anna, P., Golabek, I., Bartus, S., Malczewska-Malec, M., and Szczudlik, A., 1998, Determination of nitrite/nitrate in human biological material by the simple Griess reaction: Clinica Chimica Acta, v. 274, p. 177-188.

Hansen, W.R., 1991, Suggestions to authors of the reports of the United States Geological Survey (7th ed.): U.S. Government Printing Office, p. 119-121.

MacKown, C.T. and Weik, J.C., 2004, Comparison of laboratory and quick-test methods for forage nitrate: Crop Science, v. 44, p. 218-226.

Miranda, Katrina, Espey, M.M., and Wink, D.A., 2001, A rapid, simple spectrophotometric method for simultaneous detection of nitrate and nitrite-NITRIC OXIDE: Biology and Chemistry, v. 5, no. 1, p. 62-71.

Moody, John A., and Shaw, Frances L., 2006, Reevaluation of the Griess reaction-How much of a problem is interference by nicotinamide nucleotides?: Analytical Biochemistry, v. 356, p. 154-156.

Moorcroft, M.J., Davis, James, and Compton, R.G., 2001, Detection and determination of nitrate and nitriteA review: Talanta, v. 54, p. 785-803.

Mori, Hisakazu, 2000, Direct determination of nitrate using nitrate reductase in a flow system: Journal of Health Science, v. 46, no. 5, p. 385-388.

Mori, Hisakazu, 2001, Determination of nitrate in biological fluids using nitrate reductase in a flow system: Journal of Health Science, v. 47, no. 1, p. 65-67.

Noller, Carl R., 1966, Chemistry of organic compounds, (3d ed.): Philadelphia, W.B Saunders Company, p. 542.

Norwitz, George, and Keliher, P.N., 1985, Study of interferences in the spectrophotometric determination of nitrite using composite diazotization-coupling reagents: Analyst, v. 110, p. 689-694. 
Norwitz, George, and Keliher, P.N., 1986, Study of organic interferences in the spectrophotometric determination of nitrite using composite diazotization-coupling reagents: Analyst, v. 111, p. 1033-1037.

Novak, C.E., 1985, Preparation of water-resources data reports: U.S. Geological Survey Open-File Report 85-480, $331 \mathrm{p}$.

Nydahl, Folke, 1974, On the reduction of oxygen in aqueous solution by electrolytically precipitated cadmium: Talanta, v. 21 , p. $1259-1267$.

Nydahl, Folke, 1976, On the optimum conditions for the reduction of nitrate to nitrite by cadmium: Talanta, v. 23, p. 349-357.

Pai, Su-Cheng, Yang, Chung-Cheng, and Riley, J.P., 1990, Formation kinetics of the pink azo dye in the determination of nitrite in natural waters: Analytica Chimica Acta, v. 232, p. 345-349.

Patton, C.J., 1983 Design, characterization, and applications of a miniature continuous flow analysis system-Ph.D. Dissertation, Michigan State University [abs.]: Dissertation Abstracts International, v. 44, p. 778-B.

Patton, C.J., Fischer, A.E., Campbell, W.H., and Campbell, E.R., 2002, Corn leaf nitrate reductase-A nontoxic alternative to cadmium for photometric nitrate determinations in water samples by air-segmented continuous-flow analysis: Environmental Science and Technology, v. 36, p. 729-735.

Patton, C.J. and Kryskall, J.R., 2011, Colorimetric determination of of nitrate plus nitrite in water by enzymatic reduction, automated discrete analyzer methods: U.S. Geological Survey Techniques and Methods, book 5, chap. B8, 34 p.

Patton, C.J., and Rogerson, P.F., 2007, Reduction device for nitrate determination: U.S. Patent 7,157,059 B1 [filed September 18, 2002; issued January 2, 2007].

Patton, C.J., and Wade, A.P., 1997, Chapter 4-Continuous flow analyzers, in Ewing, Galen, editor, Analytical instrumentation handbook ( $2 \mathrm{~d}$ ed.): New York, Marcel Dekker, p. 125-220.

Pinto, Paula C.A.G., Lima, Jose J.F.C., and Saraiva, M. Lucia M.F.S., 2005, An enzymatic analysis methodology for the determination of nitrates and nitrites in water: International Journal of Environmental Chemistry, v. 85, no. 1, p. 29-40.

Pollard, J.H., 1979, A handbook of numerical and statistical techniques: New York, Cambridge University Press.

Senn, D.R., and Carr, P.W., 1976, Determination of nitrate at the part per billion level in environmental samples with a continuous-flow immobilized enzyme reactor: Analytical Chemistry, 46, no. 7, p. 954-958.
Skipper, Lawrie, Campbell, W.H., Mertens, J.A., and Lowe D.J., 2001, Pre-steady-state kinetic analysis of recombinant Arabidopsis NADH:nitrate reductase: Journal of Biological Chemistry, v. 276, no. 29, p. 26998-27002.

Stainton, M.P., 1974, Simple, efficient reduction column for use in the automated determination of nitrate in water: Analytical Chemistry, v. 46, p. 1,616.

U.S. Environmental Protection Agency, 1997, Guidelines establishing test procedures for the analysis of pollutants (App. B, Part 136, Definition and procedures for the determination of the method detection limit): U.S. Code of Federal Regulations, title 40, revised as of July 1, 1997 , p. $265-267$.

U.S. Geological Survey 2002, Policy for storing and reporting significant figures for chemical data: Office of Water Quality Technical Memorandum No. 2002.11, accessed September 6, 2005, at http://water.usgs.gov/admin/memo/ QW/qw02.11.html.

Weishaar, James L., Aiken, George R., Bergamaschi, Briana A., Fram, Miranda S., Fujii, Roger, and Mopper, Kenneth, 2003, Evaluation of specific ultraviolet absorbance as an indicator of the chemical composition and reactivity of dissolved organic carbon: Environmental Science and Technology, v. 37, p. 4702-4708.

Wershaw, R.L., Rutherford, D.W., Leenheer, J.A., Kennedy, K.R., Cox, L.G., and Koci, D.R., 2003, Biogeochemical processes that produce dissolved organic matter from wheat straw: U.S. Geological Survey Water-Resources Investigations Report 2003-4213, 14 p.

Willis, R.B., 1980, Reduction column for automated determination of nitrate and nitrite in water: Analytical Chemistry, v. 52, p. 1376-1377.

Willis, R.B., and Gentry, C.E., 1987, Automated method for determining nitrate and nitrite in water and soil extracts: Communications in Soil Science and Plant Analysis, v. 18, p. 625-636.

Wood, E.D., Armstrong, F.A.J., and Richards, F.A., 1967, Determination of nitrate in sea water by cadmium-copper reduction to nitrite: Journal of the Marine Biological Association of the United Kingdom, v. 47, p. 23-31.

Zhang, J.Z., Fischer, C.J., and Ortner, P.B., 2000, Comparison of open tubular cadmium reactor and packed cadmium column in automated gas-segmented continuous flow nitrate analysis: International Journal of Environmental Analytical Chemistry, v. 76, p. 99-113. 
Manuscript approved for publication on November 1, 2012

USGS Publishing Service Center staff:

Mary Kidd, Editor

Joy Monson, Layout

For more information about this publication, contact:

National Water Quality Laboratory

U.S. Geological Survey

P.O. Box 25585

Denver Federal Center

Denver, C0 80225-0585

For additional information, visit http://nwql.usgs.gov 


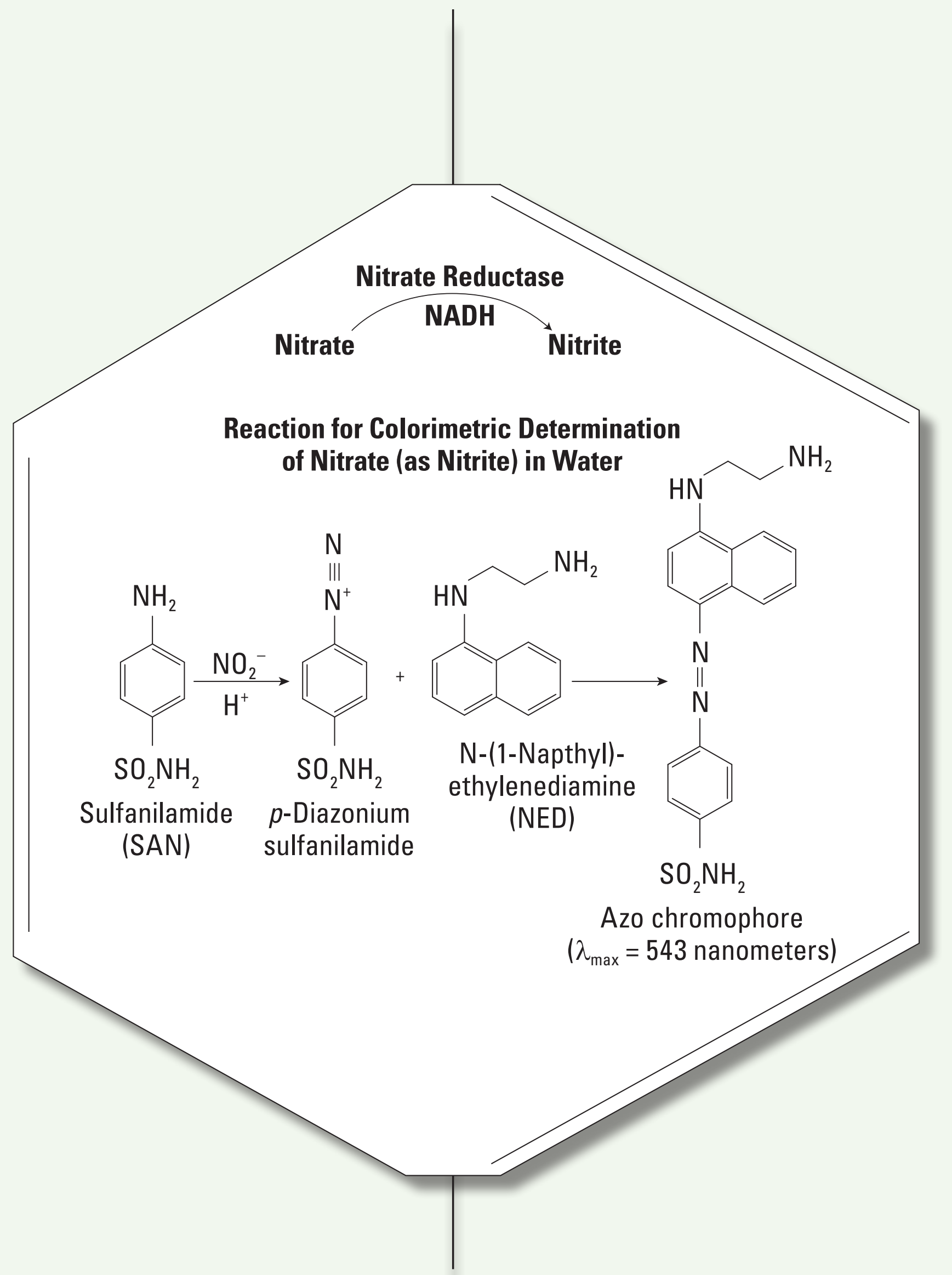

